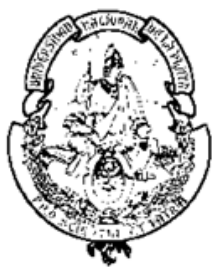

Universidad Nacional de La Plata

Facultad de Humanidades y Ciencias de la Educación

Secretaría de Posgrado

\title{
De Roque Pérez a la Universidad Nacional de La Plata: experiencias de movilidad y curso de vida en jóvenes migrantes estudiantiles en La Plata, Provincia de Buenos Aires
}

\author{
Lic. Agustín Cleve \\ Tesis para optar por el grado de Magíster en Ciencias Sociales \\ Directora: Dra. Mariana Chaves
}

La Plata, diciembre de 2017 


\section{INDICE}

AGRADECIMIENTOS ….....................................................................................................5

RESUMEN .......................................................................................................................... 7

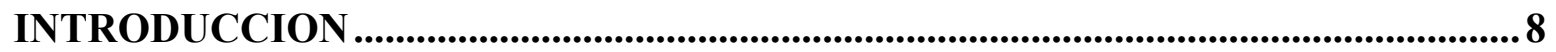

I Presentación del problema y objetivos de la investigación .............................................. 8

II Algunas herramientas conceptuales ........................................................................ 11

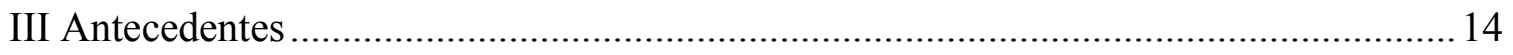

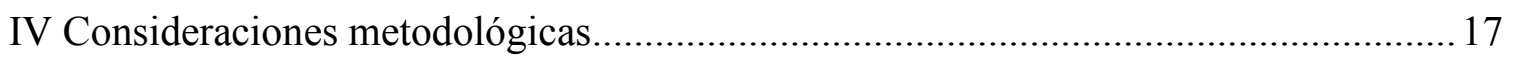

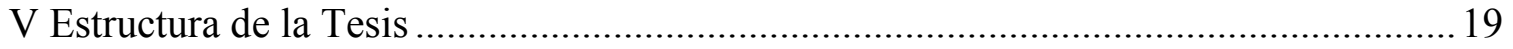

CAPÍTULO 1 Pueblo chico, pueblo grande y ciudad: los lugares de la experiencia ..21

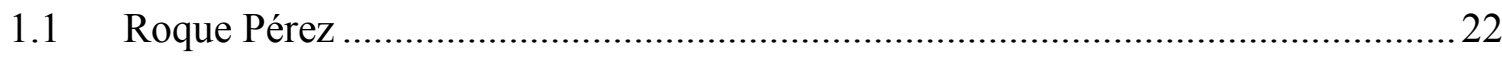

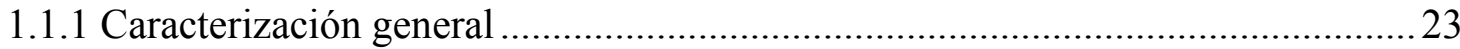

1.1.2 Imaginarios urbanos juveniles sobre Roque Pérez............................................... 31



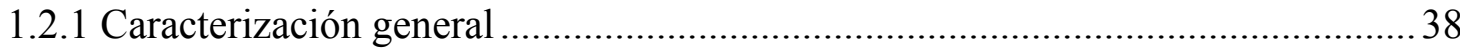

1.2.2 Imaginarios urbanos sobre La Plata de originarios de Roque Pérez .....................44

1.3 Comunidad-Sociedad, Anonimato-Presencia: conclusiones .......................................55

CAPÍTULO 2 Llegar a la ciudad y a la universidad: momentos de transición en el curso de vida ............................................................................................................................60

2.1 Llegar a la ciudad: redes, sentimientos y vida doméstica..............................................61

2.1.1 Parientes que sostienen en Roque Pérez y La Plata: redes familiares en el lugar de origen y destino.

2.1.2 "Tener que cocinar es un mundo aparte": la organización de la vida doméstica en

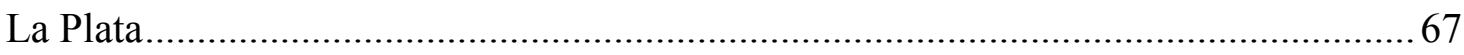

2.1.3 "Te mandan al mundo": sentimientos al llegar a la ciudad ....................................71

2.1.4 Vivir en el Centro de Estudiantes de Roque Pérez............................................... 73

2.2 Llegar a la universidad: transiciones y nuevas redes .................................................. 78

2.2.1 Sobre la Universidad Nacional de La Plata...........................................................79 
2.2.2 "La universidad fue un cambio muy grande": transiciones etarias 84

2.2.3 Compañeros, amigos, amores: nuevas redes sociales …................................ 88

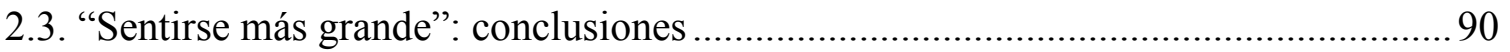

CAPÍTULO 3 Nuevas experiencias en La Plata: la política, lo artístico, la sexualidad y formas de gestión de la privacidad.............................................................................93

3.1 "Militar y ver el mundo de otra manera": experiencias políticas .............................94

3.1.1 "En La Plata encontré otra forma de hacer política": La trayectoria de Darío ....95

3.1.2 “Acá pude abrir la cabeza ”: La trayectoria de Celina .................................... 99

3.2 “Acá no hay que preocuparse por el que dirán”: experiencias de gestión de las esferas

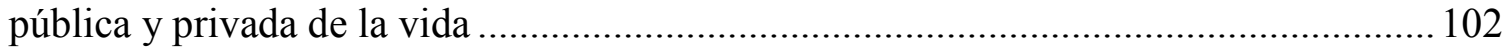

3.2.1 "Me vine a La Plata para vivir libremente mi sexualidad": la trayectoria de

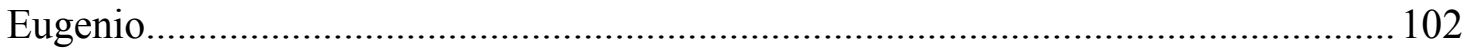

3.2.2“En Roque Pérez es difícil preservar la privacidad”: la trayectoria de Malena. 105

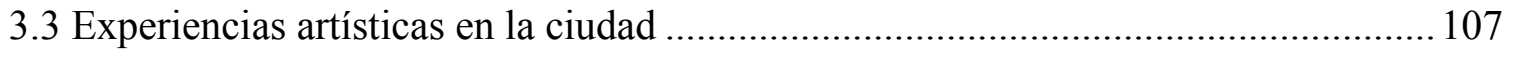

3.3.1 "En esta ciudad me di cuenta que quería ser artista": la trayectoria de Marina.. 108

3.3.3 “Acá conocí el arte”.: la trayectoria de Daniel............................................... 110

3.4 La Plata "lugar privilegiado" para la experiencia juvenil: conclusiones ................. 113

CAPÍTULO 4 Universidad y movilidad social: expectativas, proyecciones y

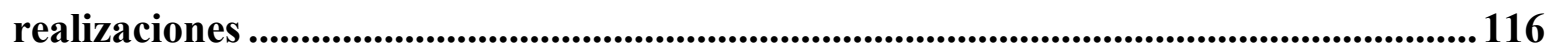

4.1 Familias de "clase media": educación, trabajo y vivienda de los grupos familiares 117

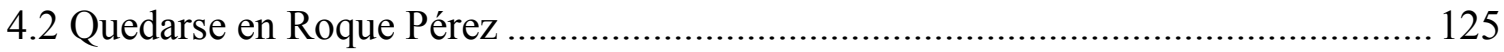

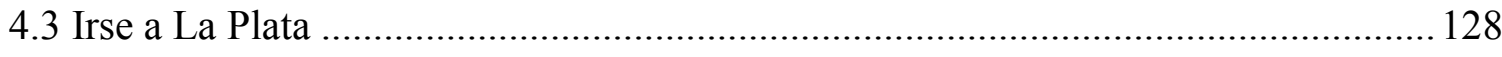

4.3.1 "Me voy para progresar": movilidad social y "enriquecimiento personal” ....... 129

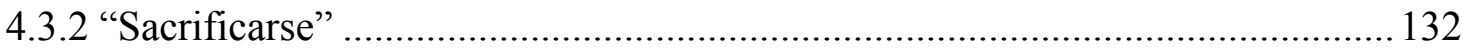

4.3.3 "Merecer estudiar en La Plata": el estudio como orden moral ......................... 133

4.3.4 "Hay que irse del pueblo para no ser maestra jardinera o niñera": género y proyecciones de movilidad social .................................................................... 135

4.4 Volver a Roque Pérez (o no): proyecciones ...................................................... 137

4.5 Autopercepción de clase y apuesta por la movilidad social: conclusiones............... 139

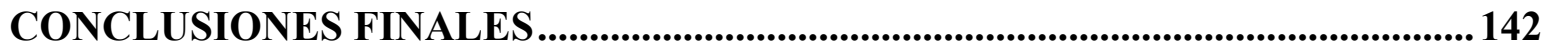

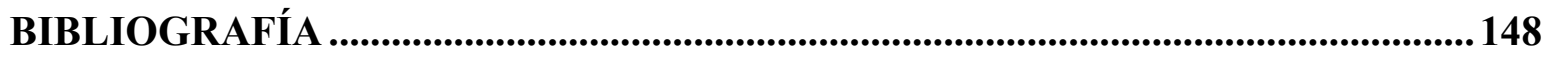


FUENTES DOCUMENTALES ........................................................................... 162

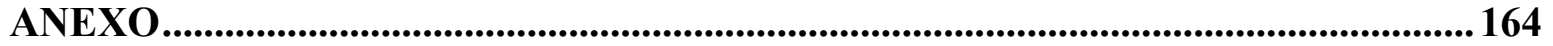




\section{AGRADECIMIENTOS}

Para realizar esta tesis recibí el apoyo y acompañamiento de diferentes personas a quienes quiero agradecer.

A Mariana Chaves por haberme acompañado desde el comienzo de la investigación y por su capacidad de escucharme y comprenderme a lo largo del proceso. A Adriana Cuenca por su generosidad en aceptar dirigir la beca que posibilitó esta investigación y por guiarme en mis primeros pasos como investigador y docente universitario.

Al Consejo Nacional de Investigaciones Científicas y Técnicas (CONICET) cuyo financiamiento, a partir de una beca de posgrado, posibilitó el desarrollo de este trabajo. También al Laboratorio de Estudios en Cultura y Sociedad (LECyS) de la Facultad de Trabajo Social de la Universidad Nacional de La Plata que se convirtió en mi "lugar" laboral durante estos años.

A mis compañeros de trabajo diario. Por un lado, miembros del LECyS que me acompañaron en este recorrido: Josefina Cingolani, Elená Bergé, Carlos Galimberti, Tomás Bover, María Celeste Hernández, Marcos Mutuverría, Ramiro Segura, Gabriela Flaster y Ana Sabrina Mora. Por otro lado, a mis compañeras de la cátedra Investigación Social I de la Facultad de Trabajo Social con quienes comparto el maravilloso oficio de enseñar: María Valeria Branca, Vanesa Martello, María Soledad Carreño, Susana Lozano, Julieta Gianfrancisco, Cecilia Corominas, Sol Córdoba y Carolina Doñate.

A las personas (compañeros de trabajo y amigos) que, en estos últimos meses, me ayudaron a poder concluir con la escritura de la tesis, dedicando horas de lectura atenta y aportando valiosos comentarios: Paula Hanlon, Josefina Cingolani, Carlos Galimerti, Elena Bergé y Tomás Bover. Gracias también a mi querida amiga María Soledad Carreño por su ayuda en la edición final.

A los amigos que me acompañaron con su afecto durante estos últimos años y me alentaron a que avance con mi trabajo: Martina Juárez, Araí Acuña, Emiliano Bentivenga y Luz Espiro. 
A las personas de Roque Pérez que me abrieron las puertas de sus casas para contarme sus historias y me ensañaron mucho de ese maravilloso "pueblo". En especial a mi amiga Luciana Del Barrio por su apoyo y calidez y a Héctor y Susana Del Barrio por compartir su casa (y su deliciosa comida) conmigo cuando estuve haciendo trabajo de campo. A Cecilia Soria por sus aportes y su ayuda incansable y también a Luciano Forti que, a pesar de no ser roqueperense, me acompañó en mis caminatas "etnográficas" por el lugar.

A mi familia que siempre me acompaña. A mis papás Claudia y Eduardo por apoyarme y brindarme su cariño en todos estos años de trabajo. A mi hermana Abril por su compañía diaria y su paciencia para "aguantarme" en los momentos complicados de la investigación. A mis abuelos Eduardo "Tito”, José, Gladys e Inés quienes están siempre a mi lado.

Por último, a mi compañero de ruta Michele Tanzi por su amor de todos los días.

A todos ellos, ¡muchas gracias!

Agustín Cleve

La Plata, 7 de diciembre de 2017 


\section{RESUMEN}

En la presente investigación analizamos las experiencias de jóvenes que migran desde Roque Pérez, una localidad pequeña y de economía agropecuaria de la Provincia de Buenos Aires, hacia la ciudad de La Plata (capital provincial) para estudiar en la Universidad Nacional de La Plata, una institución de carácter pública. En particular, abordamos sus experiencias prestando atención a la relación entre tres aspectos: la movilidad entre localidades, la movilidad en el curso de vida y la condición estudiantil universitaria. El argumento que guía la tesis sostiene que la migración de ciudad genera cambios en los cursos de vida de los sujetos, produciendo experiencias juveniles diferentes a las que se tenían en el lugar de origen. A su vez, analizamos el modo en que el paso por la institución universitaria se vuelve central en sus vidas en base a dos grandes razones. Primero porque constituye una apuesta por la movilidad social ascendente y, segundo, porque la condición estudiantil universitaria se convierte en organizadora de sus experiencias en la ciudad de La Plata. La investigación se desarrolló en base a una estrategia metodológica de tipo cualitativa que permitió adentrarnos de manera profunda en los modos de significación y prácticas de los sujetos. El trabajo de campo se desarrolló entre los años 2014 y 2016 y, en ese marco, se llevaron adelante observaciones participantes, entrevistas y se registraron fuentes secundarias.

\section{Palabras clave:}

Migración estudiantil- Curso de Vida- Experiencia-Juventud 


\section{INTRODUCCION}

\section{Presentación del problema y objetivos de la investigación}

Esta tesis es el resultado de un proceso de investigación que comenzó varios años atrás sobre jóvenes que migraban de ciudad para iniciar estudios universitarios. El interés en el tema tuvo una doble motivación. Por un lado, aun siendo estudiante de grado en la carrera de Trabajo Social, me incluí como pasante en un proyecto de investigación sobre Circuitos y Trayectorias de jóvenes en el espacio urbano ${ }^{1}$. En ese marco comencé a delimitar un tema propio que pudiera dialogar con el interés general del proyecto y la migración de estudiantes hacia la ciudad de La Plata fue el "caso particular" construido. La segunda motivación estuvo ligada a mi propia experiencia biográfica como estudiante migrante. Si bien nací en La Plata, viví mi infancia y adolescencia en el Partido de La Costa, una localidad del interior de la Provincia de Buenos Aires. A los 17 años, cuando terminé la escuela secundaria, me fui (regresé) a La Plata para estudiar Trabajo Social en la Universidad Nacional de La Plata (UNLP).

El comienzo de esta investigación fue posible a partir de una Beca de Estímulo a las Vocaciones Científicas otorgada por el Consejo Interuniversitario Nacional (CIN), mientras era estudiante de grado, que me permitió comenzar a "sumergirme" en el tema. Leí bibliografía especializada sobre migraciones juveniles, estudiantiles y también sobre experiencia universitaria. También en ese marco realicé un "pequeño" trabajo de campo que consistió en cinco entrevistas a jóvenes que provenían de una localidad del interior de la Provincia de Buenos Aires y se encontraban estudiando en La Plata ${ }^{2}$. Allí indagué en sus experiencias de migrar, las redes que posibilitaban la permanencia en la ciudad y los

\footnotetext{
${ }^{1}$ Proyecto 11/ T055 Circuitos y trayectorias juveniles en ámbitos urbanos. 2009-2012 Directora: Dra. Mariana Chaves. Co- director: Dr. Ramiro Segura. Programa de Incentivos a la investigación SCyT-Mrio Educación.

${ }^{2}$ Para esta primera investigación, seleccionamos jóvenes originarios del Partido de Trenque Lauquen, Provincia de Buenos Aires.
} 
sentimientos vinculados al cambio de localidad. A partir de ese trabajo, decidí continuar con el tema para realizar mi formación de posgrado y una beca del Consejo Nacional de Investigaciones Científicas y Técnicas (CONICET) lo posibilitó. Esta tesis es producto de esa investigación de posgrado.

En ese proyecto formulé como objetivo general comprender las experiencias de jóvenes que se trasladan desde la localidad de Roque Pérez (Provincia de Buenos Aires) hacia la ciudad de La Plata (capital de dicha provincia) para realizar estudios universitarios, analizando las relaciones entre: migración de localidad, movilidad en el curso de vida y condición estudiantil universitaria. Me interesaba tomar a estas dos localidades como origen y destino de los migrantes estudiantiles por sus amplias diferencias urbanas. Roque Pérez es una localidad de poco más de 12.000 personas y de economía principalmente agropecuaria. En cambio, La Plata es una ciudad de más de 600.000 habitantes y, desde varias décadas atrás, se ha constituido en un polo de atracción para la migración estudiantil nacional e internacional debido a la existencia de la Universidad Nacional de La Plata, una de las instituciones de educación superior más grande del país. ${ }^{3}$

Los objetivos específicos del proyecto fueron: i) caracterizar y analizar las particularidades de las trayectorias de los y las jóvenes que migran a estudiar; ii) indagar los sentidos de los y las jóvenes sobre la experiencia de migrar hacia otra ciudad en términos de movilidad en el curso de vida, prestando atención a los elementos que operen como marcadores de pasaje y transición entre edades o etapas; iii) analizar los imaginarios urbanos sobre los lugares de origen y destino de la migración con el propósito de comprender los sentidos y valoraciones que aparecen sobre ambos; iv) identificar e indagar sobre las redes sociales en las que participan las y los jóvenes que migran tanto en el lugar de origen como el de destino y; v) analizar los modos en que la condición estudiantil se encuentra presente en la vida de los y las jóvenes, poniendo atención a los lugares a los que asisten, prácticas y sociabilidades.

La hipótesis de partida sostenía que la migración de ciudad produce, en los jóvenes, una transición en términos etarios hacia un tipo de experiencia juvenil diferente a la que se tenía en el lugar de origen. Es necesario aclarar que no se asociaba la transición con el

\footnotetext{
${ }^{3}$ En el capítulo 1 se desarrollan en profundidad las características de ambas localidades.
} 
pasaje de la condición juvenil a la condición adulta sino que se lo entendía como un cambio en los modos de experimentar la propia condición juvenil. A su vez, se quería explicar el modo en que estas experiencias variaban de acuerdo a las particularidades de las trayectorias de los jóvenes.

La investigación fue realizada, casi en su totalidad, entre los años 2014 y 2015. ${ }^{4}$ En ese tiempo gobernaba a nivel nacional Cristina Fernández de Kirchner (2007-2015), y a nivel provincial, Daniel Scioli (2007-2015). El intendente de La Plata era Pablo Bruera (2007-2015) y el de Roque Pérez Juan Carlos Gasparini (2011 a la actualidad). Todos ellos pertenecientes al espacio político Frente para la Victoria. El escenario histórico nacional en donde transcurren las experiencias de los jóvenes estuvo caracterizado por un crecimiento hacia mayores niveles de igualdad que no implicaron la ausencia de tensiones y continuidad de ciertas desigualdades. Antes de Cristina Kirchner, la presidencia fue ocupada por su esposo Néstor Kirchner (2003-2007). Durante su gobierno se produjo una sostenida política de generación de empleo y protección del mercado interno en un contexto que venía marcado por fuertes índices de desempleo y pobreza, producto de las medidas neoliberales implementadas en la década anterior (Benza, 2016). Su sucesora continuó esta orientación política aunque algunos estudios (Falappa y Adrenacci, 2009; Barberis, 2011) señalan que disminuyó la generación de puestos de empleos. Además, durante su gestión, se impulsaron una serie de políticas públicas dirigidas a la protección de los sectores asalariados mediante subsidios (Falappa y Andrenacci, 2009) y también se creó la Asignación Universal por hijo para extender los beneficios de seguridad social a sectores de empleo informal.

En particular sobre políticas educativas para el sistema universitario, durante la gestión de los Kirchner se crearon 17 universidades nacionales, llegando a 53 en todo el país, y se aumentó significativamente el presupuesto en esta materia. De estas nuevas universidades, 7 fueron radicadas en el Conurbano Bonaerense, lo cual promovió el ingreso a la formación universitaria en sectores sociales que históricamente no había podido

\footnotetext{
${ }^{4}$ Solo tres entrevistas se hicieron durante los primeros meses del 2016. En diciembre del 2015 se produjo un cambio en la orientación política a nivel nacional y provincial con el triunfo electoral de "Cambiemos" y la llegada al poder de Mauricio Macri a la nación y María Eugenia Vidal a la provincia. No abordamos en esta tesis ese período histórico puesto que el trabajo de campo había casi concluido.
} 
acceder a ella ${ }^{5}$ o que debían movilizarse todos los días a ciudades como Buenos Aires o La Plata para poder cursar estudios universitarios. Además, durante el gobierno de Cristina Kirchner se impulsó el Programa de Respaldo a estudiantes de Argentina (Progresar) ${ }^{6}$ desde la Administración Nacional de Seguridad Social (ANSES). También creció significativamente el presupuesto a los organismos de ciencia y técnica como el CONICET, entre otros. De este modo, el escenario histórico de las experiencias de los jóvenes que aquí se analizan puede considerarse favorable para cursar estudios superiores, aunque se verá que estas experiencias no están exentas de dificultades y conflictividades.

\section{Algunas herramientas conceptuales}

Si bien a lo largo de la tesis iremos desarrollando y utilizando diferentes conceptos, consideramos necesario hacer aclaraciones sobre algunas categorías principales: experiencia, curso de vida, migración y condición estudiantil. En primer lugar, el concepto de "experiencia" que utilizamos se propone articular condicionamientos sociales, capacidades de agencia de los sujetos y modos de interpretar al mundo. Como sostiene el historiador Martin Jay “la 'experiencia' se halla en el punto nodal de la intersección entre el lenguaje público y la subjetividad, entre los rasgos comunes expresables y el carácter inefable de la interioridad individual.” (2009:20). Utilizaremos esta categoría como una herramienta conceptual que permita reflexionar sobre la imbricación entre los lugares (sociales y discursivos) socialmente disponibles y los modos en que los sujetos los habitan y se mueven dentro de ellos (Scott, 1999).

A partir del análisis de las experiencias de los jóvenes reconstruimos los modos en que ellos las vivencian y las significan, contemplando las condiciones sociales que producen esas experiencias. En este sentido, retomamos la afirmación de Alfred Schutz

\footnotetext{
${ }^{5}$ Sobre las experiencias universitarias de estos sectores, se destaca el trabajo de Colabella y Vargas (2013) sobre estudiantes de la Universidad Arturo Jauretche en Florencio Varela.

${ }^{6}$ Este se encuentra destinado a jóvenes de entre 18 y 24 años que no trabajen o tengan un trabajo cuyo ingreso sea inferior al salario mínimo, vital y móvil, y su grupo familiar esté en iguales condiciones. El programa les aporta un apoyo económico para comenzar o continuar sus estudios en cualquier nivel educativo.
} 
(1962) que el mundo social es pre interpretado por los actores que lo producen y reproducen con sus propias acciones y que las interpretaciones de los investigadores sociales son siempre de segundo orden o, en términos de Giddens (1993), las ciencias sociales se caracterizan por una doble hermenéutica.

En segundo lugar, para el análisis del curso de vida, recuperamos las herramientas analíticas del enfoque homónimo desarrollado por el sociólogo norteamericano Glen Elder (1994). Este enfoque teórico- metodológico surge en Estados Unidos en los años setenta como propuesta para analizar las conexiones entre los eventos históricos y las trayectorias individuales, proponiendo un abordaje novedoso para retomar la preocupación sociológica por las conexiones entre lo social y lo individual ${ }^{7}$ (Blanco, 2011). El enfoque posee cinco principios fundamentales que retomaremos a lo largo de la tesis: i) Principio de desarrollo a lo largo del tiempo: sostiene que para investigar un momento específico de una trayectoria de vida, es necesario tener en cuenta los momentos precedentes de la misma; ii) Principio de tiempo y lugar: alude a la importancia de lo contextual, entendiendo que los cursos de vida se sitúan en marcos históricos y geográficos; iii) Principio del timing: remite a los modos en que se realizan gradaciones de acuerdo a la edad y a los roles y expectativas sobre cada momento del curso de vida; iv) Principio de las vidas interconectadas: sostiene que las vidas de las personas siempre se viven en relaciones de conexión e independencia; v) Principio de agencia: destaca que los sujetos no son entes pasivos a los que se les imponen los condicionamientos estructurales sino que llevan adelante actividades y realizan elecciones que les posibilitan construir sus propios cursos de vida.

A su vez, el enfoque propone tres categorías centrales para el análisis de los cursos de vida. La primera es la noción de trayectoria que se entiende como: "una línea de vida o carrera, un camino a lo largo de toda la vida que puede variar en dirección, grado y proporción" (Elder, 2001:63). Las trayectorias abarcan una variedad de ámbitos (como el trabajo, la escolaridad, la migración y la vida familiar, entre otras) que son

\footnotetext{
${ }^{7}$ Dentro de las ciencias sociales, el estudio de trayectorias biográficas no ha sido desarrollado solamente por el enfoque del curso de vida originado en Estados Unidos. En Europa se destaca el denominado enfoque biográfico que ha tenido como referentes a Franco Ferraroti (1993) y Daniel Bertaux (1989) entre otros. Ambas corrientes se asemejan en su intención por estudiar las articulaciones entre lo social y las vidas particulares (Roberti, 2015). En esta tesis nos posicionamos principalmente desde el enfoque del curso de vida.
} 
interdependientes entre sí. La segunda es la de transición que refiere a "cambios de estado o de posición, no necesariamente predeterminados o previsibles aunque, en términos generales, hay algunos cambios que tienen mayores o menores probabilidades de ocurrir (por ejemplo: entradas y salidas del sistema educativo, del mercado de trabajo, del matrimonio, etc.) debido a que continúa prevaleciendo un sistema de expectativas en torno a la edad, que varía por ámbitos, grupos de diversa índole y culturas o sociedades." (Blanco, 2011: 13). La tercera es la de turning point que hace referencia a eventos que provocan modificaciones e introducen virajes en la dirección del curso de vida. A diferencia de los conceptos anteriores, que pueden tener algún tipo de probabilidad de ocurrencia, estos solo pueden ser analizados contemplando cada historia particular. Para un sujeto un turning point puede surgir a partir de la muerte de un familiar o algún otro evento significativo que le implique un cambio de situación en el curso de vida.

Con respecto a la migración, la entendemos como un tipo particular de movilidad espacial que refiere a los desplazamientos de personas entre países o regiones de un mismo país. En esta tesis nos detenemos en dinámicas migratorias internas que pueden entenderse como aquellas que se producen dentro de la frontera de un país, tanto interprovinciales, intraprovinciales, rurales- urbanos o entre ciudades de distinta envergadura. Existen diversas razones que motivan a las personas a migrar y aquí particularizamos entre aquellas que están orientadas en la búsqueda de formación educativa y que denominamos migración estudiantil.

Por último, en relación a la condición estudiantil, nos posicionamos desde la perspectiva del sociólogo francés Francois Dubet quien sostiene que la condición de estudiante incluye y articula dos dimensiones: una experiencia juvenil y una condición escolar. Señala el autor que: "El estudiante no se puede reducir ni a su papel ni a su condición, sino que elabora una experiencia que articula una manera de ser joven y una relación con los estudios. El estudiante vive el encuentro de la juventud y de la universidad. A veces, este encuentro es tan débil que los estudiantes solo aparecen como jóvenes que van a la universidad algunos días a la semana, pero otras aparecen, al contrario, como "verdaderos estudiantes" totalmente definidos por el tipo de estudios que hacen." (2005:3). 
A lo largo de la tesis veremos cómo ambas condiciones se articulan en las experiencias de los sujetos que presentaremos más adelante.

Por otro lado, retomamos también aportes de la perspectiva de la experiencia universitaria desarrollada por Sandra Carli (2012). La misma explora los modos en que los estudiantes transitan la vida universitaria, combinando las narrativas de los sujetos con las características propias de las instituciones. Nos interesa dialogar con esta perspectiva porque permite analizar los modos en que la condición estudiantil atraviesa la vida tanto dentro como fuera de la institución universitaria, produciendo sociabilidades y circuitos específicos en la ciudad. Profundizaremos estos contenidos en el capítulo 2.

A lo largo de la tesis iremos retomando estos aportes y también incorporaremos y explicaremos otros conceptos y enfoques teóricos con los que hemos dialogados durante la investigación.

\section{Antecedentes}

En este apartado presentamos una revisión de diversas investigaciones que constituyen antecedentes con los cuales nuestra tesis dialoga. En primer lugar nos detendremos sobre algunos estudios sobre migraciones juveniles y, en segundo lugar, particularizaremos en otras investigaciones que se han focalizado en las migraciones de estudiantes.

Con respecto a los estudios sobre migración juvenil, la CEPAL y la OIJ (Organización Iberoamericana de la Juventud) identifican al menos cinco tipos de migración juvenil en Iberoamérica: i) migración laboral; ii) migración educativa; iii) migración nupcial; iv) migración emancipatoria; y v) migración familiar. Este fenómeno suele estar relacionado con sucesos significativos en las vidas de los jóvenes, entre estos se destacan la unión y el inicio de la reproducción, la entrada a la universidad y al mercado de trabajo. Es necesario aclarar que muchos de estos tipos de migración se producen por más de una sola razón (por ejemplo: educación e inserción laboral) (OIJ-CEPAL, 2007). A 
continuación retomamos algunos estudios sobre migraciones (internacionales e internas) de jóvenes originarios de países latinoamericanos.

Con respecto a dinámicas migratorias internacionales, la antropóloga Liliana Suárez Návaz (2006) realizó una exhaustiva recopilación de investigaciones sobre el tema, arribando a la conclusión de que la juventud se ha convertido en un actor significativo de los procesos migratorios de principios de siglo XXI. Esta investigadora recupera estudios sobre migraciones de la frontera México-Norteamericana (Ramirez Parra, 2003) y sobre migrantes de países latinoamericanos hacia Europa (Giménez y Suárez, 2000; Suárez Návaz, 2006). Estos autores afirman que las dinámicas del capitalismo global de principios de siglo XXI producen que los países de tercer mundo se vuelvan centros de emisión de jóvenes migrantes. Estos estudios abordan las particularidades de los factores que motivan las migraciones de los jóvenes, en donde se conjugan objetivos en el plano material (búsqueda de ingresos monetarios), como así también en el plano simbólico y personal, relacionado a la adquisición de experiencia, madurez y autonomía.

Sobre migraciones juveniles internas dentro de países latinoamericanos, destacamos el trabajo de Rodriguez Vignoli (2008) que realiza una interesante revisión de estudios sobre esta temática, sosteniendo que el sector juvenil es el que más tendencia tiene hacia la migración interna en relación a otros grupos de edad y que principalmente se desplaza hacia grandes centros urbanos (Rodriguez y Busso, 2009). Las motivaciones centrales de estas movilidades son laborales (principalmente para sectores socioeconómicos bajos aunque también para otros) y educativas (sobre todo para sectores socioeconómicos medios y altos).

Dentro de las investigaciones sobre migración juvenil nos interesa particularmente destacar aquellas que relacionan la migración con transiciones en términos etarios. Algunas de ellas (Dolado y Fernández Yusta, 2002 y Rodríguez, 2004) sostienen que la migración puede significar, para algunos jóvenes, una búsqueda de identidad y una forma de postergar las responsabilidades adultas que deberían asumir en el lugar de origen. Es decir, migrar les permite vivir una condición juvenil asociada a la moratoria social. Este concepto, que será retomado más adelante, alude a un período de tiempo en el cual los sujetos pueden postergar las responsabilidades propias del mundo adulto y dedicarse al estudio y también 
al ocio (Margulis y Urresti, 1998). Otros estudios (Martí, 2011 y Miranda, Cravino y Martí, 2012) analizan la relación entre la migración de trabajadores paraguayos y las transiciones a la vida adulta a partir de la hipótesis de que migrar implica asumir responsabilidades propias del mundo adulto en el país de destino. A pesar de que los tipos de migración que analizan estas investigaciones difieren notablemente de las migraciones que interesan a esta tesis, rescatamos su interés teórico por vincular las migraciones con las movilidades en el curso vital.

Con respecto a las investigaciones sobre movilidades estudiantiles en jóvenes, diferenciamos entre aquellas que analizan migraciones internacionales de aquellas que se detienen en migraciones internas. Con respecto a las primeras, la socióloga ecuatoriana Rosa Bermúdez Rico (2015) realizó un incipiente estado de la cuestión dando cuenta de que, en la última década, hubo un crecimiento significativo de profesionales que se movilizaron para realizar estudios de posgrado, lo cual se establece como un flujo específico de la migración calificada. Cabe destacar que los flujos migratorios de estudiantes de posgrado son los que más han atraído la atención de las ciencias sociales en estos últimos años. Para algunos investigadores, las migraciones estudiantiles internacionales no se asocian exclusivamente con la formación educativa sino que se vinculan con factores relacionados a la adquisición de experiencia y recreación. Es así como estas migraciones se han conceptualizado como una "cultura juvenil de movilidad" (Luchillo, 2006) o como una migración “económica-cultural” (Jensen y Perret, 2011). Los planteos de estos estudios son valiosos para nuestra investigación porque proponen analizar una serie de motivaciones, en los migrantes, que no se reduce exclusivamente a las mejoras en términos de nivel educativo.

La migración estudiantil interna ha sido menos estudiada aunque se encontraron en nuestro país algunos trabajos al respecto. Desde un enfoque psicológico, Ana Tosi (2009) analizó procesos migratorios y sus impactos en la subjetividad en jóvenes que se trasladaron a la ciudad de Rosario para estudiar en la universidad nacional local. Desde una perspectiva similar, se puede mencionar el trabajo de Ferreira Dos Santos, Korolik, Jaimsky y Schlafman (2013) que se detiene en la relación entre la migración y los efectos psíquicos en adolescentes tardíos que migran desde el interior del país a la ciudad de Buenos Aires 
para estudiar en la universidad. También destacamos los trabajos de Arias (1998) y Di Doménico (1998) sobre la migración de jóvenes hacia la ciudad de Mar del Plata.

Los investigadores argentinos Gustavo Gamallo y Pedro Nuñez (2013) realizaron una investigación sobre estudiantes universitarios originarios de la Provincia de Río Negro que se encontraban en las ciudades de Bahía Blanca, Buenos Aires y La Plata. En ese trabajo se reconstruyen tipos ideales de trayectorias de acuerdo al éxito o fracaso del proyecto migratorio. Una cuestión interesante que señalan es la construcción de una diferenciación entre los que migran y los que se quedan en Río Negro. En este sentido, las representaciones sobre los migrantes suelen estar asociadas a una idea de mejora en la vida, mientras que los no migrantes gozan de menos prestigio, lo cual permite ver el modo en que las migraciones operan como generadoras de capital simbólico.

Más allá de estos estudios mencionados, se puede evidenciar una escasez de investigaciones sobre migración interna estudiantil en la Argentina. En este sentido, nuestra tesis pretende aportar al conocimiento del fenómeno a partir de un estudio particular.

\section{Consideraciones metodológicas}

La estrategia metodológica seleccionada fue de tipo cualitativa porque consideramos que constituye el camino privilegiado para la comprensión de las experiencias singulares y los sentidos que los sujetos asignan al mundo (Vasilachis, 2006). El trabajo de campo, tanto en Roque Pérez como en La Plata, fue realizado entre los años 2014 y 2016. En ambos lugares utilizamos como principales técnicas para la producción de datos la observación participante y la entrevista. Con respecto a la primera, entendemos que consiste en una serie de actividades atravesadas por la presencia directa del investigador en el campo, que se caracteriza por una mirada y escucha atenta a lo que acontece (Guber, 2009). La entrevista la entendemos como una relación social entre el sujeto que conoce y el sujeto investigado en donde se busca comprender su perspectiva sobre los hechos que interesan al investigador (Marradi, Archenti y Piovani, 2007). Dentro de esta técnica, utilizamos entrevistas en profundidad individuales, entrevistas grupales y cuestionarios para 
conocer datos sobre las familias de los jóvenes (principalmente sobre educación, vivienda y trabajo).

Hemos analizado las experiencias de 16 jóvenes que migraron desde Roque Pérez hacia La Plata para estudiar en la Universidad Nacional de La Plata (UNLP). 13 de ellos se encontraban viviendo en La Plata cuando fueron entrevistados (10 eran estudiantes y 3 graduados). Los otros 3 habían migrado a La Plata pero regresaron a Roque Pérez y vivían allí cuando los conocimos (1 se había graduado y los otros 2 abandonaron sus carreras). Estos últimos fueron contactados porque nos interesaba contar con los relatos de quienes habían regresado al lugar de origen. Con el fin de construir una muestra heterogénea, se buscaron jóvenes que difieran en el género (mujeres y varones), el tiempo de residencia en La Plata (desde pocos meses hasta más de cinco años), el tipo de vivienda en la que residían (departamentos, pensiones, Centro de Estudiantes) y si trabajaban o no. Se utilizó la estrategia de bola de nieve para contactar con nuevos informantes. (Ver tabla con datos de los entrevistados en el ANEXO).

En Roque Pérez realizamos observaciones en diferentes espacios públicos (plazas, parques, lugares de recreación juveniles) para conocer la localidad en profundidad y buscamos información en diferentes fuentes (documentales, estadísticas, medios locales y redes sociales) para caracterizarla en términos históricos, económicos y sociodemográficos. A su vez, entrevistamos a dos funcionarios municipales, padres de jóvenes migrantes y a un docente de una escuela secundaria para conocer más sobre la migración estudiantil. También mantuvimos charlas informales con directivos escolares y realizamos un taller en una de las escuelas secundarias de Roque Pérez, con estudiantes del último año, sobre sus proyecciones acerca de irse (o no) a estudiar a otra ciudad con el fin de ampliar nuestros conocimientos sobre el fenómeno.

En La Plata llevamos adelante el trabajo de campo en diferentes contextos de interacción. En primer lugar nos pusimos en contacto con jóvenes que vivían en el Centro de Estudiantes de Roque Pérez (CERP), un edificio perteneciente a la Municipalidad de Roque Pérez destinado a albergar a migrantes estudiantiles ${ }^{8}$. Allí realizamos observaciones en diferentes momentos y entrevistamos a varios jóvenes residentes. Por otra parte,

\footnotetext{
${ }^{8}$ Sobre este sitio nos detendremos en profundidad en el capítulo 2.
} 
asistimos a fiestas, eventos musicales y movilizaciones políticas con varios sujetos y realizamos entrevistas en sus propios domicilios en La Plata. Asimismo, utilizamos fuentes secundarias para poder caracterizar la capital provincial en términos históricos, sociodemográficos y económicos.

El corpus de datos quedó constituido por registros de observación, transcripciones de entrevistas y fuentes secundarias (documentos con información histórica, económica y estadística) que analizamos a partir de diferentes estrategias. La información de los registros de observación fue volcada dentro de matrices que contenían diferentes ejes temáticos de interés que posibilitaron su sistematización y organización. Las transcripciones de entrevistas fueron utilizadas, por un lado, para la reconstrucción de trayectorias a partir de las propias narrativas biográficas y, por otro, para identificar ejes que permitieron analizar similitudes y diferencias en las experiencias de los jóvenes. Fue de gran ayuda para este corpus de datos, la utilización del software Atlas Ti., que posibilitó identificar y seleccionar fragmentos de relato y codificarlos de acuerdo a temas de interés. Particularmente, con ayuda de este programa, pudimos reconstruir una serie de representaciones sociales vinculadas a las categorías nativas de "pueblo" y "ciudad" sobre las cuales nos explayaremos en el capítulo 1.

El tercer corpus de datos estuvo compuesto por las fuentes secundarias sobre Roque Pérez y La Plata. Entre ellas, analizamos datos estadísticos del Censo Nacional de Poblaciones realizado en el 2010, anuarios de la Universidad Nacional de La Plata, información proveniente del Ministerio de Economía de la Provincia de Buenos Aires (que nos permitió caracterizar aspectos económicos de ambas localidades), y también de la Dirección Provincial de Escuelas para relevar información sobre establecimientos educativos. Por otra parte, se relevaron fuentes históricas extraídas del Archivo Histórico de la Provincia de Buenos Aires para obtener datos sobre ambas ciudades.

\section{Estructura de la Tesis}

Los contenidos de la tesis se organizan de la siguiente manera: 
En el capítulo 1 nos detenemos sobre los lugares de origen y destino de los jóvenes: Roque Pérez y La Plata con un doble propósito. El primero es caracterizarlos en términos históricos, económicos y sociodemográficos y, el segundo, analizar los imaginarios urbanos de los jóvenes sobre ambas localidades. Estos imaginarios, como veremos en los capítulos siguientes, cobran una vital importancia para entender las prácticas migratorias de los sujetos.

En el capítulo 2 analizamos dos momentos que se constituyen como indicadores de transición en el curso de vida de los jóvenes: la llegada a La Plata y el ingreso a la institución universitaria. Analizamos la producción de nuevas autonomías vinculado con la noción de "sentirse más grande" y el papel de las redes (familiares y de amistad) en el desarrollo del proyecto migratorio.

En el capítulo 3 focalizamos en tres nuevas experiencias que se producen viviendo en La Plata: políticas, artísticas y de gestión de la privacidad (vinculado a elecciones sexuales y afectivas). Para ello se reconstruyen trayectorias de diferentes jóvenes donde analizamos cómo la vida en la capital bonaerense genera las condiciones para la producción de una experiencia juvenil diferente a la del lugar de origen.

En el capítulo 4 abordamos las expectativas, proyecciones y realizaciones de movilidad social de los jóvenes en torno a la educación universitaria. Allí veremos las lógicas que se configuran en torno a la búsqueda de capital escolar y el modo en que atraviesa sus decisiones de quedarse, irse o volver a Roque Pérez.

Sobre el final presentamos las conclusiones donde retomamos diferentes aspectos trabajados en cada capítulo y se realizan una serie de reflexiones que cierran la tesis. 


\section{CAPÍTULO 1 Pueblo chico, pueblo grande y ciudad: los lugares de la experiencia}

En este capítulo nos detenemos en los lugares de origen y destino de los jóvenes (Roque Pérez y La Plata) con un doble propósito. Por un lado, para caracterizar estos escenarios de sus experiencias y, por otro, para analizar los imaginarios urbanos juveniles que circulan y forman parte de ellos. Nuestro interés por el estudio de estos imaginarios se vincula con la hipótesis de que los mismos son orientadores de las prácticas migratorias de los sujetos, interviniendo en sus deseos de permanecer o irse de los lugares. El interrogante que intentaremos abordar en este capítulo es ¿De qué modo inciden estos imaginarios en la movilidad espacial de los sujetos?

Para la caracterización de ambas localidades relevamos y sistematizamos fuentes secundarias que permitieron reconstruir aspectos históricos, geográficos y sociodemográficos generales. También describimos algunos espacios, dentro de cada ciudad, que fueron referenciados por los sujetos como lugares significativos de ocio y encuentro juvenil. Para el análisis de los imaginarios urbanos utilizamos las transcripciones de entrevistas y, con ayuda del software Atlas ti, seleccionamos todos los fragmentos de relato en que los jóvenes referían a Roque Pérez y La Plata. Luego identificamos ejes y construimos una tipificación de significados a partir de ciertas regularidades encontradas. Esto nos permitió reconstruir un conjunto de representaciones sociales ${ }^{9}$ que agrupamos después bajo la formación de los diferentes imaginarios.

\footnotetext{
${ }^{9}$ Tomamos los aportes de Jodelet quien sostiene que las representaciones sociales: "corresponden a una forma específica de conocimiento, el conocimiento ordinario, que es incluido en la categoría de sentido común y tiene como particularidad la de ser socialmente construido y compartido en el seno de diferentes grupos. Esta forma de conocimiento tiene una raíz y un objetivo práctico: apoyándose en la experiencia de las personas, sirve de grilla de lectura de la realidad y de guía de acción en la vida práctica y cotidiana". (2011: 134)
} 
"Pueblo"10 y "ciudad" fueron los términos principales con que los jóvenes denominaron a ambas localidades. A Roque Pérez siempre se lo menciona como "pueblo" y a La Plata, la mayoría de las veces, como "ciudad" aunque a veces también se la denomina "pueblo grande". Veremos, en el análisis de los imaginarios, que con estos dos términos los sujetos referencian a estilos de vida y formas de sociabilidad diferentes. Nuestro interés en los imaginarios radica en que entendemos que los espacios urbanos no se reducen solo a su dimensión física sino que también son construidos por operaciones simbólicas que involucran discursos e imágenes y que modelan nuestra percepción de la vida (Silva, 2006). Coincidimos con García Canclini en que estos corresponden a "elaboraciones simbólicas en donde confluyen aspectos que observamos, lo que nos atemoriza y lo que desearíamos que existiera, remitiendo a un campo de imágenes diferenciadas de lo empíricamente observable" (2007:90). Los mismos son compartidos socialmente tanto por círculos pequeños o por grandes grupos sociales (Lindón, 2007).

Además de esta introducción y unas interpretaciones de cierre, el capítulo está organizado en dos partes principales, una por cada localidad (Roque Pérez y La Plata). A su vez, estas dos partes se subdividen en dos secciones. En la primera se caracteriza cada ciudad utilizando fuentes secundarias (datos históricos, económicos, demográficos, educativos y geográficos) y fuentes primarias (registros de observación y transcripciones de entrevistas). En la segunda se presenta el análisis de los imaginarios urbanos juveniles, mencionando también las representaciones sociales que los conforman.

\subsection{Roque Pérez}

Mi primer viaje a Roque Pérez fue el 24 de junio de 2014. Ese día el partido celebraba su cumpleaños número 101, de modo que pude presenciar el desfile y los festejos organizados por el gobierno municipal. Recuerdo que hice ese primer viaje en la camioneta de los padres de una amiga, quienes me hospedaron en su casa todas las veces que estuve haciendo mi trabajo de campo. El viaje desde La Plata duró alrededor

\footnotetext{
${ }^{10}$ Utilizamos las comillas para referenciar las categorías nativas. Como este capítulo está centrado en los imaginarios juveniles sobre los lugares de origen y destino, analizaremos las denominaciones de "pueblo" y "ciudad" como categorías nativas.
} 
de dos horas. Cuando llegamos a la entrada de la localidad, me recibió un cartel que decía: "Pueblo de Buenas Costumbres." De esa manera Roque Pérez me dio la bienvenida.

Al igual que el cartel, las personas que fui conociendo nombraban "pueblo" a Roque Pérez. Entramos a la localidad por el Acceso Pedro Gutiérrez, una avenida asfaltada rodeada de árboles por ambos costados. Por detrás de los árboles se observan grandes extensiones de campo y también galpones y contenedores en donde se guarda parte de la producción agrícola y ganadera de la localidad. Junto a algunos contenedores, pude ver un cartel que decía "CRIAVE", el nombre de la principal empresa avícola del lugar. A medida que fuimos adentrándonos, el área se fue urbanizando cada vez más. Las casas que se pueden observar son de material y están casi todas edificadas una al lado de la otra. La mayoría de ellas son de una sola planta, algunas tienen dos, no hay edificios más altos que eso. El día que llegamos había muchos autos en la calle. Los padres de mi amiga me explicaron que tenía que ver con el desfile por el aniversario de la localidad ya que no era común ver tantos vehículos circulando.

(Registro de observación en Roque Pérez, 24 de junio de 2014).

\subsubsection{Caracterización general}

Aspectos geográficos, demográficos y económicos

El Partido de Roque Pérez es uno de los 135 partidos que conforman la Provincia de Buenos Aires. Se encuentra situado al noreste de la provincia, entre $\operatorname{los} 59^{\circ}$ y $60^{\circ}$ de longitud oeste y $35^{\circ} 38^{\prime}$ de latitud sur. Limita políticamente con los siguientes partidos: al noroeste Lobos, al este Monte, al sudeste con General Belgrano y Las Flores, al sudoeste con Saladillo y al noroeste con 25 de Mayo. Se sitúa a una distancia de $160 \mathrm{Km}$ de la ciudad de Buenos Aires (capital nacional) y a $159 \mathrm{Km}$ de La Plata (capital provincial). Las vías de acceso a la ciudad de Roque Pérez son la Ruta Nacional N²05, que la comunica con el centro de la provincia, y la Ruta Provincial $N^{\circ} 30$ que la conecta con el sudeste. (Mapa 1, Roque Pérez en la Provincia de Buenos Aires). 


\section{Mapa 1: Partido de Roque Pérez en la Provincia de Buenos Aires (Argentina)}



Extraído de: Municipalidad de Roque Pérez. Ubicación geográfica (Mapa del Partido de Roque Pérez en la Provincia de Buenos Aires)

La extensión del partido es de $1570,93 \mathrm{Km}^{2}$ y se encuentra dividido en ocho cuarteles. El primero corresponde a la ciudad cabecera que se denomina también Roque Pérez y conforma el área de mayor urbanización del partido. Los otros poseen diferentes parajes de características rurales (tipo amanzanamiento): Carlos Beguerie, Santiago Larre, La Reforma, Juan Tronconi, La Paz, La Paz Chica, Forastieri, Cuartel Quinto, El Arbolito y Atucha. Según datos del censo nacional 2010 el partido cuenta con 12.513 habitantes. Del 
total de la población censada 6220 son varones y 6293 mujeres, siendo el índice de masculinidad de 98,8\% ${ }^{11}$. La Superficie total del partido es de $1572,22 \mathrm{~km}^{2}$ y su densidad es de $8,0 \mathrm{hab} / \mathrm{km}^{2}$. La participación en la población provincial es del 0,8\%.

La economía del partido es principalmente agrícola- ganadera. El primer cultivo es el de soja, teniendo en 2016 una superficie sembrada de 37.000 hectáreas y una producción de 115.240 toneladas $^{12}$. Luego de la soja, el segundo tipo de cultivo más abundante es el maíz. Para el 2016 hubo una superficie sembrada de 9000 hectáreas y la producción fue de 56.760 toneladas. También, en menor medida, hay producción de trigo. En 2016 hubo una superficie sembrada de 4550 hectáreas y una producción de 4790 toneladas.

Existen dos grandes empresas ganaderas que constituyen las fuentes de trabajo de mayor importancia de la localidad. Una de ellas es una compañía avícola denominada CRIAVE $^{13}$ perteneciente a ECOAVE S.A. Esta organización emplea alrededor de 800 personas en el lugar dedicándose a la cría y faena de pollos para su comercialización en diferentes partes de la Provincia de Buenos Aires y del país. El otro establecimiento ganadero de importancia es el de cría porcina Pacuca S.A., ubicado en la estancia "La Biznaga" que es propiedad de la familia Blaquier. ${ }^{14}$

\section{Algunos datos históricos}

El Partido de Roque Pérez se creó por la ley Nº 3488 el 24 de junio de 1913 a partir de territorios pertenecientes a los Partidos de Saladillo y 25 de Mayo. ${ }^{15}$ La zona había comenzado a poblarse unas décadas antes cuando se habilitó el Ramal del Ferrocarril Oeste

\footnotetext{
${ }^{11}$ Datos extraídos del Censo 2010.

${ }^{12}$ Datos extraídos del Ministerio de Economía de la Provincia de Buenos Aires.

${ }^{13}$ CRIAVE comenzó a funcionar en el año 2000 y tiene la mayor parte de sus instalaciones en el Partido de Roque Pérez

${ }^{14}$ La familia Blaquier constituye uno de los grupos empresarios más ricos del país y su apellido forma parte de los sectores aristocráticos argentinos. Uno de sus miembros, Carlos Pedro Blaquier es el dueño de la empresa agroindustrial Ledesma S. A. cuya sede central se ubica en la Provincia de Jujuy.

${ }^{15}$ Datos extraídos del Registro oficial de la Provincia de Buenos Aires. Año 1913. Pág 674.
} 
(luego Ferrocarril del Sud) el 21 de septiembre de 1884 cuyo tramo iba de la localidad de Lobos al Partido de Saladillo. ${ }^{16}$

El nombre del Partido, y su localidad cabecera, fue elegido en honor al abogado José Roque Pérez nacido en la Provincia de Córdoba en 1815 y fallecido, como víctima de la epidemia de fiebre amarilla en la ciudad de Buenos Aires, en 1871. José Roque Pérez está señalado como una de las principales figuras de la masonería porteña (Galeano, 2009) y fue reconocido por su labor como presidente de la Comisión Popular de Salubridad en la época de esparcimiento de la fiebre amarilla. Esta comisión, junto con otros organismos estatales $^{17}$ accionaba para evitar la proliferación de la epidemia en la capital nacional (Galeano, 2009). La familia de Roque Pérez era propietaria de unas extensiones de tierras por la zona en donde ahora se encuentra el partido que lleva su nombre y, durante la epidemia, varios de sus miembros se trasladaron hacia allí. José Roque Pérez decidió quedarse en la ciudad, presidiendo la Comisión Popular, y eso lo llevó a contagiarse y morir poco tiempo después. Según un historiador local, Walter Murga (2013), cuando se construyó la estación de tren en 1884, un estanciero de la zona llamado Juan Espelosín propuso que la misma se llamara Roque Pérez. De este modo, la estación fue la primera en llevar su apellido y, tres décadas después, se creó el partido que lo mantuvo.

Murga relata que el primer amanzanamiento en la zona fue trazado en tierras cedidas por un estanciero llamado Pedro Gutiérrez quien había adquirido alrededor de siete mil hectáreas en 1819. Gutiérrez fue el fundador de una estancia llamada "La media luna", y otras estancias fueron surgiendo en la zona a lo largo del siglo XIX. Durante esa época las tierras, donde ahora se emplaza el partido, solían ser transitadas por carretas que salían desde Saladillo hacia la ciudad de Buenos Aires. Marchaban en caravana rodeadas de jinetes para prevenirse de los riesgos de "malón" 18 y de regreso, luego de aproximadamente

\footnotetext{
${ }^{16}$ Información extraída de Memoria del directorio del ferrocarril del oeste. Biblioteca de la Honorable Cámara de Senadores de la Provincia de Buenos Aires, 1884.

${ }_{17}$ Los principales organismos que intervinieron sobre esta epidemia fueron: la Comisión Municipal de Higiene, el Consejo de Higiene Pública, comisiones parroquiales y el Departamento General de Policía. (Galeano,2009)

${ }^{18}$ Según la historiadora Florencia Carlón (2014) El término “malón” se utiliza para referir a una práctica en el marco de las conflictividades existentes entre grupos indígenas de la región pampeana y patagónica con la población hispana-criolla en los siglos XVIII y XIX. Este término históricamente se ha utilizado para referir a las acciones mediante las cuales los grupos indígenas se apoderaban de bienes de los criollos.
} 
20 días de viaje, eran esperados por los primeros pobladores porque traían mercaderías de Buenos Aires. (Murga, 2013).

Otro dato de interés en la historia nacional y en el conocimiento sobre Roque Pérez, es su presentación como el lugar en donde nació Juan Domingo Perón. El rancho de adobe en donde habría nacido el famoso presidente argentino en el año $1893^{19}$ funciona actualmente como museo dentro del partido. Utilizamos la expresión "habría" porque según la primera biografía oficial, Perón nació en la localidad de Lobos. De hecho, en la entrada de ésta última ciudad se encuentra un cartel que dice que allí nació el ex presidente. Lo cierto es que Roque Pérez, como partido, no existía en ese entonces y Perón fue inscripto en el Registro Civil de Lobos al poco tiempo de nacer. ${ }^{20}$

\section{Educación}

Como esta tesis está centrada en la experiencia de jóvenes que migran de localidad para continuar sus estudios, consideramos necesario hacer referencia a algunos aspectos educativos del lugar de origen. En Roque Pérez existen $57^{21}$ unidades educativas públicas de gestión estatal. De acuerdo al ordenamiento según niveles, en el nivel inicial se registran 17 establecimientos, en el primario $24 \mathrm{y}$ en el secundario 5. Existe también un establecimiento secundario de educación técnica profesional. En la ciudad cabecera se encuentra este último y también dos de los establecimientos educativos secundarios

\footnotetext{
${ }^{19}$ En la primera biografía de Perón, escrita por Enrique Pavón Pereyra (1953), se sostiene que el ex presidente nació el 8 de octubre de 1895 en la Localidad de Lobos. Sin embargo, otro biógrafo, Hipólito Barreiro, sostiene que Perón afirmó haber nacido en 1893 y que fue inscripto en el Registro Civil de Lobos dos años después como recién nacido.

${ }^{20}$ La propiedad donde se encuentra el rancho, que ahora es museo, fue adquirida por la Municipalidad de Roque Pérez en el año 2000. En su interior se encuentra el rancho de adobe y otro edificio que funciona como centro administrativo del museo. Sobre el parque de la propiedad, se observan una bandera argentina y una bonaerense como también un cartel que indica que allí nació Perón, mostrando que ese terreno estuvo escriturado a nombre de su madre Juana Sosa Toledo. Un embajador de Perón, Hipólito Barreiro, fue quien se encargó de realizar las investigaciones históricas para que ese lugar sea reconocido como el espacio natal del presidente argentino. Arqueólogos de la Facultad de Ciencias Naturales y Museo de la Universidad Nacional de La Plata hicieron excavaciones en los años 2001 y 2002 para buscar evidencias sobre la utilización de ese espacio a fines del siglo XIX. A partir de este trabajo, pudieron dar cuenta de que no existieron edificaciones previas en el terreno y encontraron una moneda del año 1892, la cual constituye el objeto que más se acerca a la fecha en donde nació el ex presidente.

${ }^{21}$ Datos extraídos de la Dirección General de Cultura y Educación de la Provincia de Buenos Aires.
} 
(Escuela de Educación Secundaria $\mathrm{N}^{\circ} 1$ y Escuela de Educación Secundaria $\mathrm{N}^{\circ} 4$ ). Las otras tres escuelas de este nivel se encuentran en parajes rurales ${ }^{22}$ (la Escuela de Educación Secundaria N`5 en el Paraje "El arbolito", la Escuela de Educación Secundaria N’3 en el Paraje Tronconi y la Escuela de Educación Secundaria ํ2 en Carlos Begueríe).

Las escuelas que funcionan en los parajes fueron construidas hace una década aproximadamente. Antes las personas que vivían allí y terminaban la primaria debían trasladarse a la ciudad cabecera para continuar sus estudios. Varios de los jóvenes que crecieron en parajes rurales se fueron a vivir a esta ciudad para ir a la secundaria. Otros iban y volvían todos los días desde los parajes. Los que se radicaron en la ciudad de Roque Pérez vivieron en casas que sus padres tenían en el pueblo o se mudaron con otros familiares. Además, hasta hace pocos años existía una pensión para jóvenes de los parajes, financiada por el Municipio, que dejó de funcionar luego de que se abrieron las escuelas secundarias rurales. La pensión se ubicaba en la antigua estación de tren de Roque Pérez, por donde pasaba la línea Gral. Roca. En ese lugar ahora funciona la Secretaría de Asuntos Docentes y la Jefatura Distrital de Educación.

La mayoría de los jóvenes de este estudio fueron a la Escuela de Educación Secundaria $\mathrm{N}^{\circ} 1$ a la cual denominan "escuela media" (nominación anterior del sistema educativo). Otros, en menor medida, fueron a la Escuela de Educación Técnica, nombrada como "escuela técnica". Estos dos establecimientos fueron los más referenciados porque eran las únicas dos escuelas secundarias que existían en la ciudad cabecera cuando la mayoría de ellos vivían allí. La Escuela Secundaría $\mathrm{N}^{\circ} 4$ y las escuelas secundarias de los parajes tienen menos de una década de funcionamiento.

La oferta de establecimientos de educación terciaria en Roque Pérez y los partidos vecinos es la siguiente. En la Escuela Secundaria $\mathrm{N}^{\circ} 1$ funciona la extensión del Instituto Superior de Formación Docente y Técnica $N^{\circ} 43$ de Lobos, donde se dicta el Profesorado de Nivel Inicial y la Tecnicatura Superior en Industrias Cárnicas. En Roque Pérez se pueden cursar dos materias del Ciclo Básico Común de la Universidad de Buenos Aires (Introducción al Conocimiento de la Sociedad y Estado e Introducción al Pensamiento

\footnotetext{
${ }^{22}$ El gobierno municipal financia un vehículo que traslada a los niños y jóvenes que viven en el ámbito rural hacia las escuelas.
} 
Científico). En las localidades vecinas de Lobos y Saladillo también hay oferta de carreras terciarias. En Lobos, además del Instituto Superior de Formación Docente y Técnica ${ }^{\circ}$ $43^{23}$, se encuentra un Centro Tutorial de Educación a Distancia de la Universidad Fasta ${ }^{24}$. En Saladillo se encuentra el Instituto Superior de Formación Técnica №135 "Ing. Mario Deraldo Michelini”" ${ }^{25}$ y también existe una extensión de la Universidad Empresarial Siglo XXI. ${ }^{26}$ Algunos de los jóvenes que participaron en esta investigación estudiaron en algunas de estas instituciones antes de migrar a La Plata.

\section{Espacios de ocio de los jóvenes antes de migrar a La Plata}

Este apartado tiene el propósito de contribuir con la caracterización de Roque Pérez mencionando los principales lugares de ocio $^{27}$ y encuentro juvenil que aparecieron referenciados por los sujetos que en la actualidad viven en La Plata. Estos espacios formaron parte de sus experiencias juveniles en Roque Pérez antes de migrar y, en algunos casos, siguen siendo lugares de encuentro y diversión para ellos cuando van de visita a su localidad natal. Los más mencionados fueron los espacios verdes (plazas, parques) y los bares nocturnos que, para algunos, constituyeron también espacios laborales.

Uno de los lugares privilegiados de ocio y encuentro juvenil estuvo conformado por los espacios verdes (plazas y parques). Varios de los jóvenes comentaban que solían pasar

\footnotetext{
${ }^{23}$ Allí se pueden estudiar las siguientes carreras: Profesorado en Educación Física, Profesorado de educación secundaria en inglés, Profesorado de educación secundaria en geografía, Tecnicatura Superior en Análisis, Desarrollo y Programación de Aplicaciones, Tecnicatura Superior en Enfermería, Tecnicatura Superior en Tecnología en Salud con especialidad en Laboratorio de Análisis Clínicos y Tecnicatura Superior en Comunicación multimedial.

${ }^{24}$ Allí pueden cursarse a distancia materias de carreras como abogacía o contador público y también diferentes licenciaturas como marketing, administración de empresas y educación entre otras.

${ }^{25}$ Las carreras que allí se dictan son: Tecnicatura Superior en Administración Agropecuaria, Tecnicatura Superior en Análisis de Sistemas, Tecnicatura Superior en Psicopedagogía, Tecnicatura Superior en Comunicación Multimedial, Tecnicatura Superior en Administración con orientación en PyMes, Tecnicatura Superior en Trabajo Social, Tecnicatura Superior en Industrias Agroalimentarias, Tecnicatura Superior en Análisis, Desarrollo y Programación de Aplicaciones, Tecnicatura Superior en Alimentos, Tecnicatura Superior en Administración General, Tecnicatura Superior en Higiene y Seguridad del Trabajo, Tecnicatura Superior en Producción Agrícola-Ganadera y Tecnicatura Superior en Recursos Humanos.

${ }^{26}$ Entre las licenciaturas que se pueden cursar a distancia están: Derecho, Relaciones Internacionales, Administración y Contador Público.

${ }^{27}$ Referimos a los lugares de encuentro y diversión juvenil cuando no se encuentran en la escuela, el trabajo o el ámbito doméstico.
} 
mucho tiempo fuera de sus casas y que los principales lugares de encuentro para sociabilizar con otros jóvenes eran los lugares abiertos. En donde se encuentra la vieja estación de tren hay un parque denominado "La Roma" que tiene juegos de plaza y un playón para jugar al fútbol. Otro lugar al que concurrían con mucha frecuencia era el predio municipal denominado "33 hectáreas" que varios llaman “33”, donde solían juntarse para practicar algún deporte o sentarse a tomar mate bajo el sol. También muchos de los jóvenes iban al Country Club "Gimnasia y Esgrima de Roque Pérez" sobre todo en el verano porque cuenta con una pileta de natación. Estos lugares siguen siendo frecuentados por varios de ellos cuando van a Roque Pérez.

Con respecto a la oferta de lugares para las salidas nocturnas, los jóvenes de más edad recuerdan que, cuando vivían en Roque Pérez, iban a dos bares durante la noche de los fines de semana. Uno se llamaba "La esquina" y el otro "Dulcinea". Ninguno de los dos existe en la actualidad. Muchos de ellos recuerdan que cuando vivían allí iban a un boliche llamado "Jadbalá" que cerró hace unos años y ahora en su lugar hay una sucursal bancaria. Además de espacios de diversión, estos lugares conformaron fuentes de trabajo para varios de ellos. Dos de las jóvenes habían sido mozas en "Dulcinea" y otros habían sido empleados en "Jadbalá". Varios afirman que la renovación permanente de lugares nocturnos se debe a que la gente se "aburre" de ir y entonces los empresarios deciden cambiar. En la actualidad cuando van a Roque Pérez algunos fines de semana, los bares a los que suelen salir se llaman "Belarmino" y "Cronos". También hay un boliche bailable, "Mora".

Una práctica que muchos jóvenes recuerdan de cuando vivían en Roque Pérez era la denominada "vuelta del perro", un circuito que solían hacer en grupo, ya sea a pie o en bicicleta. Esta vuelta se realizaba cuando comenzaba el anochecer y consistía en pasar por determinadas calles que abarcaban parte del centro comercial y también otras en donde se encontraban las casas de los chicos o chicas que "les gustaban" a algunos de los miembros del grupo. Una de las jóvenes comentaba que todos los días hacía la "vuelta del perro" con sus amigas porque no había otras actividades para hacer y eso les permitía circular por las calles y sociabilizar. Esta idea, compartida por la mayoría de los sujetos, de que en Roque 
Pérez los jóvenes tienen pocos lugares a donde ir y pocas actividades para hacer será retomada en el análisis de los imaginarios.

\subsubsection{Imaginarios urbanos juveniles sobre Roque Pérez}

Como anticipamos en la introducción, en este apartado presentamos los imaginarios urbanos juveniles reconstruidos a partir de las representaciones sociales de los jóvenes sobre Roque Pérez. En este sentido, coincidimos con Lindón (2007) en que las percepciones de las personas se transforman, analíticamente, en representaciones y estas por un proceso simbólico se constituyen en imaginarios. Por ello, es necesario diferenciar dos momentos analíticos: el de las representaciones y el de los imaginarios. En primer lugar presentamos el listado completo de representaciones sociales analizadas $\mathrm{y}$, en segundo lugar, desarrollamos los imaginarios que, veremos a lo largo de la tesis, intervienen en la organización de la migración y la elección de lugares a donde ir.

Para el análisis de las representaciones sociales utilizamos como fuente de información las transcripciones de entrevistas que fueron colocadas en una unidad hermenéutica del software Atlas Ti. Sobre ellas seleccionamos todos los fragmentos de relato que referían a Roque Pérez contemplando los términos que se le asociaban. Sobre estos identificamos ejes a partir de las regularidades encontradas y construimos una tipificación de significados utilizando categorías nativas. Por ejemplo: cada vez que los sujetos referían a Roque Pérez utilizaban el término "pueblo". A su vez, los jóvenes lo adjetivaron con diferentes palabras como "chico", "tranquilo", "aburrido" y "de relaciones cálidas" entre otros. Sobre todas estas adjetivaciones se buscaron regularidades que nos permitieron construir la tipología que presentamos a continuación.

Las representaciones sobre Roque Pérez que identificamos son:

1) Pueblo chico: Aquí Roque Pérez aparece asociado a las escalas (geográfica y demográfica) pequeñas, siendo también pequeña la oferta de lugares y actividades para jóvenes principalmente. 
2) Pueblo como estilo de vida: Esta escala de Roque Pérez condicionaría las formas de sociabilidad, de interacción y las prácticas de las personas. La principal característica radicaría en que todos los habitantes se conocen mucho entre sí.

3) Pueblo de buenas costumbres: Esta representación se centra en los comportamientos de las personas con una carga moral altamente positiva.

4) Pueblo de relaciones cálidas y afectuosas: Aquí los tipos de relaciones sociales son vistos como altamente personalizados y afectivos.

5) Pueblo como lugar ideal para la crianza de niños: Roque Pérez aparece como un espacio ideal para el desarrollo del proyecto familiar y para vivir la infancia.

6) Pueblo donde se está pendiente de la vida del otro: El hecho de conocerse entre todos generaría que los rumores y los chismes sobre las vidas de las personas circulen constantemente.

7) Pueblo donde no es posible mantener el anonimato: Como todas las personas se conocen entre sí, parecería que es casi imposible resguardar la privacidad ante los demás.

8) Pueblo seguro para vivir: Roque Pérez aparece aquí como un escenario poco propenso al delito y el robo.

9) Pueblo tranquilo: Es una representación sobre la vida en la localidad donde impera la rutina y ocurren pocas cosas por fuera de ella.

10) Pueblo de pocas oportunidades laborales: La oferta de trabajos de Roque Pérez aparece como escasa y pareciera no existir otra opción laboral por fuera del trabajo rural, el empleo en comercios o en el ámbito doméstico.

En un segundo nivel analítico pasamos a trabajar con la noción de imaginarios que nos permite agrupar representaciones que se utilizan juntas y componen un nuevo significado, no necesariamente por novedoso, sino por el efecto simbólico que produce su uso. Como sostiene Lindón "los imaginarios producen efectos concretos en los sujetos (...) crean imágenes guías o imágenes actuantes que son guías para la acción” (2007:10). Como veremos, estos imaginarios están presentes en los discursos de muchos jóvenes cuando explican las razones que los hicieron querer irse de Roque Pérez o desear volver. Los cuatro 
imaginarios que hemos reconstruido son: Pueblo, Pueblo como lugar de las Buenas Costumbres, Pueblo como Infierno Grande y Pueblo Tranquilo. A continuación desarrollaremos cada uno, mencionando las representaciones que engloban.

Pueblo

"En Roque Pérez por ahí hay como, las costumbres son muchas de las cosas que por ahí más llaman la atención y eso... el estilo de vida, como se relaciona la gente, se conocen todos con todos, todos sabemos la vida de todos, tirar una característica de alguien y ya sabemos quién es..." (Celina, 26 años. Egresada de la carrera de Trabajo Social, vive en La Plata desde el año 2006)

El modo en que aparece nombrado Roque Pérez en todos los relatos de los jóvenes es como "pueblo" y esta categorización también la utilizaron otras personas a quienes conocimos a lo largo de la investigación (padres, funcionarios, docentes y directivos escolares). Englobamos en este imaginario las representaciones que se centran en la relación entre escala (demográfica y geográfica) y algunas dinámicas de interacción social. Roque Pérez aparece como un lugar pequeño y de pocas personas lo cual condiciona su estilo de vida y sus formas de sociabilidad. Se incluyen las representaciones de: i) Pueblo chico y ii) Pueblo como estilo de vida.

En términos generales, la idea de "pueblo" aparece ligada a escalas pequeñas tanto demográfica como geográficamente. El pueblo es pequeño en su extensión y también en la cantidad de personas que viven allí. A su vez, aparece dimensionada como pequeña la oferta de actividades y lugares para jóvenes especialmente. Esta reducida escala condicionaría un "estilo de vida" propio del pueblo principalmente caracterizado por el conocimiento mutuo de sus habitantes. La frase "nos conocemos todos" pareciera explicar su tipo de sociabilidad por excelencia. Este "conocerse entre todos" tiene sus aspectos positivos porque habilita interacciones calificadas como cordiales y amables, pero también tiene sus consecuencias negativas por otros aspectos que veremos más adelante. 
Para muchos el parentesco aparece como una de las principales formas de organización para la identificación de personas. Lucía, una joven de 28 años que reside actualmente en La Plata, relataba que en diversos lugares era identificada por ser la hija de un profesor de escuela secundaria y de una médica. Algo similar le pasaba a Malena, de 31 años, quien regresó a vivir a Roque Pérez luego de que se graduó en La Plata. Su mamá era maestra en un jardín de infantes, lo cual le atribuyó el rótulo de la "hija de la seño del jardín” por muchos años. También las personas sienten que son identificadas por los trabajos que realizan o los lugares donde viven, entre otras características.

En los relatos aparece una idea del "pueblo" como lugar conocible en toda su extensión y a todos sus habitantes. Como señalaba Elena, una joven estudiante de Bioquímica de 19 años, Roque Pérez es "tan chiquito que uno puede conocerse todo el pueblo de punta a punta”. Veremos más adelante que los imaginarios sobre Roque Pérez actualizan una cierta noción de comunidad.

\section{Pueblo como lugar de Buenas Costumbres}

“A mi por ejemplo me encanta acá (Roque Pérez) que hay, yo veo como mucho afecto todo el tiempo, eso me parece genial, porque voy a alguien siempre conoces, vas por la calle, en el supermercado, es el papá de un alumno siempre, o es alumno o primo de alumno siempre, entonces esta eso y es buena onda, o sea, hay buena onda y siempre hay como un lazo, que hay por detrás." (Malena, 31 años. Diseñadora gráfica que regresó a vivir a Roque Pérez unos años después de graduarse. Actualmente ejerce como docente en una escuela.)

Como ya hemos señalado, en la entrada de la localidad se encuentra un cartel que brinda la presentación de Roque Pérez hacia sus visitantes: "Pueblo de Buenas Costumbres". Este ilustra la principal representación del lugar producida por el estado municipal. Roque Pérez no solo aparece nombrado como un "pueblo" sino que además se le otorga una carga moral altamente positiva como un lugar "bueno" en donde viven "personas buenas". A esto podemos sumarle el relato heroico sobre el Dr. José Roque Pérez quien habría sacrificado su vida por combatir la fiebre amarilla a finales de siglo XIX, 
convirtiéndose en fuente de inspiración para nombrar al partido. Este imaginario oficial estatal es actualizado muchas veces por los sujetos.

Dentro de este imaginario, agrupamos las representaciones que ubican a Roque Pérez como un lugar caracterizado por vínculos sociales estrechos y fuertemente afectivos. Incluye a las representaciones de i) Pueblo de Buenas Costumbres, ii) Pueblo de relaciones cálidas y afectuosas y iii) Pueblo ideal para la crianza de los niños. Por ejemplo Camilo, un egresado de Comunicación Social de 26 años, comentaba que en Roque Pérez todo el mundo se saluda cuando se encuentra en la calle. El joven mencionaba que si dos personas se cruzan y no se conocen entre sí, seguramente conocerán a alguien de la familia del otro y se quedarán charlando.

Términos como "cálido", "cordial" "amable" "afectuoso" son utilizados para calificar también las relaciones entre las personas dentro del "pueblo". Esto es explicado por muchos jóvenes no solo por el hecho de conocerse entre todos sino porque la costumbre en el "pueblo" es ser "bien educado". Como sostenía Ariel, un joven de 22 años que se fue a estudiar a La Plata pero regresó a los pocos meses, la gente de "pueblo" es "simple" y "amable". Él comentaba que muchos de sus amigos que se fueron a vivir a otra ciudad para estudiar seguían siendo "simples" porque, a pesar de cambiar de contexto urbano, habían crecido en un "pueblo". Se establece de este modo una vinculación entre la pequeña escala urbana y los comportamientos "amables" y "cordiales" de los habitantes.

El "pueblo" aparece también como el espacio óptimo para el desarrollo de la infancia. Casi la totalidad de los jóvenes sostuvieron que volverían a vivir en Roque Pérez si quisieran formar una familia y tener hijos. En este sentido, las calles menos peligrosas y el trato amable de las personas parecieran conformar un escenario mucho más óptimo para la crianza de los niños. De este modo, Roque Pérez aparece como un espacio privilegiado sobre el que se despliega el imaginario del niño como sujeto de protección, amor y cuidado (Aries, 1987).

Pueblo como infierno grande 
"Hay algo que por ejemplo a mi cuando era chica me incomodaba mucho que era esta cuestión de no poder mantener el anonimato o la privacidad ¿no? ¿Ante la ciudad no es cierto? Un pueblo, ante la comunidad por ejemplo, que unas cosas que si o si sabian, movimientos de tu vida que a mí me ponían, me ponían de malhumor, me irritaban, yo lo tomaba como por ese lado. Cosa que en La Plata se puede llegar, depende en qué ámbitos también ¿no? Pero más o menos algo de eso uno puede decidir también qué da a conocer y qué no, cuando acá a lo mejor te dicen "vi el auto de fulanito estacionado en tu casa" y todo ese tipo de cosas." (Malena, 31 años. Diseñadora gráfica)

Conocerse entre todos no siempre es valorado como positivo. Los chismes y los rumores sobre las vidas de los otros circulan todo el tiempo y la posibilidad de anonimato ${ }^{28}$ (Delgado, 1998) en el "pueblo" es casi nula. Por lo menos así lo perciben muchos de los jóvenes. Es por ello que algunos refirieron a una conocida frase para describir a Roque Pérez que es la de "pueblo chico, infierno grande." Utilizamos esta expresión nativa para denominar a este imaginario. Aquí agrupamos las representaciones de i) Pueblo donde se está pendiente de la vida del otro ii) Pueblo donde no es posible mantener el anonimato.

Lo que define al "infierno grande" es que el derecho a la invisibilidad o el anonimato que caracteriza a las grandes ciudades ${ }^{29}$ se encuentra vedado para la totalidad de las personas. En palabras simples, en el pueblo no se puede ser un desconocido ante los demás. Las personas conocen los nombres, las familias, los amigos, las parejas, las ubicaciones de las casas, entre otras informaciones personales, lo cual se vuelve insoportable para muchas de ellas.

Eugenio, un joven estudiante de derecho de 25 años, se sentía viviendo en un "infierno" porque todos en el "pueblo" sabían que era homosexual y eso lo volvía objeto de burlas y de maltratos. Para Malena era un infierno que las personas opinaran de su vida privada, sobre qué cosas hacía y con quienes se vinculaba. Cuando ella era chica le

\footnotetext{
${ }^{28}$ Sostiene Manuel Delgado que: “...es el anonimato lo que posibilita la vida urbana. El anonimato, con sus distintos grados de intensidad, se conforma de este modo como una forma -la única posible-, al mismo tiempo de protección de las individualidades identitarias y de estructuración de esa misma diversidad. La calle es de todo el mundo y nadie reclama la exclusividad sobre ese ámbito en que el espacio público alcanza su propia literalidad." (1998: 11)

${ }^{29}$ No obstante, Delgado (2007) sostiene que no todos los habitantes de las grandes ciudades gozan del derecho al anonimato. Es decir, la posibilidad de pasar desapercibido ante los demás, es algo de lo que no gozan ciertos grupos sociales que son estigmatizados por sus pertenecías de clase, etnia u otra.
} 
incomodaba no poder mantener el anonimato o privacidad en el "pueblo". Para Celina era un "infierno" que todos se involucraran y "chusmearan" sobre la vida de todos. Dentro de este imaginario, los miembros de la pequeña comunidad son los miembros del gran infierno.

Para muchos de los jóvenes que sostienen que la vida en el pueblo es un "infierno", la posibilidad de migrar hacia otra ciudad no solo se relaciona con la búsqueda de educación universitaria sino también con alejarse del contexto del "pueblo". Así lo comenta Eugenio quien pudo "vivir libremente" el ejercicio de su sexualidad cuando se fue a vivir a La Plata. En casos como estos, existe una fuerte valoración por las posibilidades de anonimato que ofrecen las ciudades de mayor tamaño. Retomaremos esto en el capítulo 3.

\section{Pueblo tranquilo}

“aparte el hecho de que sea tan tranquilo Roque Pérez, ir a la tarde y no anda nadie y cosas así, hasta se vuelve... cómo es?... triste. O sea, vos salís y no anda nadie por la calle y... te volvés a tu casa. Te volvés a tu casa y de pronto no hay nadie..." (Darío, 32 años. Estudiante de Derecho)

"Allá (en Roque Pérez) por ahí, es más raro que te roben. Por ahi muy escasas son las situaciones que te roban, eh... a la noche podés andar tranquilo" (Lucía, 28 años. Egresada de la carrera de Trabajo Social)

Roque Pérez es nombrado muchas veces como un lugar "tranquilo". Interpretamos que esa tranquilidad tiene un doble sentido. Por un lado, es visto como un espacio en donde predomina la seguridad principalmente relacionada con la ausencia de delitos. Numerosas veces los entrevistados cuentan que a cualquier hora de la noche se puede andar por la calle o dejar la bicicleta sin candado y no correr el peligro que la roben. Esto no significa que no haya situaciones de delitos, pero el contexto del pueblo es representado como un lugar seguro para vivir. 
Por otro lado, el pueblo se muestra como un lugar tranquilo porque hay poco para conocer y hacer. Hay pocas personas a diferencia de la ciudad y también son reducidos los lugares a donde ir a divertirse. Esta escasez parecería ser un problema principalmente para los jóvenes y, es por ello, que para muchos irse a estudiar implica una oportunidad para acceder a la oferta de bienes y espacios culturales juveniles en otra ciudad. También aparece el "pueblo" como un lugar con poca oferta educativa. Si bien en Roque Pérez y las localidades vecinas existe una oferta principalmente de carreras terciarias, los lugares que aparecen como privilegiados para estudiar son La Plata y Buenos Aires, sobre todo en la universidad.

A su vez, la "tranquilidad" sería un atributo central de la vida diaria del habitante de Roque Pérez. Darío un estudiante de derecho de 32 años describía un día cotidiano del oriundo del pueblo diciendo que se levanta, va a su trabajo, regresa, va a visitar a un amigo, luego toma su cena y se va a dormir, presentando de este modo la cotidianeidad como una continua rutina de la que no se podría escapar. El joven sostuvo que quizá cuando se graduara de la universidad y quisiera formar una familia, elegiría volver a Roque Pérez y llevar una vida de ese tipo, pero no lo haría en la actualidad porque le resultaría sumamente aburrido.

\subsection{La Plata}

\subsubsection{Caracterización general}

\section{Datos históricos, geográficos y sociodemográficos}

Iniciamos esta caracterización con algunos datos sobre la fundación de la ciudad que nos permitirán entender con mayor precisión varios de los imaginarios que presentaremos posteriormente. La ciudad de La Plata fue fundada el 19 de noviembre de 1882 como capital de la Provincia de Buenos Aires por orden del gobierno nacional de Julio Argentino Roca. Dos años antes, la ciudad de Buenos Aires había sido federalizada dejando de pertenecer al territorio de la provincia homónima. El impulsor del proyecto fue el entonces 
gobernador bonaerense, Dardo Rocha, quien inspirado en los valores atribuidos por la ideología del progreso (Vallejo, 2001) buscó planificar una nueva ciudad con un diseño urbano basado en una concepción secular y racionalista del mundo (Chaves, 2010).

Se decidió emplazar la nueva capital en el territorio denominado "Lomas de Ensenada", adyacente al Río de La Plata, lo cual le permitiría desarrollarse como una ciudad portuaria. En ese territorio existían solo dos poblados durante esa época: Ensenada y Tolosa. Según Segura (2015) el diseño escogido para la nueva ciudad representó una síntesis de diferentes ideas sobre el urbanismo que estaban vigentes a fines del siglo $\mathrm{XIX}^{30}$. El mismo consistió en un cuadrado de 40x40 manzanas, delimitados por una avenida denominada Circunvalación. Dentro del cuadrado, predomina una geometría ortogonal, con avenidas cada seis cuadras y espacios verdes equidistantes. (Segura, 2015).

Como hemos señalado, los fundadores de la capital bonaerense la imaginaron como una gran ciudad portuaria. Sin embargo, este proyecto se vio frustrado a los pocos años porque el puerto de la joven ciudad no pudo competir con su par de Buenos Aires (Badenes, 2014, Segura, 2015). Este fracaso, relata Badenes (2014), fue un duro golpe para la capital provincial que encontró una nueva razón de ser, algunas décadas más adelante, en el desarrollo de un importante complejo universitario. El crecimiento de la Universidad Nacional de La Plata no solo le proporcionó una identidad a la ciudad sino que también la convirtió en un lugar de destino para jóvenes de diferentes lugares del país y de otros países que impactó (y continúa impactando) en el negocio inmobiliario local (Lódola y Brigo, 2011).

En términos geográficos, la ciudad se encuentra ubicada en el noreste provincial a $34^{\circ}$ de latitud y $57^{\circ}$ de longitud y es la cabecera del partido homónimo que tiene una superficie de $940,38 \mathrm{~km}^{2}$, constituyendo un 0,3\% de la superficie provincial. El Partido limita al este con Berisso y Ensenada, al sudeste con Magdalena, al sur con Brandsen, al sudoeste con San Vicente y al norte con Berazategui y Florencio Varela. La separan $58 \mathrm{~km}$ de la ciudad de Buenos Aires. (Ver Mapa 2).

\footnotetext{
${ }^{30}$ Sostiene el autor: "En el plano fundacional, se combinan elementos de la ciudad ideal del Renacimiento, ya que fue pensada como una obra acabada. Los espacios públicos, las diagonales y la representación física del poder en un eje monumental manifiestan una influencia barroca. La preocupación por la circulación y los espacios verdes proviene del higienismo y de la racionalidad de la ciudad industrial del siglo XIX. Y, por último, se conservó la cuadrícula, elemento tradicional del urbanismo en América Latina” (2015:39).
} 
Mapa 2: Partido de La Plata en la Provincia de Buenos Aires (Argentina)

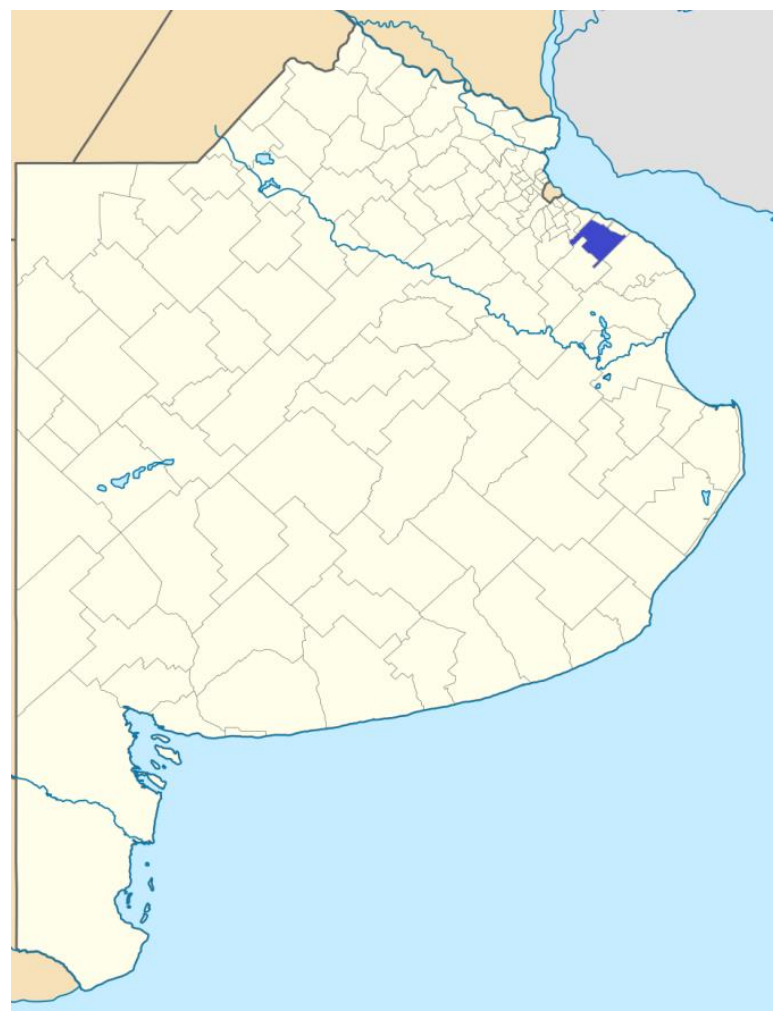

Extraído de: Hernández, Celeste (2017) Mapa del Partido de La Plata en la Provincia de Buenos Aires.

El partido está organizado por una ciudad cabecera (denominada Casco Fundacional) y delegaciones que son: El Peligro, Arturo Seguí, Villa Elisa, El Rincón, City Bell, Joaquín Gorina, Los Porteños, Manuel B. Gonnet, Villa Castells, Ringuelet, Tolosa, San Carlos, Abasto, Melchor Romero, Los Hornos, Sicardi-Villa Garibaldi, Lisandro Olmos, Ángel 
Etcheverry, Altos de San Lorenzo, Villa Elvira y Eduardo Arana. A diferencia del Casco Fundacional que fue planificado urbanísticamente desde sus orígenes, en las otras delegaciones esto no sucedió. El proceso de suburbanización de los alrededores del Casco Fundacional comenzó tempranamente por la preexistencia de Tolosa y la formación de Los Hornos (lugar donde se produjeron los ladrillos utilizados para construir la ciudad), y continuó desarrollándose a lo largo de las décadas (Segura, 2015). De acuerdo a los datos del censo nacional 2010, el partido cuenta con 654.324 habitantes, lo cual constituye el $4,2 \%$ de la población provincial. De este total, 315.268 son varones y 339.061 son mujeres, siendo el índice de masculinidad de 93,0. La densidad poblacional es de 742,3 habitantes/ $\mathrm{Km}^{2} \cdot 31$

La actividad económica del partido contempla diferentes ramas de la producción. Una de ellas es la administrativa, que abarca el conjunto de actividades relacionadas al empleo público. En La Plata se asientan las jefaturas del Poder Ejecutivo Provincial, los ministerios que éste comprende, dependencias del Poder judicial y las cámaras legislativas. Además de la administración provincial se encuentran las dependencias gubernamentales municipales (Lódola y Brigo, 2011). También juega un papel económico fundamental la Universidad Nacional de La Plata que, según cifras del año 2015, emplea a 12.263 docentes y 2.912 trabajadores no docentes ${ }^{32}$ y que tiene una cantidad de 105.592 estudiantes. A su vez, como hemos mencionado la migración estudiantil impacta en el negocio inmobiliario platense.

Otra actividad económica está compuesta por la producción agrícola. Al estar el partido ubicado en el cinturón verde del Gran Buenos Aires ${ }^{33}$, se cultivan frutas, hortalizas y flores que abastecen al mercado regional, provincial y nacional. Otra rama de producción está vinculada a la actividad industrial ya que existen industrias manufactureras que abarcan la fabricación de alimentos y bebidas, elaboración de productos químicos y fabricación de insumos para la construcción. En la vecina ciudad de Ensenada se ubica el Complejo Industrial La Plata, perteneciente a la empresa Yacimientos Petrolíferos Fiscales (YPF) que

\footnotetext{
${ }^{31}$ Datos extraídos del Censo 2010

${ }^{32}$ Datos extraídos del Anuario Estadístico de la UNLP. Año 2015.

${ }^{33}$ Refiere a un territorio que se extiende desde la localidad bonaerense de Campana hasta la ciudad de La Plata en donde predomina la producción de hortalizas para abastecer a la población urbana.
} 
constituye uno de los complejos más importantes de América del Sur. ${ }^{34}$ También en esta ciudad se ubica el Puerto de La Plata que en el año 2014, bajo la gestión del gobernador Daniel Scioli, fue ampliado y modernizado con una inversión privada de 420 millones de dólares para mejorar su capacidad operativa.

Nos ha interesado detenernos en estas características para poder realizar una breve descripción del escenario de la experiencia de los jóvenes. Cuando se movilizan por la ciudad, los espacios verdes, las diagonales, los edificios públicos, los locales comerciales, entre otras edificaciones, forman parte del paisaje urbano cotidiano. En el próximo apartado nos detendremos mejor sobre algunos lugares destacados de sociabilidad y ocio a los cuales frecuentan.

\section{Educación y lugares de ocio de los jóvenes de Roque Pérez en La Plata}

Caracterizamos aquí algunos espacios de La Plata que aparecen referenciados por los jóvenes como lugares significativos de ocio, sociabilidad y formación con el fin de contribuir a la caracterización de la ciudad. En primer lugar, como se trata de una tesis sobre estudiantes universitarios, mencionaremos la oferta educativa de este nivel. En segundo lugar, caracterizamos la oferta de centros y actividades culturales que forman parte de la experiencia de los jóvenes. En tercer lugar, mencionamos los principales espacios verdes y abiertos a los que concurren. Es necesario aclarar que los lugares que componen el circuito universitario de estos jóvenes originarios de Roque Pérez, algunos de los cuales describimos aquí, serán detallados con mayor profundidad en el capítulo 3.

En lo que respecta a la educación, la ciudad de La Plata tiene 843 unidades educativas de las cuales 518 son de gestión estatal y 325 privados. ${ }^{35}$ En el nivel secundario hay en total 165 y 46 en el nivel superior. También hay 12 unidades de educación técnico profesional para el nivel secundario. Recordemos que los jóvenes que participaron en esta investigación cursaron sus estudios primarios y secundarios en Roque Pérez, por lo cual no nos

\footnotetext{
${ }^{34}$ Información extraída del Programa de Desarrollo Territorial: Diagnóstico preliminar y líneas de acción para la discusión. Año 2012.

${ }^{35}$ Datos extraídos de la Dirección General de Cultura y Educación de la Provincia de Buenos Aires. Año 2013
} 
detendremos sobre estos niveles en La Plata. Con respecto a la oferta educativa universitaria, en la ciudad existen tres establecimientos de este tipo: La Universidad Nacional de La Plata ${ }^{36}$, la Universidad Católica de La Plata y la Universidad del Este. Además, en la vecina ciudad de Berisso, hay una de las 29 facultades regionales de la Universidad Tecnológica Nacional (UTN).

Sobre la oferta de lugares y actividades culturales y artísticas, La Plata es una ciudad que posee una variada gama en esta materia, de la cual los jóvenes asisten y participan activamente. Como señala el investigador platense Matías López (2017) en la capital bonaerense han germinado abundantes experiencias ligadas al ámbito de la cultura, las artes y la comunicación. Entre ellas hay decenas de centros culturales (públicos, colectivizados y privados), talleres de arte, colectivos artísticos, grupos musicales, artes visuales y producciones literarias. Varios de los jóvenes solían frecuentar centros culturales, como el Centro Cultural Islas Malvinas y el Centro Cultural Estación Provincial, e iban a fiestas organizadas en los centros universitarios regionales. También algunos solían ir a festivales folklóricos y de rock, entre otros. ${ }^{37}$

Una de las jóvenes “descubrió su amor por el teatro" cuando decidió tomar clases en un taller el primer año que vivió en La Plata. La ciudad ofrece una diversidad de espacios estatales, privados e independientes para la formación teatral ${ }^{38}$ (Del Mármol, 2017). Otra de las jóvenes comenzó una carrera de danza contemporánea en la Escuela de Danzas Clásicas de La Plata a la par que cursaba en la Facultad de Bellas Artes de la UNLP ${ }^{39}$, y otra inició un profesorado en danzas folklóricas en la Escuela de Danzas Tradicionales Argentinas “José Hernández”. Además de estos establecimientos, hay más espacios públicos y privados en donde se dictan talleres de danza de diferentes géneros.

\footnotetext{
${ }^{36}$ Además de poseer 17 facultades, la UNLP cuenta con tres escuelas secundarias (El Colegio Nacional "Rafael Hernández", el Liceo "Víctor Mercante" y el Bachillerato de Bellas Artes) y una escuela primaria, la Escuela Graduada Joaquín V. González (denominada escuela anexa).

${ }^{37}$ Como señalan Bergé y Cingolani (2017) en la ciudad existe una alta actividad vinculada al Rock Platense ya que existen en la ciudad múltiples agrupaciones musicales de este género además de que han proliferado programas radiales, prensa especializada y festivales.

${ }^{38}$ El teatro más grande es el Teatro Argentino financiado por la Provincia de Buenos Aires. También hay un teatro de gestión municipal, el Teatro Coliseo Podestá y teatros independientes. A su vez, hay una Escuela Provincial de Teatro y también colectivos independientes que tienen una larga tradición en el campo teatral platense (Del Mármol, 2017).

${ }^{39}$ En esta institución, la antropóloga Sabrina Mora (2010) realizó su investigación doctoral analizando temas vinculados al cuerpo y la danza que recomendamos para quienes deseen conocer más sobre el tema.
} 
También la ciudad ofrece una multiplicidad de lugares nocturnos (bares y boliches) para salir a divertirse. Una de las jóvenes comentaba que lo que le gustaba de La Plata es que había mucha variedad de lugares con diferentes "estilos" para salir por las noches. En algunos se podía ir a escuchar bandas y en otros bailar diferentes tipos de música. Otro joven comentaba que en La Plata conoció por primera vez un boliche gay. En todos los casos, la diversidad de lugares nocturnos es valorada a diferencia de la oferta de Roque Pérez que es percibida como escasa. Sin embargo, varios de ellos no suelen salir con mucha frecuencia a estos lugares principalmente por dos razones: una es el costo económico y otra el miedo a circular por las calles durante la noche. Retomaremos esto en el análisis de los imaginarios.

Otro sector de la ciudad que es ampliamente frecuentado por los jóvenes está compuesto por los espacios verdes. En el Casco Fundacional, que es donde circulan mayormente, existen 23 lugares entre plazas y parques. El espacio verde más grande de la ciudad se denomina Paseo del Bosque y dentro de este se encuentra una laguna artificial, el Jardín Zoológico y Botánico, el Museo de Ciencias Naturales, el Observatorio Astronómico, el Anfiteatro Martín Fierro y los dos estadios de fútbol de los clubes de la ciudad: Gimnasia y Esgrima de La Plata y Estudiantes de La Plata. Muchos de los jóvenes suelen ir al paseo del bosque a tomar mates durante los fines de semana y también utilizan otros parques de la ciudad.

\subsubsection{Imaginarios urbanos sobre La Plata de originarios de Roque Pérez}

Presentamos aquí los imaginarios urbanos sobre La Plata de los jóvenes originarios de Roque Pérez, utilizando la misma metodología que para el caso de los imaginarios sobre el lugar de origen. La principal categoría con la que se nombra a La Plata es "ciudad" y solo en pocas ocasiones como "pueblo grande". Tomaremos ambas denominaciones para nombrar a las representaciones y a los imaginarios. Primero detallamos las representaciones y luego los imaginarios urbanos juveniles. Por último, ponemos en diálogo nuestros hallazgos con otras investigaciones sobre imaginarios de la ciudad de La Plata. 
Las representaciones sobre La Plata son:

1) Ciudad grande: Aquí La Plata aparece vinculada a una gran escala (demográfica y geográfica) que condiciona los modos de vida de sus habitantes.

2) Ciudad donde la gente no se conoce: Relacionado con estas escalas, la ciudad aparece como un lugar de desconocidos en donde la posibilidad de conocer a todos los habitantes es nula.

3) Ciudad donde las relaciones son frías: En esta representación los vínculos sociales de las personas que viven en La Plata son adjetivados como "fríos, distantes e impersonales".

4) Ciudad peligrosa: Aquí la capital provincial, sobre todo sus calles y lugares públicos en las noches, es vista como un escenario propenso para el delito.

5) Ciudad en donde se vive inseguro: asociada a la representación anterior, existe una sensación de que en La Plata se vive con mayor temor y tomando cuidados permanentemente para no sufrir ningún episodio de delito.

6) Ciudad de muchas oportunidades y actividades (principalmente para jóvenes): aquí la capital bonaerense aparece como una ciudad que ofrece muchos espacios y actividades (artísticas, deportivas, recreativas, intelectuales) sobre todo para jóvenes.

7) Ciudad estudiantil: En esta representación, La Plata se muestra como un escenario óptimo para ser estudiante universitario tanto por la calidad de sus instituciones de nivel superior como por los lugares de sociabilidad y diversión estudiantil.

8) Ciudad en donde la gente tiene mayor "apertura mental": La vida en la ciudad llevaría a las personas a tener una mayor capacidad para reconocer y aceptar diversidades tanto sobre temas políticos, de sexualidad o estética personal, entre otros.

9) Ciudad en donde es fácil aprender a moverse: La Plata aparece como una ciudad en donde las personas que se van a vivir allí pueden acostumbrarse rápido a su dinámica de vida urbana. 
10) Pueblo Grande: Aquí se actualizan algunas representaciones de "pueblo" pero en una escala mayor.

Estas representaciones las agrupamos en cuatro imaginarios urbanos juveniles: ciudad, ciudad peligrosa, ciudad universitaria y pueblo grande, que detallamos a continuación.

\section{Ciudad}

“(La Plata es) Como una gran ciudad... lo que tiene La Plata por ahi es que no nos conocemos...yo...que después los platenses te dicen también se conocen entre todos...que por ahi no te conocés con todo el mundo y no estás pendiente de la vida del otro pero en cambio en Roque Pérez estás pendiente en la vida del otro, la sabés y eso influye en un montón de cosas para mi” (Celina, 26 años. Egresada de la carrera de Trabajo Social)

Este imaginario abarca las representaciones que relacionan escalas (demográfica y geográfica) grandes con formas particulares de interacción y sociabilidad. Entre ellas están: i) ciudad grande ii) ciudad donde la gente no se conoce iii) ciudad donde las relaciones son frías y iv) ciudad donde la gente tiene mayor "apertura mental". La adjetivación que muchos le otorgan a La Plata es "grande". En ella hay mucha gente, edificios, autos, transportes públicos, ruidos, plazas y negocios. Celina contaba que cuando llegó a La Plata se sentía "muy chiquita" para estar en un lugar "tan grande". Sobre todo porque debía caminar por calles que siempre estaban transitadas, esquivando a personas para no chocarse. Ella venía de un "pueblo" en donde conocía a todos y en La Plata las personas eran completamente desconocidas para ella. Todos los días, cuando iba a la facultad, se encontraba con personas que no conocía.

Varios jóvenes describen a la "ciudad" como un lugar "frío", en donde la "calidez" de las interacciones sociales que ellos vivieron en el pueblo está ausente. Victoria, una estudiante de medicina de 21 años, señalaba que en La Plata la gente se trata con suma indiferencia. Camilo, egresado de periodismo de 26 años, se sentía extraño cuando saludaba 
a las personas que se cruzaba por la calle en la capital bonaerense y estas no devolvían a sus saludos. Para muchos jóvenes roqueperenses, los platenses aparecen en su mayoría como personas "frías".

Para otros la frialdad y la indiferencia que sienten en las relaciones sociales dentro de la ciudad son valoradas positivamente porque permiten el derecho al anonimato que en el "pueblo" tienen vedado. Como señalaba Elena, una estudiante de bioquímica de 19 años "es un alivio poder salir a dar una vuelta y que nadie te conozca". Existe una sensación de que el cambio de contexto urbano permite que los jóvenes no tengan que estar tan pendientes de resguardar su vida privada ante los demás porque las personas que habitan la "ciudad" no se interesarán en ella.

Eugenio, un estudiante de derecho de 25 años, comentaba que las personas en La Plata también tienen una mayor "apertura mental" porque están acostumbradas a "ver más cosas" que en el "pueblo". En particular, el joven señala mayor "apertura" en lo que respecta a temas políticos, sexuales y de estética personal. Con respecto a los primeros, porque las personas están más acostumbradas a ver movilizaciones y actos políticos principalmente en las zonas céntricas. Sobre lo segundo, Eugenio comenta que no es algo infrecuente ver a dos mujeres o dos varones caminando de la mano en La Plata y que eso en su lugar de origen sería "muy mal visto". También comentaba que en la "ciudad" se pueden ver muchos jóvenes con diferentes estéticas en sus vestuarios que forman parte de un “paisaje normal” que en Roque Pérez serían fuertemente criticados.

Las mayores distancias geográficas a recorrer dentro de la "ciudad" son remarcadas por varios de los jóvenes como una molestia para su movilidad diaria. Vanesa, una estudiante de medicina de 20 años, aseguraba que "todo estaba lejos" cuando debía movilizarse en la "ciudad". Eran muchas cuadras las que separaban el lugar donde vivía de su facultad y también estaba a muchas cuadras de distancia con respecto del centro comercial. Por esa razón, ella decía que no salía mucho a bailar ya que debía movilizarse en taxi y eso era muy costoso para su economía. Muchos jóvenes empezaron a familiarizarse con el sistema de transporte público por primera vez cuando se fueron a vivir a La Plata. Liliana, estudiante de veterinaria de 26 años, comentó que una vez se subió a un micro equivocado y terminó yendo a un barrio muy alejado de su facultad. Como estaba 
oscureciendo, decidió pagar un taxi hasta allí y de ahí en adelante no quiso usar más el transporte público.

\section{La ciudad peligrosa}

“También eso, si te vas a poner a ver que acá cada tanto andan acuchillando a alguno (se rie) cosas raras que en Roque Pérez no pasan tan frecuentemente. Acá, dos por tres, siempre hay alguien que le roban en la puerta y vos decís... eso no pasa tanto en Roque Pérez, yo en Roque Pérez hasta ahora ando tranquila a cualquier hora de la noche, me cruzo todo el pueblo caminando porque no me da un toque, nada de miedo. Acá me molesta caminar tres cuadras. Ya salir porque este barrio está siempre... te roban en la esquina, te roban en la otra cuadra y eso también. No es algo divertido. Eso no me gustaría." (Noelia, 23 años. Estudiante de Ingeniería)

“... o sea, que acá hay un toque de queda. A las 8 de la noche más o menos... hasta para andar en bici, porque te agarran... te acorralan con las motos igual asi que es medio peligroso por eso" (Liliana, 26 años. Estudiante de Veterinaria)

“que tenés que tener cuidado de no salir de noche. Yo allá en Roque Pérez me voy a la casa de cualquiera, a todos lados en bicicleta y la dejo apoyada ahí en el cordón, cuando salgo a las 6 de la mañana, la bicicleta está todavía ahí.” (Victoria, 21 años. Estudiante de Medicina)

En todos los relatos, la ciudad de La Plata aparece como un escenario propenso para el miedo, el peligro y el delito. En este imaginario abarcamos las representaciones de La Plata como i) una ciudad peligrosa y ii) una ciudad en donde se lleva una vida insegura. Principalmente por las noches, las calles de la ciudad son vistas como espacios peligrosos de los cuales hay que cuidarse. Pero además los jóvenes explicitan una sensación de que la 
vida es más "insegura" en la capital bonaerense. Esta "inseguridad" ${ }^{40}$ es señalada como la principal diferencia entre la vida en La Plata con respecto a Roque Pérez.

A veces las situaciones de delito son vividas en carne propia como en el caso de Emilio, un joven de 28 años que se fue a estudiar a La Plata una carrera terciaria y decidió regresar a Roque Pérez luego de vivir un episodio de robo. También algunos jóvenes cuentan que dejaron sus bicicletas atadas para entrar a algún lugar y que cuando regresaron, notaron que se las habían robado. Otras veces el miedo a ser víctima de un delito viene por los relatos de otros, conocidos o también por los medios de comunicación. En estos casos, aunque la "inseguridad" no fue vivida en carne propia, igualmente opera como una representación que condiciona prácticas y comportamientos.

Esta centralidad de la "inseguridad" como problema que encontramos en los sujetos, nos remite a la noción de "sentimiento de inseguridad" acuñada por el sociólogo Gabriel Kessler. Según este autor: "la idea de sentimiento de inseguridad, en la cual las referencias al temor no dejan de ocupar un lugar central, incluye otras emociones suscitadas, como la ira, la indignación o la impotencia y comprende también las preocupaciones políticas, los relatos sobre sus causas y las acciones que conformarán la gestión de la inseguridad” (2011:85). En sintonía con este argumento, hemos analizado que en la totalidad de los jóvenes, el sentimiento de estar inseguros atraviesa sus vidas en la ciudad y organiza sus prácticas para gestionar la inseguridad. Esto refiere a: "acciones defensivas y elusivas, la incorporación de dispositivos y la adscripción a servicios cuyo objetivo común es lograr una sensación de control sobre las amenazas percibidas, intentando un equilibrio entre las precauciones y el mantenimiento de las rutinas habituales" (2011:92). Por ejemplo, dos jóvenes comentaban que nunca habían sufrido ningún robo puntual pero que igualmente, desde que vivían en La Plata, cuando comenzaba a oscurecer, ya no salían de sus casas. Evitar salir de la casa por las noches, esquivar determinadas zonas, intentar no caminar solo por la calle cuando está oscuro constituyen las estrategias principales mediante las cuales los jóvenes gestionan su inseguridad en la capital bonaerense.

\footnotetext{
${ }^{40}$ Sobre este concepto, Gabriel Kessler (2011) ha identificado dos sentidos. El primero relacionado con el "miedo al crimen" al cual ha referido la mayor parte de la literatura criminológica. Otras corrientes teóricas han vinculado la inseguridad con la crisis de los sistemas de seguridad social en el marco de la caída de los Estados de Bienestar. El uso que hacen los jóvenes del término “inseguridad” se relaciona más con la primera acepción.
} 


\section{Ciudad universitaria}

"La cantidad de gente que podes conocer, la cantidad de actividades que podes hacer, eso también es una ventaja que tiene la ciudad que el pueblo no tiene y La Plata es una ciudad de más de un millón de habitantes...con muchas actividades para los estudiantes en general (...)” (Eugenio, 25 años. Estudiante de Derecho)

El imaginario de La Plata como una ciudad universitaria se fue consolidando a lo largo de las décadas en estrecha vinculación con el crecimiento de la universidad local. Dentro de este imaginario agrupamos las representaciones que establecen a la capital provincial como un lugar óptimo para vivir la juventud y en especial para ser joven estudiante universitario, comprendiendo las representaciones de i) ciudad estudiantil y ii) ciudad de muchas oportunidades y actividades principalmente para jóvenes.

La representación de ciudad estudiantil se vincula con el impacto de la universidad en la vida social, política y económica de La Plata. En 1897 se funda la Universidad Provincial de La Plata, que se nacionaliza en 1905, y a lo largo de las décadas fue creciendo hasta constituirse en la tercera universidad más grande en cantidad de estudiantes y trabajadores del país ${ }^{41}$, luego de la Universidad de Buenos Aires y la Universidad Nacional de Córdoba. Daniel Badenes (2012) sostiene que la idea de "ciudad universitaria" se construye sobre un imaginario más amplio que es el de La Plata como "capital cultural". Esta noción alude a que la ciudad ha sido cuna y hogar de numerosos científicos, artistas y escritores que le han impreso el sello de lugar de la cultura. Según el autor el proyecto universitario le brindó a la ciudad una "razón de ser" a principios de siglo XX tras el fracaso del puerto que aspiraba a convertirla en una gran capital portuaria.

Este imaginario de la capital provincial como ciudad universitaria y capital cultural la convirtió en un polo de atracción por excelencia para la juventud de diferentes lugares del país o de otros países que deseaba formarse académicamente (Biagini, 2012). En los

\footnotetext{
${ }^{41}$ Como ya hemos señalado, según cifras del año 2015, emplea a 12.263 docentes y 2.912 trabajadores no docentes y que tiene una cantidad de 105.592 estudiantes
} 
relatos de los jóvenes este imaginario sobre La Plata se actualiza principalmente en el reconocimiento del prestigio que le conceden a la Universidad Nacional de La Plata. A su vez, varios entrevistados aseguraban que sus padres querían que estudien en La Plata y no en otros lugares por la valoración positiva que tenía la universidad nacional de allí.

La otra representación que conforma este imaginario vincula a la ciudad con una abundancia de lugares y actividades para jóvenes. La Plata aparece como un lugar privilegiado para ser joven estudiante por su oferta de experiencias políticas, de sociabilidad y de recreación, entre otras. En la ciudad hay abundancia de jóvenes para conocer y para vincularse. Plazas para ir a tomar mate los fines de semana, bares y centros culturales donde se pueden ir ver algunas bandas musicales o a bailar. En este sentido, el imaginario de ciudad universitaria no solo se vincula con la formación académica y la búsqueda de aprendizajes profesionales sino también con la posibilidad de desarrollar una experiencia de vida estudiantil que involucra actividades, lugares y sociabilidades que desarrollaremos con profundidad en el capítulo 3 de esta tesis.

\section{Pueblo Grande}

“claro, bueno eso sí. Bueno eso es lo que siempre comparo cuando estoy acá en La Plata... es más... un pueblo grande... más que una ciudad, como Roque Pérez pero mucho más grande... a diferencia de Buenos Aires. Yo no sé si me podrí... he ido a Buenos Aires varias veces y no me ubico para nada" (Darío, 32 años. Estudiante de Derecho)

“Cuando vine con mi abuelo para acá, para La Plata como que la veía muy grande a la ciudad. Después no sé, me fui acostumbrando y... Yo la siento como mía... ya no la veo tan grande ni tan complicada la veo más un pueblo que una ciudad”. (Esteban, 36 años. Egresado de la carrera de Derecho)

La primera impresión de varios de los jóvenes cuando llegan a La Plata es la de una "ciudad grande". Por sus calles y avenidas circulan cantidades de autos y también micros con diferentes colores y números que trasladan a la gente a distintos puntos del partido. A 
su vez, en esa ciudad se pueden observar edificios de muchos pisos (en Roque Pérez la mayoría de las construcciones tienen una planta o dos) y también a numerosas personas caminando por la calle. Comparado con Roque Pérez, La Plata pareciera poder atribuirse el calificativo de gran ciudad. Sin embargo, a medida que pasan los años viviendo en la capital provincial, algunos dejan de verla con esos aires de gran urbe y empiezan a calificarla de otra manera, como un "pueblo grande". En este imaginario agrupamos las representaciones de i) ciudad en donde es fácil aprender a moverse y la de ii) pueblo grande.

Esta noción de pueblo grande parece estar refiriendo a una instancia intermedia entre el "pequeño pueblo" y la "gran ciudad". Las analogías que varios utilizaron para describir a La Plata fueron que no era un pueblo como Roque Pérez pero tampoco era como la ciudad de Buenos Aires. Muchos jóvenes eligieron ir a vivir a La Plata porque Buenos Aires les parecía una ciudad demasiado grande, con demasiada gente y ruido de ciudad. Comparada con la capital nacional, La Plata aparece como un lugar más pequeño y con distancias más cortas entre los lugares que ellos frecuentan a diario.

En cambio, comparada con Roque Pérez, La Plata parecería brindar "cosas de ciudad" que en el "pueblo chico" no existen. Una joven contaba que la primera vez que fue a pasear al centro, se sentía maravillada por la cantidad de locales comerciales y de personas paseando. Cruzaba la calle con cuidado porque había muchos autos y colectivos. Sin embargo, a medida que fueron pasando los años, se aburrió de ir al centro porque siente que "lo conoce de memoria." De hecho, comentaba, entre risas, que la primera vez que fue al centro se sentía perdida entre tantos desconocidos y, luego de vivir unos años en La Plata, comenzó a cruzarse con personas conocidas con mayor frecuencia cuando salía de compras

El imaginario de Pueblo Grande también permite que varias de las familias de los jóvenes prefieran que ellos migren a La Plata en vez de hacerlo a Buenos Aires. Muchos comentaban que sus padres no querían que vayan a Buenos Aires porque era demasiado grande y ello la tiñe de una mayor sensación de inseguridad y miedo. La capital bonaerense en cambio, aparece como algo intermedio entre el pequeño pueblo y la gran ciudad que hace que muchas familias estén más tranquilas cuando sus hijos migran allí. 


\section{Diálogos con otros estudios sobre imaginarios de La Plata}

Para cerrar con el análisis de los imaginarios que describimos anteriormente, los pondremos en diálogo con los resultados de otras investigaciones sobre el tema. Para ello retomaremos los aportes de tres investigadores: Badenes (2012), Segura (2016) y Chaves (2010). En primer lugar, mencionamos los imaginarios analizados por cada uno de ellos. En segundo lugar, hacemos referencia a aquellos que no han aparecido en nuestra investigación y, en tercer lugar, nos detenemos en los imaginarios que efectivamente se han actualizado de diferentes maneras en nuestro trabajo.

Iniciamos con el trabajo de Daniel Badenes (2012) quien reconstruyó cuatro imaginarios de la ciudad a partir del análisis de fuentes literarias y publicaciones gráficas platenses en el contexto de los festejos por su centenario en 1982. Estas son: i) ciudad perfecta (por su trazado urbanístico), ii) ciudad de los poetas y la bohemia (por ser lugar de creación y expresión literaria artística), iii) ciudad universitaria o capital de la cultura (por el lugar destacado del conocimiento científico anclado en la portación de su universidad nacional), y iv) ciudad de la unidad y conciliación nacional (refiriendo a los discursos de "pacificación social" que emergen al finalizar la última dictadura militar sosteniendo la teoría de los dos demonios ${ }^{42}$ ).

El segundo autor que referenciaremos es Ramiro Segura (2016) quien sostiene que, durante los festejos por el centenario de la capital provincial, volvió a cobrar fuerza el imaginario de ciudad de trazado ideal que existió en su fundación. A este imaginario lo denominó "persistencia de la forma", argumentando que la ciudad volvió a ser identificada con el plano de su construcción y que la historia de su desarrollo urbano fue considerada como un desvío con respecto a él. ${ }^{43}$ Además agrega que este imaginario constituye una

\footnotetext{
${ }^{42}$ Refiere a una concepción mediante la cual los actos de terrorismo realizados por la dictadura militar que tuvo lugar en Argentina entre 1976 y 1983 pueden ser justificados como respuesta a los actos de violencia de organizaciones políticas armadas.

${ }^{43}$ Sin embargo, el autor señala que existen otras representaciones que han buscado "desestabilizar la forma" mostrando otras imágenes de la ciudad en donde se encuentra descentrada y amorfa. Por ejemplo se menciona
} 
clave de lectura para representar la ciudad que ha fortalecido una distinción entre el centro (casco fundacional) y sus periferias. De hecho, el autor encuentra que en los habitantes de las periferias la multiplicidad de representaciones sobre la ciudad mantiene un punto en común que es el de resaltar la diferencia, distancia y separación entre el centro y la periferia.

La tercera producción es de Mariana Chaves (2010) quien reconstruye cinco imaginarios a partir de un estudio con jóvenes platenses Los imaginarios que establece son: i) Estigma (remite a los sectores de la ciudad que se asocian al peligro o que son negativamente valorados) ii) Opacidad (zonas asociadas al tiempo nocturno, la oferta de servicios sexuales y la venta de drogas) iii) Transparencia (refiere a los lugares representados como deseables, sobre todo espacios verdes sin ruidos y sin contaminación) iv) Postales (vinculada a los lugares en donde se encuentran los edificios históricos o emblemas de la ciudad) v) Placeres (refiere a espacios que permiten salir del ámbito doméstico y socializar o poder "estar sin hacer nada").

Algunos de estos imaginarios no aparecieron en nuestro trabajo. Entre ellos podemos mencionar a los imaginarios de ciudad perfecta, persistencia de la forma y ciudad de la unidad y la conciliación nacional. Es decir, no se refirió a La Plata como una ciudad de trazado urbano ideal y tampoco se hicieron referencias explícitas a la distinción entre centro (Casco Fundacional) y periferias. Sobre ello, debemos decir que la mayoría de estos jóvenes circulan casi siempre dentro del Casco Fundacional y sus relatos siempre refirieron a él. Tampoco se hicieron referencias explícitas a los discursos de conciliación nacional existentes luego del regreso de la democracia en 1983.

Otros imaginarios, en cambio, se actualizaron de diversas maneras en nuestra investigación. Para comenzar destacamos el imaginario de ciudad universitaria en el cual identificamos dos sentidos. Por un lado, La Plata aparece como una ciudad que proporciona conocimiento y formación académica prestigiosa, en sintonía con el imaginario que analiza Badenes (2012). Por otro lado, la ciudad es vista como un escenario ideal para ser estudiante universitario por su oferta de actividades y espacios de sociabilidad para jóvenes que cursan sus estudios en ese nivel. Este imaginario se asocia a representaciones y

el dibujo de Clorindo Testa publicado en 1982 en el Anuario de la Sociedad de Arquitectos de La Plata en donde la ciudad aparece descentrada, amorfa y extendida, desestabilizando la relación centro-periferia. 
valorizaciones altamente positivas. Si lo ponemos en diálogo con el imaginario de placeres (Chaves, 2010) veremos que los lugares que son vistos como "placenteros" componen, en su mayoría, parte del circuito estudiantil que analizaremos mejor en el capítulo 3. Es interesante remarcar que los espacios asociados al imaginario de transparencia que plantea Chaves aparecieron más ligados a lugares de Roque Pérez que de La Plata.

Con respecto a los imaginarios que condensan mayor cantidad de representaciones y valoraciones negativas, podemos establecer un vínculo entre nuestro imaginario de ciudad peligrosa con los imaginarios de opacidad y estigma que señala Chaves (2010). En ambos se destacan las sensaciones de miedo referidas a la ciudad. No obstante, en los imaginarios que analiza la autora, los lugares que revisten temor y opacidad están sectorizados a diferencia de nuestro imaginario de ciudad peligrosa en donde los temores o las sensaciones de miedo no están restringidos hacia barrios o zonas geográficas específicas sino en la vía pública en general y principalmente durante la noche.

Para finalizar este apartado, debemos precisar que el imaginario de ciudad no puede escindirse de las características particulares de los sujetos que analizamos. Se trata de personas que se han socializado en un contexto urbano de menor escala y eso marca un contraste con una ciudad de las características de La Plata. A su vez, muchos de ellos escucharon relatos sobre la ciudad de La Plata mientras vivían en Roque Pérez (por amigos o hermanos mayores que vivían allí y también a través de medios de comunicación) que fueron reforzando sus ideas sobre cómo sería la ciudad. En este sentido, el imaginario de ciudad se vincula con la condición de migrantes y se construye en oposición al pueblo. Como veremos en el cierre de este capítulo, los imaginarios de ambas localidades cobran sentido a partir de las oposiciones entre ellos. Solo el imaginario de pueblo grande es el único que combina elementos de los imaginarios de pueblo y ciudad que aparecen como opuestos.

\subsection{Comunidad-Sociedad, Anonimato-Presencia: conclusiones}


En este capítulo nos hemos detenido sobre Roque Pérez y La Plata, los lugares de origen y destino de los jóvenes. Ambos escenarios se diferencian en sus características demográficas, económicas y sociales, apareciendo como contrastantes en varios de los imaginarios juveniles. Roque Pérez es un partido de pequeña escala demográfica y de economía agropecuaria. En él se encuentran una ciudad cabecera y varios parajes rurales (tipo amanzanamientos) en donde varios de los jóvenes transcurrieron sus infancias. La Plata es una ciudad mucho mayor demográficamente, con una economía que implica actividades en la administración pública, producción agrícola e industria. Además, la importancia que adquirió su universidad pública la ha constituido en un polo de atracción para la juventud de diferentes partes del país y de otros países (Biagini, 2012).

De las descripciones y análisis realizados emergen dos ejes analíticos estrechamente vinculados, que nos permiten relacionar nuestros hallazgos con campos de discusiones más amplios dentro de las ciencias sociales. El primero lo ligamos con la oposición comunidadsociedad, y el segundo con la tensión anonimato-presencia. A continuación desarrollamos cada uno de ellos.

Con respecto al eje comunidad-sociedad ${ }^{44}$ los imaginarios juveniles sobre ambos lugares retoman la dicotomía en tres formas. En primer lugar, los imaginarios sobre Roque Pérez (Pueblo, Pueblo como lugar de Buenas Costumbres, Pueblo como Infierno Grande y Pueblo Tranquilo) pueden ser pensados con la noción sociológica de comunidad del sociólogo alemán Ferdinand Tonnies. El autor sostiene que se trata de "un tipo de organización social inspirada en el modelo de los lazos familiares, fundamentada en posiciones sociales heredadas y objetivables y en relaciones personales de intimidad y confianza, vínculos corporativos, relaciones de intercambio, sistema divino de sanciones, etc.” (Delgado, 2007:1). Casi como calcadas aparecen las referencias a los tipos de sociabilidad y los comportamientos de las personas dentro de los imaginarios sobre Roque Pérez, realzando un modelo de comunidad caracterizado por vínculos estrechos, familiares y altamente afectivos.

\footnotetext{
44 La noción de "comunidad" constituye una de las ideas elementos (Nisbet, 2009) que acompañaron el desarrollo de la sociología desde sus orígenes. La misma era entendida como el conjunto de lazos sociales caracterizados por la cohesión emocional, la profundidad y la continuidad. Su antónimo sería la noción de "sociedad" que referiría a los vínculos de gran escala, impersonales y contractuales.
} 
La segunda forma en que se actualiza la dicotomía consiste en que casi la totalidad de imaginarios sobre La Plata sostienen una visión de ciudad ligada a la sociedad que contrasta fuertemente con la comunidad ya detallada. Si esta última aparece como el lugar de primacía de los lazos afectivos y personalizados, la sociedad en cambio se caracteriza por la impersonalidad, la frialdad, y también con las posibilidades de transitar múltiples espacios y circuitos. Es más, ambas se construyen a partir de la oposición como dos estilos de vida contrastantes que recuerdan a la dicotomía campo-ciudad ${ }^{45}$ analizada por Raymond Williams (2001). Como señalara Williams la noción de comunidad está asociada a la idea de algo que es conocible a diferencia de la ciudad (ligada a nuestra noción de sociedad) en donde se hace imposible conocer a todos, siendo el sentimiento de lo común más débil y las subjetividades más pronunciadas. No es de extrañar que, a diferencia de la calidez de las relaciones en el pueblo, los vínculos sean adjetivados como "fríos".

El tercer formato no profundiza la dicotomía sino que combina en un mismo espacio La Plata- ambos polos bajo el imaginario de "Pueblo Grande". Este tiene elementos de comunidad y también de sociedad, lo que la vuelve más atractiva para muchos jóvenes. Existe la posibilidad de ser un anónimo, hay muchas personas para conocer y sociabilizar, hay muchos lugares a donde ir para aprender y divertirse pero también uno "aprende a manejarse" rápido y va conociendo a la ciudad porque no es tan grande, sobre todo si se la compara con otras ciudades como Buenos Aires.

El segundo eje analítico, dijimos, era la tensión anonimato-presencia estrechamente vinculado con las nociones de comunidad y sociedad. Como hemos señalado, los imaginarios que retrotraen a la idea de comunidad refieren a vínculos estrechos y relaciones fuertemente personalizadas que no posibilitarían el derecho al anonimato entre sus miembros. Podríamos decir que la presencia, basada en el prolongado conocimiento mutuo, es lo que caracteriza a las sociabilidades en este contexto. Esta imposibilidad de pasar inadvertido hace difícil que las personas puedan resguardar aspectos de su privacidad.

\footnotetext{
${ }^{45}$ Raymond Williams sostiene que "campo" y "ciudad" son dos palabras muy potentes por lo que representan en la experiencia de las comunidades humanas. Así: "El campo atrajo sobre si la idea de un estilo de vida natural: de paz, inocencia y virtud simple. Mientras que la ciudad fue concebida como un centro de progreso: de erudición, de comunicación, de luces. También prosperaron las asociaciones hostiles: se vinculó a la ciudad con un lugar de ruido, de vida mundana y de ambición; y al campo con el atraso, la ignorancia y la limitación. El contraste entre el campo y la ciudad, como dos estilos fundamentalmente distintos de vida, se remonta a la época clásica." (2001:4)
} 
Difícil no significa imposible y de hecho, como veremos en el capítulo 3, los sujetos tienen sus estrategias para ocultar aspectos de sus vidas ante los demás. Sin embargo, pudimos notar que todos coincidieron en que la posibilidad de ser un anónimo en el pueblo es casi nula.

En cambio los imaginarios de ciudad, que asociamos con la noción de sociedad, se caracterizan por la existencia de un tipo de sociabilidad diferente en donde la posibilidad de ser un anónimo es mucho mayor. En la ciudad no es fundamental resguardar aspectos de la privacidad por el hecho de que las personas parecieran no conocerse ni prestarse atención. Esta indiferencia entre las personas de la ciudad, identificada por los jóvenes, nos recuerda a la "actitud de reserva"46 con la cual Simmel (1986) interpretaba las sociabilidades de los habitantes de las grandes ciudades. Esta actitud crea un sentimiento de extrañeza hacia los otros y establece las distancias que tomamos hacia ellos. A su vez, el autor explicaba que si los individuos debieran responder a todas las reacciones producto del contacto constante con otros, los gastos de energía psicológica serían extremados. Como señala Delgado (1998) esta actitud posibilita el derecho al anonimato y la vida urbana en general, protegiendo las identidades individuales de las personas.

A partir de lo señalado, podemos decir que la ciudad es representada como un escenario de posibilidad para el ejercicio del derecho al anonimato. Allí se puede salir a la calle vistiendo la ropa que se desee, caminar de la mano con cualquiera, ir a diferentes lugares y hacer muchas actividades sin tener que estar pendiente de la mirada de los demás. Una de las jóvenes comentaba que en La Plata se sentía "más libre" para expresar opiniones o hacer determinadas actividades que en Roque Pérez. De este modo, en sintonía con el planteo de Simmel, la actitud de reserva en la ciudad pareciera otorgar a los individuos un mayor grado de libertad que el que puede existir en el pueblo.

\footnotetext{
${ }^{46}$ En palabras de Simmel: "Su instinto de conservación de cara a la gran ciudad fuerza al individuo a adoptar una posición no menos negativa hacia el medio social. La actitud de los citadinos ante sus semejantes puede, de un punto de vista formal, calificarse de reserva. Si a los contactos incesantes con individuos innumerables debiera responder una cantidad igual de reacciones interiores, como sucede en las pequeñas ciudades donde uno conoce a casi todos los que encuentra y mantiene con ellos relaciones positivas, uno acabaría por atomizarse completamente y por llegar a un estado psicológico inimaginable. Es en función de estas condiciones psicológicas y de la desconfianza que tenemos derecho a experimentar ante los elementos dispares, fugitivos, de la vida urbana, que nos vemos obligados a esa reserva que hace que no conozcamos ni de vista siquiera a vecinos que habitan desde hace años nuestro edificio, y que parezcamos fríos o duros a ojos de los habitantes de las ciudades pequeñas.” (1986:4).
} 
Cerramos este capítulo retomando nuestro interrogante de partida sobre ¿cómo inciden estos imaginarios en la movilidad espacial de los sujetos? Lo primero que podemos decir es que Roque Pérez y La Plata constituyen los dos escenarios de la experiencia de los jóvenes y si bien aquí los nombramos como lugares de origen y destino, las circulaciones y movilidades por ambos espacios son constantes. A partir del análisis de sus relatos hemos notado que para muchos estos lugares se corresponden con momentos particulares del curso de vida. Para varios La Plata aparece como un escenario atractivo para vivenciar la experiencia juvenil y Roque Pérez como un lugar privilegiado para vivir cuando se forme una familia y se tenga hijos. Recuperaremos este argumento en las conclusiones de la tesis. 


\section{CAPÍTULO 2 Llegar a la ciudad y a la universidad: momentos de transición en el curso de vida}

En este capítulo nos detenemos en dos experiencias de inicio en los cursos de vida de los jóvenes: el comienzo de la vida en La Plata y el ingreso a la universidad. Veremos que estos dos eventos, con las características que se analizan dentro de cada uno, son identificados como marcadores de transición ${ }^{47}$ en sus vidas, lo que posibilita la aparición de nuevas autonomías, prácticas y responsabilidades. A su vez, analizaremos el papel que cumplen las redes en el lugar de origen y destino como soporte material y afectivo en ambas experiencias. El interrogante que guiará el contenido del capítulo es: ¿De qué modo la llegada a una nueva ciudad y a la universidad operan como indicadores de transición en las vidas de los sujetos?

Como hemos señalado en la introducción, la relación entre migración (interna e internacional) y transiciones etarias ha sido abordada por diferentes investigaciones. Algunas de ellas (Dolado y Fernández Yusta, 2002 y Rodriguez, 2004) sostienen que la migración puede significar, para algunos jóvenes, una búsqueda de identidad y la posibilidad de prolongar la moratoria social, entendida como un período de tiempo en el cual los sujetos pueden postergar las responsabilidades propias del mundo adulto y dedicarse al estudio y también al ocio. Otras (Martí, 2011 y Miranda, Cravino y Martí, 2012) analizan la relación entre la migración y las transiciones a la adultez a partir de la hipótesis de que migrar implica asumir responsabilidades propias del mundo adulto en el

\footnotetext{
${ }^{47}$ Como hemos señalado en la introducción, utilizamos este término desde el enfoque del curso de vida (Elder, 2001). Este refiere a cambios de estado o de posición, no necesariamente predeterminados o previsibles aunque, en términos generales, hay algunos cambios que tienen mayores o menores probabilidades de ocurrir (por ejemplo: entradas y salidas del sistema educativo, del mercado de trabajo, del matrimonio, etc.) debido a que continúa prevaleciendo un sistema de expectativas en torno a la edad, que varía por ámbitos, grupos de diversa índole y culturas o sociedades (Blanco,2011).
} 
país de destino. En nuestro caso veremos que el inicio de la vida en otro lugar implica la producción de nuevas experiencias, deberes y también autonomías.

Dividimos este capítulo en tres secciones. En la primera nos detenemos en la llegada de los jóvenes a La Plata. Dentro de ella, contemplamos el papel de las redes familiares tanto en el lugar de origen como en el de destino, los sentimientos de los sujetos al llegar y la organización de sus vidas domésticas en el nuevo lugar. También caracterizamos las vidas de varios jóvenes que residen en el Centro de Estudiantes de Roque Pérez (CERP) en La Plata, una casa de convivencia para migrantes estudiantiles perteneciente a la Municipalidad de Roque Pérez. En la segunda sección analizamos el modo en que el ingreso a la universidad produce transiciones etarias y también lazos de sociabilidad que se convierten en parte de la red de los sujetos en La Plata. En la tercera analizamos cómo estos dos inicios -nueva ciudad, nueva institución educativa-, contribuyen a que los jóvenes identifiquen un momento de transición en sus cursos vitales.

\subsection{Llegar a la ciudad: redes, sentimientos y vida doméstica.}

\subsubsection{Parientes que sostienen en Roque Pérez y La Plata: redes familiares en el lugar de origen y destino}

Para casi todos los jóvenes la posibilidad de ir a estudiar a otra ciudad implicó la movilización de recursos por parte de diferentes miembros de sus grupos familiares. Es decir, ellos se desplazaron entre localidades dentro de una red que posibilitó la migración y la permanencia en la ciudad de destino. Cuando hablamos de redes nos referimos a que los

sujetos se encuentran en un entramado de relaciones que movilizan recursos, ejercen condicionamientos, poseen normativas y establecen sistemas de intercambio entre ellos (Ramella, 1994). Asimismo los sujetos utilizan estratégicamente esas redes para conseguir determinados fines. Veremos más adelante que, a medida que pasa el tiempo, el sistema de redes de los jóvenes se va ampliando e incluyendo a personas que no están vinculadas por el lazo de parentesco. 
Nuestro interés por las redes familiares ha sido compartido por numerosas investigaciones argentinas sobre movimientos migratorios en los últimos años. Estas han mostrado que las familias funcionan como unidades, con arreglos y normativas, a pesar de las distancias geográficas que separan a sus miembros ya sea dentro de un país o entre países. La mayor parte de estas investigaciones se han enfocado en migraciones de escala internacional (Parella Rubio, 2012; Pedone, Romero y Gil Araujo, 2012, Zenklusen, 2016) prestando atención a la asignación de recursos y renegociaciones de los roles por parte de los miembros de la red familiar. Dentro de varios de estos estudios, se ha popularizado el concepto de "familia transnacional"48 (Bryceson y Vuorela, 2002). Sobre migraciones internas actuales existen menos investigaciones. Particularmente sobre migración interna estudiantil, los trabajos de Gamallo y Nuñez (2011), Cleve (2016) y Arias (1998) analizan el papel de las de redes en lugares de origen y destino en migrantes estudiantiles como sostenes económicos y afectivos. Nos interesará tomar los aportes de estos estudios para el análisis de las redes en este tipo de movilidad estudiantil que abordamos.

Como señalamos, focalizamos en los procesos mediante los cuales las familias organizan el traslado y sostienen la permanencia de sus miembros jóvenes en La Plata. Para ello analizaremos la red familiar existente tanto en los lugares de origen y destino, abordando específicamente cuatro situaciones que fueron referenciadas como centrales: i) la elección del lugar donde vivir, ii) el traslado de objetos para equipar las viviendas, iii) el envío de dinero o alimentos para sostenerse en La Plata, y iv) los beneficios de la red en el lugar de destino. Sostenemos que estos procesos constituyen estrategias familiares para la reproducción (Eguía, 1994) de las familias que buscan el aumento de capital escolar en sus miembros más jóvenes. ${ }^{49}$ Estas estrategias refieren a conjuntos de mecanismos, comportamientos y relaciones que despliegan las unidades domésticas para lograr su reproducción integral en las mejores condiciones posibles.

La elección del lugar en donde vivirán los jóvenes comienza mucho antes del traslado definitivo a la ciudad. Las familias intervienen en la búsqueda de departamentos o

\footnotetext{
${ }^{48}$ Bryceson y Vuorela (2002) utilizaron el término de "familia transnacional" definiéndolo como: «aquella familia cuyos miembros viven una parte o la mayor parte del tiempo separados los unos de los otros, siendo capaces de crear vínculos que permiten que sus miembros se sientan parte de una unidad y perciban su bienestar desde una dimensión colectiva, a pesar de la distancia física» (2002: 2).

${ }^{49}$ En el capítulo 4 nos detendremos sobre esto con mayor profundidad.
} 
pensiones a través de internet o, en varios casos, viajan a La Plata para ir a verlos. Una historia que permite ilustrar esto es la de Celina, actualmente trabajadora social de 26 años. Unos meses antes de terminar la secundaria, informó a sus padres que iría a estudiar a La Plata y viviría con una de sus amigas de la escuela. Las familias de ambas comenzaron a movilizarse para conseguir un lugar en dónde las chicas pudieran vivir. En diciembre, Celina, su papá y su amiga viajaron a La Plata para ir a conocer una pensión a la cual finalmente se mudaron en febrero del año siguiente. Vivió allí durante un año y medio y luego se mudó a un departamento junto a dos conocidas. Sus padres compartían los gastos con los padres de las otras chicas. Un año después, por conflictos con sus compañeras de vivienda, se fue a vivir al CERP. Allí se hizo amiga de dos jóvenes y, al año siguiente, se fue a vivir con ellas a otro departamento. En todos los casos, sus padres apoyaron económicamente los costos de vida en la ciudad.

En esta historia se puede ver el modo en que la familia participa en la búsqueda de vivienda y su financiamiento. Celina comentaba que su padre la acompañó porque quería asegurarse de que la pensión fuera cómoda y que el edificio no tuviera problemas en su estado de mantenimiento. Varios jóvenes sostenían que sus padres viajaban a elegir los lugares donde ellos vivirían por la misma razón. Los principales tipos de vivienda en donde se establecieron fueron departamentos, pensiones y el CERP. Algunos de ellos fueron cambiando de tipos de vivienda a lo largo de su estadía en La Plata tal como lo ilustramos con la historia de Celina. Varios se mudaron con conocidos o amigos de Roque Pérez y las familias, en estos casos, compartían los gastos de alquiler, expensas y servicios.

En términos generales, los principales criterios señalados para la elección del lugar donde vivir fueron tres. El primero era el económico ya que muchos buscaban precios de alquiler que no fueran muy elevados para que las familias pudieran afrontarlo durante todos los meses. El segundo era la cercanía con la facultad para que los jóvenes no tuvieran que invertir mucho tiempo diario en desplazarse. El último estaba relacionado con la "seguridad" de la zona donde se ubicaba la vivienda. Varios comentaron que sus padres no querían que el barrio fuera muy "oscuro" por las noches porque eso aumentaba el sentimiento de peligrosidad. Muchas familias habían preferido alquilar en lugares céntricos o cerca de avenidas en donde hubiera mayor movimiento de autos y personas con el 
supuesto de disminuir las probabilidades de sufrir delitos. Aquí se puede ver como el imaginario de ciudad peligrosa que analizamos en el capítulo 1 se encuentra presente en la elección del lugar de residencia.

La segunda situación que analizamos refiere al equipamiento de la vivienda. Los familiares aportaron muebles, electrodomésticos y objetos de cocina, entre otros, para abastecer las casas de los jóvenes en La Plata. Noelia, una estudiante de ingeniería de 23 años, comentaba que cuando se fue a vivir al CERP sus padres le mandaron, en la camioneta de un conocido, un mueble para que pudiera utilizar como escritorio en su habitación. Otros que viven allí también suelen traerse los mobiliarios que necesitan. Camilo, egresado de Comunicación Social de 26 años, cuando se mudó al departamento que alquiló su familia, se trajo un juego de cubiertos, platos y vasos que le regaló una familiar para que pudiera usar allí. Por su parte Eugenio, estudiante de derecho de 25 años, consiguió que un flete le llevara, hasta la pensión donde vivía, una heladera que su abuela no usaba para no tener que gastar en la compra de una nueva.

Como vemos, a través de la red familiar se moviliza el traslado de un conjunto de objetos fundamentales para que los jóvenes puedan desarrollar su vida diaria en La Plata. A diferencia de los gastos de la vivienda que suele recaer principalmente en los padres, en el equipamiento intervienen otros miembros de la familia como abuelos, primos y tíos que aportan objetos desde el lugar de origen. El traslado de estos objetos muchas veces es posible mediante la intervención de personas conocidas en Roque Pérez que tengan medios de transporte como autos y camionetas en donde se puedan cargar esos mobiliarios y que viajen a La Plata con cierta frecuencia.

La tercera situación que analizamos es la circulación de dinero y alimentos una vez que los jóvenes se encuentran instalados en La Plata. Con respecto al dinero, en algunos casos los padres hacían extensiones de las tarjetas de débito y crédito para que pudieran usarlas. En otros casos entregaban a sus hijos dinero en efectivo, ya sea cuando iban de visita a Roque Pérez o cuando los padres viajaban a La Plata. También algunos enviaban dinero a través de conocidos, amigos o algún comisionista central ${ }^{50}$. Además del dinero, otros bienes que circulaban entre los jóvenes y sus familias eran los alimentos. Varios

\footnotetext{
${ }^{50}$ El comisionista es una persona encargada de trasladar mercaderías desde Roque Pérez hacia La Plata o viceversa.
} 
comentaban que cuando volvían de visitar a sus familiares en Roque Pérez se traían comida de sus casas. Una residente del CERP contaba que cuando su papá venía de visita en auto varios familiares de otros chicos le daban tortas, paquetes de fideos, milanesas y galletitas para que les entregara a sus hijos. De esta manera, se puede ver como la red se amplía en la búsqueda del sostenimiento de los hijos en otra vivienda.

Muchos de los jóvenes identifican la aparición de un nuevo sentimiento de responsabilidad ligado a la administración de los recursos proporcionados por las familias, principalmente el dinero. Ariel Wilkis (2015) ha señalado que el uso del dinero distribuye reconocimientos y valores morales entre las personas por las cuales circula. En sintonía con su argumento, podemos notar que los sujetos pasan a sentir una mayor responsabilidad por el "buen" manejo del dinero y eso los reposiciona dentro de la red familiar. Este reposicionamiento se caracteriza por la interrelación entre autonomía de residencia y dependencia económica. El concepto de independencia remite al plano económico. Una persona es independiente cuando posee los recursos materiales suficientes para no depender de alguien más. En cambio, autonomía refiere a la situación en la cual los jóvenes pueden conducir sus vidas de acuerdo a sus propias normas. (Ballesteros Guerra, Megías Quirós y Rodriguez San Julian, 2012). En este sentido, la autonomía de residencia posibilita que los jóvenes comiencen a tomar decisiones y adquieran nuevas responsabilidades sobre la organización de sus vidas sin que ello implique la independencia económica. En varios casos, las familias asignan un determinado monto de dinero al mes y los jóvenes deben aprender a administrarlo para que les dure hasta el próximo envío de dinero. A menudo el financiamiento por parte de la familia continúa existiendo luego de la graduación universitaria, en otros casos finaliza allí y, a veces, concluye antes de terminar los estudios universitarios.

Hasta aquí nos hemos detenido en el papel de los familiares en el lugar de origen. Ahora veremos que varios de los jóvenes cuentan también con miembros de la red familiar en el lugar de destino. En su mayoría, los parientes que se encuentran en la ciudad de La Plata son hermanos o primos que se fueron a estudiar con anterioridad o en simultáneo. A su vez, luego de vivir un tiempo en La Plata, varios de ellos se constituyen en miembros de 
la red familiar para los de menor edad que migran con posterioridad. Además hay jóvenes que contaban con otros parientes en la ciudad como abuelos o tíos.

A lo largo de nuestra investigación, hemos analizado tres beneficios que los jóvenes obtienen por formar parte de una red familiar en La Plata. El primero de ellos tiene que ver con la contención afectiva. El segundo está relacionado con el aprendizaje sobre cómo movilizarse en la ciudad y el tercero es el económico. Dentro del primero, para muchos jóvenes la sensación de desarraigo, sumado al hecho de extrañar a sus familiares y su lugar de origen, hace muy difícil su estadía en la ciudad de destino y contar con miembros de su comunidad natal ayuda a sobrellevar esos sentimientos. Podemos graficar este primer beneficio señalando la historia de Liliana, estudiante de Veterinaria de 26 años, quien sostiene que, por razones económicas, no podía ir todos los fines de semana a visitar a su familia a Roque Pérez. A veces pasaba varios meses sin poder ir y eso la angustiaba mucho. No obstante, el hecho de tener a una hermana y sobrinos viviendo en La Plata la ayudaba a sentirse más contenida. Otro caso es el de Lucía, trabajadora social de 28 años, que se fue a vivir a un departamento en La Plata junto a una amiga en el mismo edificio en el cual residían sus dos hermanos. Los primeros meses vivió con su amiga y luego se volvió a Roque Pérez abandonando la facultad. Al año siguiente regresó para estudiar otra carrera y se fue a vivir con sus hermanos. Vivir junto a ellos hacía que se sintiera en un ambiente familiar y no extrañara tanto. A su vez, los domingos que no iba a Roque Pérez, aprovechaba a almorzar con su abuela, que vivía en La Plata, para no sentirse sola.

El segundo beneficio es aprender a movilizarse en la ciudad. Cuando Victoria, una estudiante de Medicina de 21 años, llegó al CERP, su hermana ya se encontraba viviendo allí. Ella fue quien le brindó a Victoria toda la información necesaria sobre el centro y la estimuló para que viniera a estudiar. La joven reconoce que su hermana fue quien le enseñó cómo llegar a la facultad desde el CERP y también cómo utilizar el transporte público, algo que suele ser problemático para muchas personas que vivieron siempre en lugares en donde no existe o no es habitual su uso. Victoria reconoció que cuando tenía que ir a algún lugar, le preguntaba a su hermana cómo llegar ya que le daba vergüenza tener que preguntárselo a otras personas. 
El tercer beneficio es el económico. Algunos parientes en La Plata les brindaban dinero a los jóvenes cuando lo necesitaban. Así contaba Lucía que, cuando se le terminaba la plata que le habían dado sus papás, les pedía a sus hermanos que le prestaran para sus gastos. Casi siempre la devolución de ese dinero no lo hacía ella sino sus padres. También, dentro de este beneficio, se encuentran las actividades laborales. Hay jóvenes que consiguieron empleo a través de sus parientes en la ciudad de La Plata y hay otros que consiguieron empleo en Roque Pérez, unos meses antes de venirse a estudiar, para ahorrar un capital que pudieran usar en la capital bonaerense. En Roque Pérez, Victoria le había dejado su puesto de trabajo, como cobradora en una obra social, a su hermana. A su vez, comentó que su hermana le había pasado ese puesto a una amiga de ella que también se iba a ir a estudiar a dicha ciudad al año siguiente.

Cerramos este apartado enfatizando en la importancia de pensar las relaciones de interdependencia ${ }^{51}$ familiar que se ponen en juego para que los jóvenes puedan ir a vivir y sostenerse en La Plata. Para ello intervienen miembros de la red familiar en el lugar de origen y el lugar de destino. También, es necesario señalar que en algunos pocos casos el traslado y el sostenimiento de la vida en la ciudad se realizaron sin apoyo económico de la familia. Solo dos de los dieciséis entrevistados manifestaron que sus familias no pudieron ayudarlos económicamente para irse a vivir a La Plata. En estos casos fueron ellos quienes consiguieron los lugares en donde vivir en la ciudad y utilizaron dinero ahorrado de trabajos que tuvieron en Roque Pérez, para solventar gastos durante las primeras semanas de vida, y luego tuvieron que buscar empleo para sostenerse. Profundizaremos sobre esto en el capítulo 4.

\subsection{2 "Tener que cocinar es un mundo aparte": la organización de la vida doméstica en La Plata}

\footnotetext{
${ }^{51}$ Como vimos en la introducción, Glen Elder (2001) afirma que uno de los principios generales del enfoque de curso de vida es el de "vidas interconectadas" que sostiene que las vidas humanas siempre se viven en interdependencia, es decir, en redes de relaciones compartidas. En este sentido, el análisis de la trayectoria de un sujeto debe ver la interdependencia con las trayectorias de otros sujetos que posibilitan el desarrollo de esa trayectoria.
} 
Para casi todos los jóvenes con el cambio de ciudad comienza la vida por fuera del hogar familiar y esto trae nuevos aprendizajes, responsabilidades y autonomías ${ }^{52}$. En este apartado analizamos dos situaciones vinculadas al comienzo de la vida doméstica en La Plata. La primera es la aparición de nuevas autonomías y, la segunda, el modo en que se organiza la vida dentro de la vivienda. Dentro de esta última nos detenemos en la influencia de la socialización diferencial por género en los modos de resolver las tareas domésticas y también en las conflictividades que se producen a partir de la convivencia con otros.

El cambio de vivienda produce la emergencia de nuevas autonomías en los sujetos y también de nuevas responsabilidades. Lo primero que se debe señalar es que estos sujetos consiguen, casi todos a la edad de 18 años, la autonomía residencial en relación a sus familias. Con nuevas autonomías queremos referir a que los sujetos comienzan a vivir a partir de algunas reglas propias (Ballesteros Guerra, Megías Quirós y Rodriguez San Julián 2012). Uno de los mayores cambios que muchos jóvenes suelen notar es el modo de organizar los tiempos dentro de la casa. Algunos comentaban que cuando vivían con sus padres los horarios del almuerzo y la cena estaban establecidos estrictamente y todos en la familia los respetaban. Cuando se fueron a vivir a La Plata, muchos almorzaban o cenaban a la hora que querían o si no tenían ganas de cocinar, su almuerzo consistía en mate y galletitas. Como señalaba Vanesa, una estudiante de Medicina de 20 años, cuando vivía en la casa de sus papás respetaba los horarios para comer en familia pero, desde que vivía en La Plata, ella era quien ponía sus propios horarios y si no quería cocinar se compraba un sándwich. Algunos de los jóvenes almorzaban en el comedor universitario ${ }^{53}$ lo que les permitía consumir una comida elaborada a bajo costo y también evitar cocinar durante el mediodía.

También los jóvenes reconocieron poner sus propias reglas sobre los horarios para ir a dormir y recibir visitas. Algunos comentaban que solían invitar amigos, conocidos o "chongos" ${ }^{\circ 4}$ en cualquier momento del día, sin tener que dar explicaciones a nadie. En el caso de los jóvenes que compartían la vivienda con amigos o vivían en pensiones o el

\footnotetext{
${ }^{52}$ Dos jóvenes que habían crecido en parajes rurales, se trasladaron a Roque Pérez para asistir a la secundaria, siendo esa su primera experiencia viviendo fuera de la casa familiar.

${ }^{53}$ El comedor universitario constituye una política de bienestar estudiantil de la UNLP que brinda el almuerzo diario a los estudiantes de la institución por un precio de 15 pesos.

${ }^{54}$ Con este término refieren a las personas con las que tienen actividad sexual con cierta frecuencia.
} 
CERP, debían establecerse acuerdos para invitar a personas externas con el fin de evitar conflictos. También otra de las autonomías que aparece es la posibilidad de irse de la casa en cualquier momento sin tener que brindar razones por ello.

Para muchos de los sujetos la organización de las actividades domésticas es vista como uno de los cambios más drásticos de sus vidas en La Plata. Antes de mudarse a la capital bonaerense, no estaban acostumbrados a cocinar, ni a realizar las compras necesarias para abastecerse, ni pagar impuestos o limpiar. Hemos hallado en nuestra investigación que existe una fuerte incidencia de la condición de género en los modos de resolución de las actividades domésticas en la ciudad de destino. La mayoría de las mujeres comentaron tener una mejor capacidad para organizarse en sus quehaceres domésticos que los varones. Interpretamos que esto se vincula con la socialización diferencial por género ${ }^{55}$ (Walker y Barton, 1983) en donde la mayoría de las mujeres aprendieron, a lo largo de sus vidas, a hacerse cargo de actividades domésticas dentro del hogar. Esto les permitió desenvolverse mejor en el ámbito doméstico luego de migrar a La Plata. Es necesario señalar que hubo excepciones en algunos casos pero se notó la recurrencia de este fenómeno en varios de los sujetos.

Para graficar esta idea utilizamos dos relatos, el de un varón y una mujer que funcionan como casos típicos. El primero es el de Camilo quien sostuvo que el hecho de tener que cocinarse "fue un mundo aparte" luego de llegar a La Plata. Mientras vivía en Roque Pérez, iba a almorzar todos los días a la casa de su abuela. Ella, que estaba jubilada, era la encargada de darle de comer a todos los hijos y nietos. Por las noches su mamá se encargaba de cocinar la cena para la familia. Durante toda su vida estuvo acostumbrado a que la elaboración de las comidas era realizada por su mamá o su abuela. Cuando se fue a vivir a La Plata no sabía qué cocinar. Su madre solía llevarle algunas viandas para que freezara y luego calentara en el microondas. Pero cuando se terminaban, el joven debía resolver la preparación de los alimentos por su propia cuenta. Entre risas, comentó que con mucha frecuencia comía fideos con salchichas porque no sabía preparar otra cosa. Otro de

\footnotetext{
${ }^{55}$ La socialización diferencial por género refiere a que las personas, en el inicio de su vida social, y a partir de la influencia de agentes socializadores, adquieren identidades diferenciadas por género que conllevan a la creación de marcos cognitivos, códigos morales, estereotipos y comportamientos asignados a cada género (Walker y Barton, 1983).
} 
los aprendizajes que señala Camilo fue tener que "limpiar a fondo" su departamento. Cuando vivía en Roque Pérez acostumbraba a ordenar sus pertenencias personales pero nunca había tenido que limpiar el baño o la cocina en profundidad y recuerda que, cuando se fue a La Plata, su madre le enseñó el modo de realizar esas actividades y luego se fue acostumbrando.

Una situación opuesta es la de Liliana quien, cuando vivía en Roque Pérez, estaba acostumbrada desde que era chica a cocinar para la familia porque sus padres trabajaban. Cuando su mamá no podía cocinar, ella se encargaba de que la comida estuviera preparada cuando sus hermanos llegaban de la escuela y sus papás del trabajo. Durante los sábados por la mañana se encargaba, junto a su mamá, de limpiar la casa en profundidad. A su vez, ganaba algo de dinero limpiando la casa de una de sus tías o planchando ropa para personas conocidas. Cuando se fue a vivir a La Plata, cocinarse y limpiar no fue algo novedoso para ella. Estas historias también se repitieron en otros jóvenes de ambos géneros, lo que nos llevó a notar una cierta regularidad que no estuvo exenta de algunas excepciones, como el caso de Eugenio que había aprendido a hacerse cargo de las actividades domésticas desde que era chico para ayudar a su abuela con quien vivía. No obstante, el lugar que la mayoría de las mujeres ocuparon dentro de la esfera doméstica desde que nacieron, y que fuera una situación desigual en ese contexto, pudo ser utilizado para desempeñarse con menos problemas que los varones en lo que respecta a la resolución de situaciones domésticas luego de migrar a La Plata.

Como ya hemos señalado, varios jóvenes se fueron a vivir junto a otras personas. La convivencia fue planteada como uno de los nudos más problemáticos de la vida en la ciudad. Muchos de los que alquilaron departamentos junto con amigos o conocidos resaltaron haber tenido conflictos en la convivencia diaria. Celina alquiló un departamento en conjunto con una conocida suya y una amiga de esta última a quien no conocía previamente. A los pocos meses de vivir con ellas, comenzó a tener muchos problemas con la amiga de su conocida. Las discusiones giraban en torno al orden y la limpieza del departamento y finalmente decidieron separarse para vivir en lugares diferentes. Veremos más adelante que dentro del CERP estas conflictividades también aparecen con frecuencia. Otro factor que suele ser motivo de conflictos y peleas es la comida. Varios jóvenes 
comentaron que, a pesar de vivir varios al interior de una misma vivienda, los alimentos no eran compartidos por todos. De hecho, Celina comentaba que así como tenían la ropa separada entre las tres chicas, la comida también estaba separada. A veces sus padres le traían alimentos de Roque Pérez y ella los administraba durante varias semanas. En una ocasión había invitado a una compañera de la facultad a estudiar a su casa y cuando fue a buscar un paquete de galletitas, que le habían traído sus papás, notó que se lo había sacado una de sus compañeras de departamento. Esto trajo una fuerte pelea entre ellas que culminó en que consensuaran que nadie podía tocar los alimentos de las otras.

Para cerrar este apartado podemos decir que, en la esfera doméstica, el inicio de la vida en La Plata produce nuevas autonomías y también responsabilidades a las cuales los sujetos deben aprender a sobrellevar. La mayoría de ellos identifica un momento de transición en sus cursos de vida luego del cambio residencial. En el siguiente apartado nos detendremos en los sentimientos que aparecen cuando llegan a la ciudad.

\subsection{3 "Te mandan al mundo": sentimientos al llegar a la ciudad}

La llegada a La Plata produjo la vivencia de una serie de sentimientos sobre los que nos detendremos aquí. Nos interesan estos sentimientos porque coincidimos con Anderson (2014) que los mismos, al igual que los afectos y las emociones, constituyen partes fundamentales de toda experiencia. Lejos de considerar que los sentimientos son fenómenos biológicos, partimos de entender que son producto de la vida social y de contextos culturales específicos (Le Bretón, 2013). En esta tesis, utilizamos la definición de Eric Shouse (2005) que sostiene que un sentimiento ${ }^{56}$ es una sensación que ha sido contrastada con experiencias anteriores y etiquetada. Por lo tanto, es personal y biográfico porque cada persona tiene un conjunto diferente de sensaciones anteriores con las cuales contrastar y etiquetar sensaciones nuevas. Nos interesa aquí detenernos sobre las etiquetas con las que los sujetos nombran las sensaciones que tuvieron al llegar a la ciudad. A partir

\footnotetext{
${ }^{56} \mathrm{El}$ autor advierte de confundir este concepto con emoción y con afecto. Una emoción es la proyección de un sentimiento y puede ser genuino o fingido de acuerdo al entorno social. El afecto es más amplio que emoción y sentimiento y alude a una experiencia no consiente, corporal y que excede lo lingüístico (Shouse, 2005).
} 
del análisis de sus relatos, hemos reconstruido cinco grandes sentimientos: i) Sentirse solo; ii) Sentirse perdido; iii) Sentirse maravillado; iv) Sentirse atemorizado; y v) Sentirse chico y grande a la vez. Estas categorías se encuentran en estrecha vinculación con los imaginarios analizados en el capítulo anterior.

Una de las sensaciones que es remarcada por varios es la de sentirse solo. Liliana comentaba que fue muy duro comenzar a vivir en La Plata. La sensación que tenía era la de estar lejos de su familia y sola en una ciudad tan grande y desconocida. Se mudó al CERP en donde se sintió contenida por el resto de las personas que vivían allí. Varios de los jóvenes comentaban que, durante el primer tiempo en La Plata, se iban todos los fines de semana para Roque Pérez. Uno de ellos, había dejado de cursar las materias de los días viernes para poder irse a Roque Pérez los jueves por la noche y regresar a La Plata los lunes por la madrugada.

El segundo sentimiento que identificamos es el de estar perdido. Elena, una estudiante de Bioquímica de 19 años, sostenía que "cuando uno llega a La Plata, la típica es perderte" haciendo referencia a algo que pareciera ser una norma para todo joven que llega desde el "pueblo". Aquí los imaginarios sobre Roque Pérez y La Plata cobran una fuerza central para explicar las razones de esta sensación de estar perdido. Victoria señalaba que al ser Roque Pérez un "pueblo tan chico", las personas se conocen todos los lugares de memoria y que cuando llegan a La Plata, una "gran ciudad", las mayores distancias, los ruidos, la cantidad de vehículos y de personas crean un escenario en donde muchos de ellos se sienten "desencajados". De hecho, esta joven comentaba que, cuando comenzó a vivir en La Plata, no se perdía porque prefería no salir a ninguna parte. En varios de ellos, el sentimiento de estar perdido se refuerza con experiencias en el transporte público en donde se desorientan dentro del recorrido o se pasan de los lugares a donde debían ir.

El tercer sentimiento que encontramos fue el de estar maravillado. Con este término calificaba Malena, una diseñadora de 31 años, su sentimiento al llegar a La Plata puesto que se encontró con una ciudad que le ofrecía educación universitaria, espacios artísticos, lugares de recreación y muchas personas para sociabilizar. Sobre todo aquellos jóvenes que sentían que Roque Pérez era un lugar demasiado tranquilo y por momentos aburrido, se sintieron sumamente encantados por la diversidad de prácticas, actividades y lugares que 
ofrece la capital bonaerense una vez instalados allí. Como relataba uno de los jóvenes, "en La Plata hay mucho de todo y uno puede ver muchas cosas que en el pueblo no las ve". Para este grupo de jóvenes, la ciudad pareciera encantarlos con sus espacios.

El cuarto es el estar atemorizado y se vincula estrechamente con el imaginario de ciudad peligrosa. Liliana marcaba tajantemente que luego de las ocho de la noche, en la ciudad había un "toque de queda" y era sumamente riesgoso circular por la calle. Varios de los jóvenes sufrieron episodios de robo en la ciudad y a partir de ello tuvieron que aprender a tomar recaudos o, en términos de Kessler (2011), aprender a gestionar la inseguridad. Victoria comentaba que por la noche intentaba no salir o, si salía, lo hacía acompañada. Darío, que utilizaba mucho la bicicleta para movilizarse por la ciudad, por las noches circulaba por avenidas principales que estuvieran iluminadas. Vanesa contaba que cuando cursaba en la facultad por las noches, salía un rato antes de la clase para evitar tener que esperar sola en la parada del micro. Emanuel es un joven que decidió regresar a vivir a Roque Pérez luego de sufrir un episodio de robo donde lo golpearon. Comentó que no pudo reponerse porque venía de un "pueblo tranquilo" en donde esas cosas casi nunca suceden y la "ciudad" comenzó a darle miedo.

Por último, encontramos un sentimiento estrechamente relacionado con lo etario que podemos denominar como sentirse chico y grande a la vez. "Chico" porque se debe abandonar el hogar familiar para irse a vivir a otra ciudad y "grande" porque aparece un sentimiento de tener que asumir nuevas responsabilidades que son vistas como un crecimiento en términos del curso de vida. Así lo relataba Celina que se sentía "muy chiquita para estar en un lugar tan grande" pero que sabía que debía afrontarlo sola. Es decir, si quería llevar adelante su proyecto de profesionalizarse, debía hacerse cargo de las responsabilidades de vivir sin su familia y organizar su vida en la nueva ciudad.

\subsubsection{Vivir en el Centro de Estudiantes de Roque Pérez}

En este apartado nos detenemos a caracterizar el Centro de Estudiantes de Roque Pérez (CERP), un edificio de alojamiento perteneciente a la Municipalidad de Roque Pérez 
para hospedar a los jóvenes que se van a estudiar a la ciudad, principalmente a aquellos que no pueden afrontar los gastos de un alquiler. ${ }^{57}$ Cinco de los sujetos que participaron en nuestra investigación vivían en el CERP y dos habían vivido unos años antes de ser entrevistados. En primer lugar realizaremos una descripción general del establecimiento. En segundo lugar, caracterizaremos los modos de ingreso y, por último, analizamos algunas dinámicas de sociabilidad.

Como hemos señalado, el CERP es un establecimiento municipal destinado a migrantes estudiantiles de Roque Pérez. El mismo funciona en un edificio ubicado dentro del Casco Fundacional de La Plata. Cuando realizamos el trabajo de campo, en el CERP vivían 20 jóvenes estudiantes. El edificio es antiguo y en su entrada tiene un cartel que dice “Centro de Estudiantes de Roque Pérez" y señala el año de su fundación, 1984. La construcción tiene dos plantas y la mayoría de las habitaciones se encuentran en la planta baja. En el piso de arriba solo hay un cuarto que se utiliza como salón de estudio. En el piso de abajo hay un patio en donde se guardan varias bicicletas, una cocina comedor y cinco habitaciones que funcionan como dormitorios, en tres de ellas duermen varones y en las otras dos, mujeres. Hay dos baños que también están diferenciados por género.

En la cocina se encuentran tres heladeras en donde los jóvenes guardan sus alimentos. Hay también un horno con varias hornallas, una mesada y un termotanque eléctrico. Del lado derecho de este espacio, se encuentran dos mesas con sillas alrededor. En una de las paredes se puede ver una pizarra de corcho en donde hay carteles pegados. Uno informaba sobre la próxima reunión de la comisión directiva. Otro mostraba un cuadro en donde indicaba que día de la semana le correspondía a cada miembro del centro realizar tareas de limpieza generales. Otro cartel informaba sobre los trámites que aún estaban pendientes de hacer. Varios de los muebles que allí se encuentran pertenecen al CERP, pero también algunos jóvenes se traen muebles desde Roque Pérez para utilizar en sus

\footnotetext{
${ }^{57}$ Existen en La Plata otras casas de alojamiento financiadas por diferentes municipios de la Provincia de Buenos Aires y de otras provincias, las cuales constituyen una política pública específica para migrantes estudiantiles. También en la vecina ciudad de Berisso se encuentra el Albergue Universitario de la UNLP que fue abierto en 2011 y en donde actualmente viven más de 120 jóvenes originarios de diferentes partes del país. El albergue es una casa de alojamiento gratuita y la UNLP es la única universidad que brinda una política de bienestar estudiantil de este tipo en el país. En esta investigación no entrevistamos personas que hayan vivido allí.
} 
habitaciones. También algunos bienes son conseguidos mediante la Federación Universitaria Bonaerense, un organismo que nuclea a los centros de estudiantes regionales.

El CERP se organiza mediante una comisión directiva de la cual participan varios de los jóvenes que viven allí. También pueden desempeñar cargos dentro de la comisión jóvenes que no vivan en el centro pero que sean originarios de Roque Pérez. Noelia, por ejemplo, se desempeñaba como secretaria y estaba encargada de realizar trámites para conseguir la personería jurídica del centro. Ella y otra chica, que oficiaba como tesorera, dormían en una habitación reservada para miembros de la comisión. Darío había sido, unos años atrás, presidente y comentaba que, en varias ocasiones, tuvo que hablar con el intendente de turno para pedir recursos económicos.

El edifico del Centro de Estudiantes pertenece a la Municipalidad de Roque Pérez. En una entrevista realizada a dos funcionarios municipales, explicaron que el origen de la subvención que se le da al centro proviene de un impuesto que se les cobra a los propietarios de animales de ganado para transportarlos. Este arancel se denomina "guía” y, a través de él, el municipio certifica que los animales que se están trasladando pertenecen al dueño que los declara. Una parte de ese dinero recaudado es destinado para becas educativas y para el centro de estudiantes. La relación entre la Comisión Directiva del CERP y las autoridades municipales no estuvieron exentas de conflicto. De hecho, el gobierno municipal les exigió tramitar la personería jurídica para continuar subsidiándolos. Otros modos que tienen los jóvenes para conseguir recursos económicos son las rifas de fin de año que venden principalmente a conocidos de Roque Pérez. A su vez, el centro cuenta con socios que, en su mayoría, son personas del lugar de origen, que abonan una cuota mensual.

Para ingresar al CERP se establece un período de inscripción que coincide con el período de inscripción a las carreras de grado de la Universidad Nacional de La Plata desde mediados de noviembre hasta mediados de diciembre. Los miembros de la comisión dejan un formulario en una fotocopiadora de Roque Pérez que los postulantes deben completar y entregar junto con una fotocopia del DNI (Documento Nacional de Identidad) y un certificado analítico de la escuela secundaria. En diciembre varios de los miembros de la comisión realizan una reunión en Roque Pérez para que los postulantes entreguen la 
documentación y les informan sobre las características y las reglas de convivencia del centro.

El requisito principal para ingresar al CERP es tener el secundario terminado e inscribirse en alguna carrera universitaria o terciaria. Se permite que los ingresantes adeuden exámenes de algunas materias de la secundaria, pero deben rendirlos dentro del plazo que otorga la universidad para no perder la condición de estudiante regular. Noelia comentaba que la comisión no siempre tiene en cuenta la situación económica de la familia como un criterio para el ingreso al centro porque la cantidad de aspirantes suele ser poca. En caso de que hubiese una gran cantidad de postulantes, si se tiene en cuenta ese criterio. No obstante, varios de los jóvenes que viven allí señalaron que no hubiesen podido trasladarse a La Plata si tuvieran que pagar un alquiler. La documentación solicitada a las personas que viven en el CERP consiste en un certificado analítico cuando finaliza el año de facultad para constatar que estén avanzando con la cursada de materias. Si bien lo ideal es que se cursen por lo menos tres materias por año, nadie fue expulsado de la casa por no haber aprobado este número de cursadas.

Darío, un estudiante de Derecho de 32 años, comentaba que se espera que los residentes del CERP estudien carreras en la UNLP. Sin embargo, existieron casos de jóvenes que querían estudiar alguna carrera terciaria y que la comisión decidió flexibilizar y aceptar sus admisiones. Sobre este punto también existen tensiones con el gobierno municipal de Roque Pérez que considera que en el centro de estudiantes solo deben residir quienes cursen carreras universitarias puesto que en la localidad y los partidos aledaños existe oferta terciaria. Existió también la situación de una chica que llegó para estudiar una carrera en una universidad privada de La Plata y eso generó debates dentro de la comisión, con respecto a si debería dársele el lugar a una persona que tenía capacidad para pagar sus estudios. No obstante, uno de los miembros de la comisión argumentó que la capacidad de pagar una carrera no significaba que tuviera capacidad económica para pagar un alquiler. Este argumento, sumado a que la carrera que la postulante quería estudiar no se dictaba en la universidad pública, llevó a que la comisión directiva aceptara su ingreso.

Por lo general, los jóvenes se enteran de la existencia del CERP por el "boca en boca". Elena comentaba que se enteró a través de una amiga cuya hermana vivía en el 
centro. Aprovechó un día que la hermana de su amiga había ido de visita a Roque Pérez para preguntarle sobre el modo de ingresar y decidió postularse. La joven reconoce que sin esa posibilidad, su padre no habría podido afrontar los gastos que implicaría su traslado a La Plata. También varios comentaron que sus docentes en la escuela les hablaron sobre el CERP y desde allí comenzaron a informarse.

En cuanto a la vida diaria en el CERP, suelen realizarse reuniones para charlar sobre asuntos relacionados con la convivencia y dividir las tareas de limpieza entre los residentes. Darío contó que en las épocas en que han sido pocos conviviendo, casi no se realizaban reuniones sino que se hacían acuerdos en charlas más informales. El joven comentaba que el año que ingresó, en el CERP solo había alrededor de 10 personas y que los arreglos de convivencia se realizaban conversando. No obstante, cuando el número de personas fue mayor, se tuvieron que realizar reuniones para organizar temas de convivencia.

En algunos casos, las dificultades en la convivencia llevaron a que los miembros de la comisión decidieran expulsar a algunos sujetos. Darío relataba la vez en que unos ingresantes fueron expulsados por realizar reuniones con amigos en donde se quedaban escuchando música hasta la madrugada en días de semana. Muchos de los jóvenes que vivían allí se quejaban de estos comportamientos y los miembros de la comisión directiva habían hablado varias veces con los ingresantes para que dejaran de hacerlo. Se les informó que si continuaban con esa actitud serían expulsados y finalmente tomaron esa decisión. Otra de las expulsiones fue para un joven que se rehusaba a cumplir con las actividades de limpieza que le correspondían de acuerdo a la división de actividades acordada en las reuniones. El joven argumentaba que él no vivía allí para ser la "mucama" de nadie y eso trajo muchos conflictos con el resto de las personas. Como iba al día con la cursada de las materias de la carrera, su situación generó discusiones dentro de la comisión directiva. De hecho, el joven utilizaba su buen desempeño en la universidad como argumento para permanecer en el lugar. Sin embargo, debido a su comportamiento, la comisión decidió expulsarlo.

Por fuera de estas situaciones no existieron otros motivos de expulsión. Incluso Darío comentaba que nadie fue dejado afuera por tener, por ejemplo, malas calificaciones en la carrera que estudiaba. Más allá de que la comisión pide un certificado analítico todos 
los años, nadie fue expulsado por no aprobar materias en la facultad. El joven lo expresó en una frase: "sin joder al de al lado, vos hacé la tuya y después vos sabrás... si tomabas mate en la carrera, es cosa tuya y de tus padres que te están bancando".

Pero a pesar de los conflictos que se generan, el CERP también es valorado como espacio de contención afectiva para los recién llegados a La Plata. El centro funciona para muchos de ellos como un lugar que permite sobrellevar los sentimientos de angustia y desarraigo. Así lo comentaba Vanesa que, cuando llegó al centro, tenía una amiga de la escuela residiendo y se hizo de más amigas en el lugar. La joven comentaba que no soportaría estar sola y que en el CERP siempre tenía alguien con quien charlar o sentarse a comer en la misma mesa más allá de que cada cual tuviera su propia comida.

Para concluir este apartado, se puede notar que el CERP constituye una política pública específica para migrantes estudiantiles que busca posibilitar el traslado para jóvenes cuyas familias no pueden afrontar los gastos que implica la vida en La Plata. Pero además el lugar también funciona como un espacio de contención afectiva para los mismos que no está exenta de conflictividades durante la vida diaria.

\subsection{Llegar a la universidad: transiciones y nuevas redes}

En esta sección nos detenemos en otra experiencia de inicio en los sujetos, el comienzo de los estudios en la Universidad Nacional de La Plata, una institución pública que oferta carreras de grado gratuitas. Nos interesa remarcarlo porque constituye una característica central como condición de posibilidad de acceder a la formación universitaria. La investigadora Sandra Carli (2012) sostiene que la gratuidad de los estudios y el carácter irrestricto del ingreso en las universidades públicas argentinas constituyen medidas que permiten interpretar una cierta "tradición plebeya" que ha posibilitado la convivencia de distintos sectores sociales en la universidad. Según la autora esta apertura quedó asociada a tres cuestiones fundamentales: un principio de igualdad de oportunidades de la educación pública, la vinculación entre educación y movilidad social y a las luchas estudiantiles por democratizar el sistema educativo. Estas características han permitido una suerte de 
"mestizaje" (Pierella, 2011) de grupos sociales dentro de la universidad que no se han dado en otros países de América Latina en donde existen exámenes de ingreso, aranceles o cupos delimitados.

Veremos que la llegada a la universidad también es relatada como un momento de transición etaria en donde se producen nuevos aprendizajes, experiencias, sociabilidades y se adquieren también nuevos deberes. En sintonía con estos argumentos, en Argentina una serie de investigaciones posicionadas desde la perspectiva de la experiencia universitaria ${ }^{58}$ (Carli, 2012) han mostrado que el ingreso a la universidad produce la exogamia familiar y el desarrollo de una serie de experiencias culturales (Pierella, 2011), formas de gestionar la identidad sexual y de género (Blanco, 2014) y experiencias políticas (Blanco, 2016). Estas investigaciones han mostrado que las experiencias estudiantiles no se agotan en cursar estudios sino que implican sociabilidades, producción de subjetividades y prácticas diversas.

En primer lugar, presentamos una breve caracterización de la Universidad Nacional de La Plata que constituye el escenario donde se anclan las experiencias de los estudiantes. En segundo lugar, analizamos el modo en que el inicio de los estudios universitarios es vivido como una transición en términos etarios. En tercer lugar, abordamos el modo en que los lazos de sociabilidad, que se producen en la facultad, pasan a formar parte de las redes sociales de los jóvenes en la nueva ciudad.

\subsubsection{Sobre la Universidad Nacional de La Plata}

"Si la erección ex nihilo de La Plata, en la Provincia de Buenos Aires, fue considerada en su momento como un fenómeno prodigioso, el complejo universitario que se levantó en ella también resultó objeto de similares apreciaciones encomiásticas. Así los Lugones, los Levene y los Sábato no vacilaron en comparar aventajadamente dicha casa de estudios con beneméritos claustros como Oxford, Salamanca o Heidelberg, mientras que otros personajes se refirieron

\footnotetext{
58 Sandra Carli sostiene: “Al emplear la expresión de 'experiencia universitaria', nos interesa introducir una nueva perspectiva en los estudios sobre universidad que atienda a las prácticas de los sujetos institucionales y sus reflexiones retrospectivas sobre vivido para poner en cuestión una mirada generalista, introducir cierto realismo en los modos de pensar la universidad y narrar la historia del presente" (2012:26).
} 
a una ciudad destinada a convertirse en la metrópoli universitaria de Sudamérica, en capital de la cultura docente, en Boston de nuestro propio hemisferio. Asimismo, el devenir de la universidad platense haría que ésta fuese asociada con el rol que cumplió la de Charcas durante la Colonia, en cuanto polo de atracción para la juventud americana." (Biagini, 2012:111)

La Universidad Nacional de La Plata (UNLP) remonta sus orígenes hacia 1897 cuando se fundó como establecimiento provincial (Universidad Provincial de La Plata) bajo la presidencia del Dr. Dardo Rocha. El historiador Fernando Barba (1998) sostiene que al poco tiempo de fundarse, los dos principales problemas que tuvo que enfrentar la joven universidad fueron la escasa matrícula de estudiantes ${ }^{59}$ y el bajo presupuesto ${ }^{60}$. Se sumaba a esto que su condición de establecimiento provincial no generaba atracción en muchos jóvenes que preferían asistir a la Universidad de Buenos Aires, que era de carácter nacional. Todo parecía indicar que el fracaso en esta nueva casa de estudios era inminente hasta que un ministro del gobierno nacional decidió tomar cartas en el asunto. Fue el Dr. Joaquín V. González, Ministro de Justicia e Instrucción Pública de la Nación, quien planeó nacionalizar la universidad platense, lográndolo el 12 de agosto de 1905 cuando se aprobó en el Senado de la Nación. Desde allí la institución ha crecido notablemente en número de unidades académicas, carreras, estudiantes y trabajadores.

En la actualidad, la UNLP cuenta con 17 facultades que expiden 355 titulaciones en los diferentes niveles académicos, de las cuales 131 se corresponden al nivel de grado. Las carreras pertenecientes a esta categoría son gratuitas y las de posgrado (especializaciones, maestrías y doctorados) son aranceladas. Los jóvenes que participaron de esta tesis se encontraban cursando carreras de grado o se habían graduado. Según las cifras publicadas en el año 2016, la universidad cuenta con 105.592 estudiantes de grado y emplea a 12.263 docentes y 2.912 trabajadores no docentes convirtiéndose en la tercera universidad más

\footnotetext{
59 "... en 1897 se inscribieron 47 alumnos, en 1898, 52; 1899, 45; 1900, 71; 1901, 96; 1902, 105; 1903,84 y en 1904 solo 75. Así el total de inscriptos solamente alcanzó 573, lo que viene a dar la razón a aquellas personas que con argumentos de tipo cuantitativo se oponían a la creación diciendo que La Plata, por aquel entonces, no tenía necesidad de una institución universitaria" (Barba, 1997:13)

${ }^{60}$ En 1898 fue de de 88.320, en 1889 de 41.400 y de 1900 a 1905 de 60.000 (Barba, 1998)
} 
grande del país en cantidad de estudiantes luego de la Universidad de Buenos Aires $(315.754)^{61}$ y la Universidad Nacional de Córdoba $(110.990)^{62}$.

Las diferentes facultades se encuentran distribuidas en diferentes zonas de la ciudad y algunas están localizadas en el vecino partido de Ensenada. Cuatro facultades (Arquitectura y Urbanismo, Ciencias Exactas, Ingeniería y Odontología) se encuentran al oeste del Paseo del bosque. Cinco (Ciencias Agrarias y Forestales, Ciencias Veterinarias, Ciencias Médicas, Ciencias Naturales y Museo y Periodismo y Comunicación Social) se encuentran al este del mismo. Al norte del paseo se encuentran las facultades de Informática, Psicología y Humanidades y Ciencias de la Educación. Estas dos últimas se ubican en Ensenada. La Facultad de Ciencias Astronómicas y Geofísicas se encuentra dentro del Paseo del Bosque, al igual que el Museo de La Plata. Bellas Artes y Trabajo Social se ubican en la zona cercana a Plaza Rocha (7 y 60) y las dos restantes, Ciencias Jurídicas y Sociales y Ciencias Económicas, se encuentran en la zona céntrica del Casco Urbano. Junto a estas dos últimas se halla el edificio de la presidencia de la UNLP. Además la institución universitaria cuenta con cuatro colegios secundarios, un primario, un jardín de infantes y un jardín maternal (Ver mapa 3, no se encuentra representada la ciudad de Ensenada).

61 Datos extraídos de las estadísticas institucionales de la Universidad de Buenos Aires. (http://www.uba.ar/institucional/contenidos.php?id=194)

62 Información extraída de anuario estadístico de la Universidad Nacional de Córdoba. (https://www.unc.edu.ar/node/596) 
Mapa 3: Ubicación de dependencias de la UNLP en casco urbano fundacional de La Plata
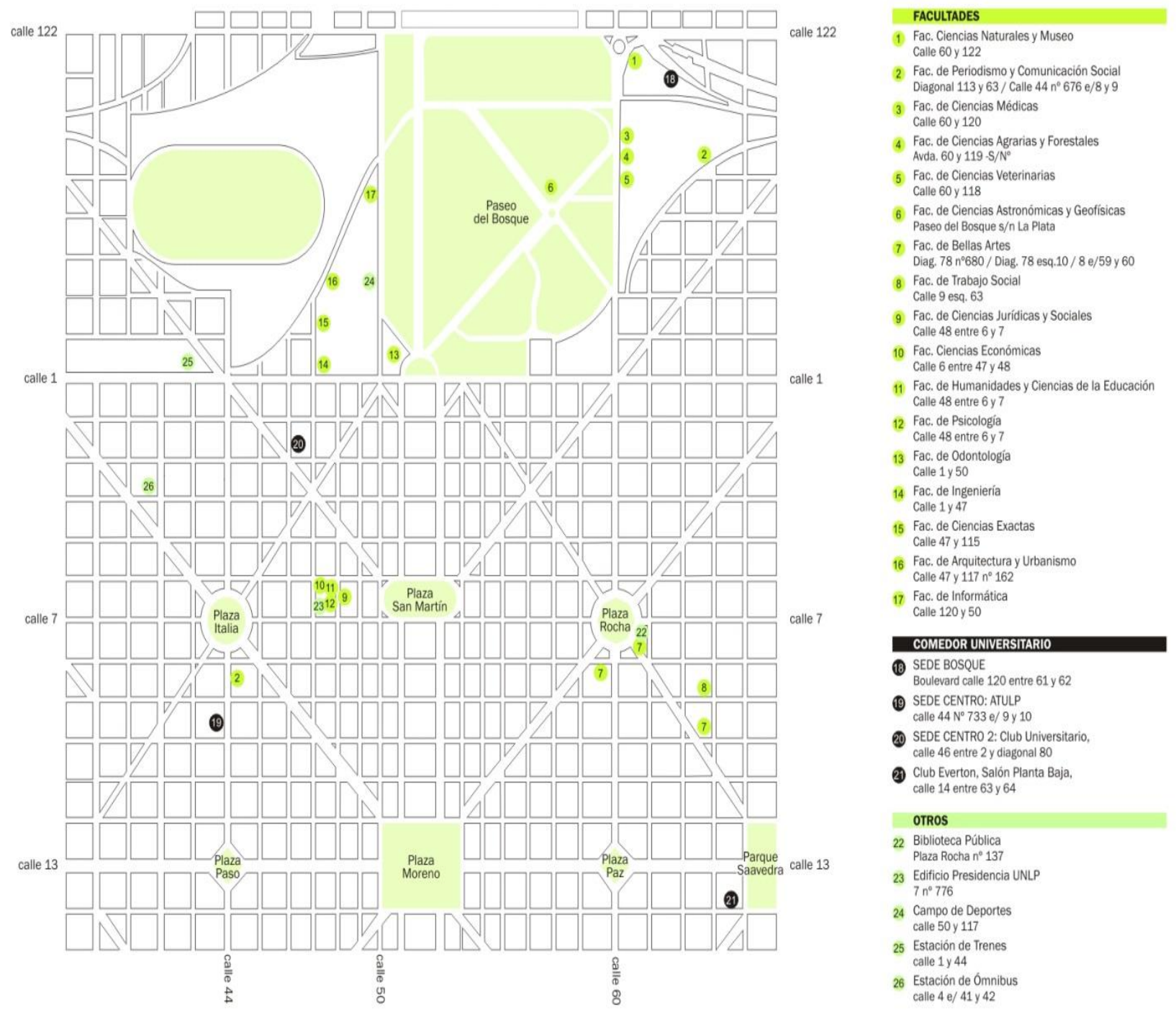

Recuperado el 24 de agosto del sitio web: http://www.unlp.edu.ar/mapa de la plata

Para que los estudiantes ingresen a las carreras, la UNLP establece un período de inscripción durante los meses de noviembre y diciembre. Primero los aspirantes deben 
realizar una preinscripción virtual desde el programa SIU GUARANÍ63 y luego deben completar una inscripción en la facultad a la que ingresan. Durante el mes de febrero inician los cursos de ingreso a cada facultad, estos constituyen el primer espacio curricular con el cual se encuentran los estudiantes. Tienen carácter obligatorio pero no eliminatorio, pueden durar entre uno o dos meses, y una vez finalizados, los estudiantes están en condiciones de cursar las materias del primer año de las carreras.

Como esta tesis se interesa por la migración estudiantil, presentaremos algunos datos relevados por la UNLP en esta materia. Es necesario aclarar que desde el año 2012 la institución ha publicado un mapa interactivo ${ }^{64}$ donde pueden localizarse geográficamente las escuelas secundarias de donde provienen los inscriptos de todas partes del mundo. Antes de ello, la universidad clasificaba el origen de los estudiantes de acuerdo a cinco categorías: i) La Plata; ii) Partidos próximos (Brandsen, Berisso, Ensenada, Florencio Varela, Berazategui y Quilmes); iii) Capital Federal y resto de Gran Buenos Aires; iv) resto de la Provincia de Buenos Aires (en donde se incluye Roque Pérez); v) otras provincias y vi) otros países. Los jóvenes de esta investigación llegaron a La Plata, en su mayoría, entre los años 2005 y 2014 y por ello recuperamos algunas cifras de esos años. Presentamos a continuación un cuadro que ilustra el origen de los estudiantes desde los años 2005 y $2012^{65}$ (Cuadro 1). Luego mostramos la cantidad de ingresantes originarios de Roque Pérez desde el 2012 hasta el 2014 a partir de los datos del mapa interactivo de la UNLP.

${ }^{63}$ El SIU GUARANÍ es un sistema de gestión de alumnos que se utiliza por vía internet. Mediante él se realizan las actividades administrativas como inscripción a las carreras, cursadas y a las mesas de examen entre otras.

${ }^{64}$ Nos referimos al Mapa interactivo de ingreso universitario. https://ingreso.unlp.edu.ar/mapas/colegios

${ }^{65}$ Vale aclarar que desde la creación del mapa de origen de los estudiantes, la UNLP no ha publicado más el cuadro de origen de los alumnos y es por ello que no contamos con los datos pertenecientes al 2013 y 2014. 
Cuadro 1. Alumnos de la UNLP discriminados por origen. Período 2005-2012

\begin{tabular}{|l|l|l|l|l|l|l|l|l|}
\hline Año & $\begin{array}{l}\text { La } \\
\text { Plata }\end{array}$ & $\begin{array}{l}\text { Partidos } \\
\text { Próximos }\end{array}$ & $\begin{array}{l}\text { Capital } \\
\text { Federal y } \\
\text { resto G.B.A. }\end{array}$ & $\begin{array}{l}\text { Resto de la } \\
\text { Prov. De Denos Aires } \\
\text { Buen }\end{array}$ & $\begin{array}{l}\text { Otras } \\
\text { provincias }\end{array}$ & $\begin{array}{l}\text { Otros } \\
\text { países }\end{array}$ & $\begin{array}{l}\text { Total } \\
\text { estudiantes } \\
\text { UNLP }\end{array}$ \\
\hline 2005 & $45,84 \%$ & $12,89 \%$ & $3,85 \%$ & $27,98 \%$ & $9,10 \%$ & $0,34 \%$ & $100 \%$ & 88.913 \\
\hline 2006 & $47,03 \%$ & $12,34 \%$ & $3,59 \%$ & $27,52 \%$ & $9,26 \%$ & $0,25 \%$ & $100 \%$ & 87.637 \\
\hline 2007 & $48,01 \%$ & $12,09 \%$ & $3,97 \%$ & $26,47 \%$ & $9,21 \%$ & $0,26 \%$ & $100 \%$ & 90.323 \\
\hline 2008 & $49,01 \%$ & $11,39 \%$ & $4,15 \%$ & $25,74 \%$ & $9,42 \%$ & $0,29 \%$ & $100 \%$ & 91.899 \\
\hline 2009 & $46,21 \%$ & $12,51 \%$ & $5,33 \%$ & $25,68 \%$ & $9,70 \%$ & $0,57 \%$ & $100 \%$ & 98.954 \\
\hline 2010 & $39,86 \%$ & $12,39 \%$ & $10,00 \%$ & $27,61 \%$ & $9,59 \%$ & 0,55 & $100 \%$ & 107.90 \\
\hline 2011 & $46,84 \%$ & $10,62 \%$ & $7,17 \%$ & $26,69 \%$ & $8,35 \%$ & $0,33 \%$ & $100 \%$ & 108.934 \\
\hline 2012 & $39,72 \%$ & $11,51 \%$ & $5,76 \%$ & $26,46 \%$ & $14,93 \%$ & $1,61 \%$ & $100 \%$ & 111.577 \\
\hline
\end{tabular}

Elaboración propia en base a los datos de Anuarios Estadísticos de la UNLP

Como señalamos, Roque Pérez corresponde a la categoría de "resto de la Provincia de Buenos Aires" y se puede notar que este sector se ha mantenido por encima del $25 \%$ en el período que tomamos. Esto nos permite ver que los estudiantes del interior de la provincia constituyen el segundo grupo más numeroso luego de los originarios de La Plata. Como hemos mencionado, la UNLP desarrolló un mapa donde se registran las escuelas secundarias de origen de sus ingresantes, allí los registros muestran que hubo 10 inscriptos en 2012, 3 en 2013 y 7 en 2014 provenientes de Roque Pérez. No se han publicado datos de este tipo sobre los años anteriores. Una vez realizada esta breve caracterización sobre la UNLP, nos detendremos sobre las experiencias de los sujetos de esta investigación.

\subsection{2 "La universidad fue un cambio muy grande": transiciones etarias}

En esta sección nos detenemos en el comienzo de los estudios en la universidad, una experiencia que fue relatada como un cambio abrupto con respecto a los recorridos

educativos previos. Es necesario aclarar que si bien estas experiencias estuvieron atravesadas por las particularidades de cada facultad, identificamos en la mayoría de los 
sujetos una idea de transición en términos etarios de "chicos" a "grandes" que va de la mano del pasaje de posición institucional de estudios secundarios a estudios universitarios. Hemos caracterizado dos grupos de situaciones en las que se marcan estos pasajes. Por un lado la diferencia entre un contexto calificado como más "personalizado" (la escuela secundaria) hacia uno más "impersonal" (la universidad) que se vislumbra por los cambios que experimentan en el sistema administrativo institucional y en el vínculo con los docentes. Y, por otro lado, la interpelación directa como personas "grandes", que describiremos a través de las responsabilidades que adquieren para construir el oficio de estudiante universitario y afiliarse a la institución.

Con respecto a lo primero, los sujetos identifican una marcada diferenciación entre las características de la escuela secundaria y la universidad. La secundaria es caracterizada como un ambiente más "familiar" con tratos sumamente personalizados mientras que la segunda aparece como un lugar de relaciones más frías e impersonales. Pareciera que la oposición comunidad-sociedad, que analizamos en el capítulo anterior, se actualiza también en los modos de vivenciar cada contexto educativo. En términos generales esta "impersonalidad" de la institución universitaria fue referenciada, como ya indicamos, en dos aspectos: en el sistema administrativo institucional y en el vínculo con los docentes.

Para abordar la relación con el sistema administrativo retomamos la historia de Vanesa a quien le costó acostumbrarse a las cuestiones administrativas y los tiempos burocráticos cuando ingresó a la Facultad de Ciencias Médicas. Primero tuvo que hacer la pre inscripción por el SIU GUARANÍ para la que pidió ayuda a una conocida suya porque el sistema on line le resultaba incomprensible, "quizás es una pavada, pero no entendía nada" nos contaba. Luego viajó a La Plata en noviembre para completar su inscripción. Se encontró con una facultad muy grande, repleta de personas, sin saber a dónde dirigirse. Se sentía completamente perdida. Fue un miembro de una agrupación política quien le indicó que debía ir al Departamento de Alumnos para realizar el trámite. Desde aquel día tuvo que acostumbrarse a que debía concurrir a esa oficina cuando necesitaba un certificado o para realizar cualquier consulta administrativa. Su sensación desde el primer momento es que la trataron como "un trámite más". En la escuela secundaria pública a la que ella iba, no 
existía una oficina de esas características y, cuando debía realizar algún tipo de trámite, siempre tenía la ayuda de algún docente o preceptor.

El segundo aspecto refiere al vínculo con los docentes universitarios. Un vínculo que, en la mayor parte de los casos, es caracterizado como más "impersonal" que el existente con el docente secundario. Así lo comentaba Darío que, al ingresar a la Facultad de Ciencias Jurídicas y Sociales, sentía que para los profesores era un "número más" porque las comisiones de cursada eran muy numerosas. Victoria señalaba que en la Facultad de Ciencias Médicas "el profesor nunca te llega a conocer" haciendo referencia a la misma cuestión. Este trato más "impersonal", desde la mayoría de los estudiantes, es explicado principalmente por la masividad de estudiantes y por el poco tiempo diario compartido en el aula entre docentes y alumnos. Esta situación difería de la escuela secundaria a la que ellos habían ido donde veían a los mismos profesores casi todos los días.

Es preciso señalar que existen diferencias entre las distintas experiencias universitarias según la cantidad de estudiantes que tienen las facultades de las que se forma parte. El caso de Lucía, una joven que transitó entre dos facultades distintas, permite graficar esta idea. Cuando llegó a La Plata en el 2005 comenzó a estudiar Psicología en la Facultad de Humanidades y Ciencias de la Educación. ${ }^{66}$ La institución a la que llegaba era una de las más numerosas en cantidad de alumnos como así también lo era la carrera en la cual se inscribía. Lucía se sentía como "un número más" dentro de esa multitud. A los pocos meses de comenzar decidió regresar a Roque Pérez porque no había podido "adaptarse" a ese contexto. Al año siguiente volvió a La Plata a estudiar Trabajo Social en la Facultad de Trabajo Social. Esta institución era mucho más pequeña y allí sintió un trato un poco más "familiar" de los docentes que le recordaba un poco más al de la escuela secundaria, en este caso la Escuela de Educación Media $N^{\circ} 1$.

El otro marcador de transición que nombramos es la interpelación directa como "grandes" que va configurando en los jóvenes un nuevo sentimiento de responsabilidad. Esta interpelación la reciben principalmente desde otros sujetos de la universidad: docentes, trabajadores no docentes y otros estudiantes, que los tratan como personas "grandes" que

\footnotetext{
${ }^{66}$ En el año 2006 se creó la Facultad de Psicología, independizándose de la Facultad de Humanidades y Ciencias de la Educación.
} 
deben "hacerse cargo" por sus recorridos dentro de la facultad. Esta responsabilidad, que encuadramos como parte del proceso de afiliación institucional, ${ }^{67}$ implica también el desarrollo de "nuevas maneras de estudiar" que contrastan con las del nivel educativo anterior. En este sentido, Esteban, egresado de Derecho de 36 años, sostuvo que cuando ingresó a la facultad a estudiar Abogacía, la carrera le pareció muy difícil reconociendo que los problemas "de base" eran suyos. Es decir, la mayor problemática fue que él sentía que "no sabía estudiar" y tuvo que aprender un nuevo modo de estudio y de comprensión de textos para desenvolverse. Por su parte Victoria, estudiante de Medicina, señaló la existencia de una "brecha" muy grande entre los contenidos que deben ser aprendidos en la secundaria y los de la universidad. Ella bromeaba que los contenidos sobre biología que había visto en tres años cuando estaba en la secundaria, los vio en una sola clase en la universidad.

Estos relatos nos permiten analizar que el ingreso a la universidad implica que los jóvenes deban construir un nuevo oficio de estudiante ${ }^{68}$ muy diferente al existente en la escuela secundaria. Para poder desenvolverse en el ámbito universitario fue necesario el desarrollo de una serie de tácticas (Carli, 2012) por parte de los estudiantes. Uno de ellos fue tomar apuntes mientras los profesores daban su clase, algo que no recuerdan haber hecho mientras estaban en la escuela secundaria. Otra fue utilizar resaltadores con diferentes colores para señalar ideas principales y secundarias de los textos que leían. También muchos conformaron grupos de estudio que les permitieron sobrellevar los requerimientos universitarios colectivamente. Profundizaremos esto en el siguiente apartado. Es necesario remarcar que varios valoraron muy positivamente algunas medidas

\footnotetext{
${ }^{67}$ El sociólogo francés Alain Coulon (en Casco, 2007) sostiene que la construcción del oficio de estudiante se desarrolla en tres tiempos. El primero es el tiempo de alienación, en donde el recién llegado entra a un ámbito educativo desconocido que contrasta con el anterior. El segundo es el de aprendizaje, en donde el estudiante tendrá que poner en marcha toda una serie de mecanismos y estrategias que le permitan adaptarse al nuevo medio y, el último, el tiempo de afiliación, en donde se logra un relativo dominio de las reglas institucionales. Coulón diferencia dos tipos de afiliación; la institucional y la intelectual. La primera está relacionada al manejo de reglas e instituidos de la vida universitaria y la segunda, al aprendizaje y utilización de los conceptos, discursos y métodos propios de la esfera educativa universitaria. Este argumento nos servirá como herramienta para interpretar algunas experiencias de inicio en la universidad que desarrollaremos a continuación.

${ }^{68}$ Si bien la categoría de "ofício de estudiante" se ha popularizado para estudiar el desempeño de los sujetos en la institución educativa también se han utilizado otros conceptos para ello. Por ejemplo la investigadora platense Claudia Bracchi utiliza la definición de habitus de Pierre Bourdieu (2010) para aplicarla a la internalización de las reglas y normas del sistema educativo universitario.
} 
que llevaron a cabo sus facultades para contribuir a su afiliación. Así algunos remarcaron que tuvieron profesores que se quedaban después de clases para ayudarlos con la escritura de trabajos prácticos o para disipar dudas de la clase. También algunos destacaron participar en el sistema de tutorías ${ }^{69}$ dentro de sus facultades.

Cerramos este apartado destacando que el ingreso a la institución universitaria es identificado como un momento de transición etaria. En términos institucionales se pasa de un contexto más "personal" a uno de mayor "impersonalidad" y, en términos de interpelación de los otros, se pasa de ser tratado como "chico" a ser tratado como "grande". A su vez, se promueve un sentimiento de deber que implica la responsabilización por el desempeño en la universidad en relación a la condición de "ser grande".

\subsubsection{Compañeros, amigos, amores: nuevas redes sociales}

La universidad aparece en todos los relatos como un espacio de sociabilidad por excelencia. Dentro de esta institución, los jóvenes construyeron lazos de compañerismo, de amistad y también relaciones de pareja. Si bien hay investigaciones (Carli, 2006 y Pierella, 2011) que han mostrado la importancia de los lazos entre los estudiantes para enfrentar los requerimientos académicos de la universidad, en el caso particular de estudiantes que provienen de otras localidades, los lazos construidos en la institución son vitales para la conformación de la red que les brinda contención afectiva para permanecer en la ciudad.

En una investigación sobre estudiantes migrantes en la Universidad Nacional de Rosario, Ana Tossi (2009) sostiene que los mismos se enfrentan a un proceso de doble inserción: a la universidad y a un contexto urbano diferente al de origen. Rescatando este señalamiento, sostenemos como hipótesis que los lazos construidos con otros estudiantes en el espacio universitario favorece esa doble inserción. En términos analíticos diferenciamos dos beneficios producto de estas nuevas redes: i) la contribución a la afiliación universitaria y ii) la contribución para sobrellevar la situación de desarraigo.

\footnotetext{
${ }^{69}$ La UNLP cuenta con un sistema de tutorías que se implementa en sus distintas facultades en el cual estudiantes avanzados se desempeñan como tutores de estudiantes que ingresan a las carreras.
} 
Con respecto al primer aspecto, los vínculos con otros estudiantes en la facultad son resaltados como centrales para cumplir con las exigencias de la institución educativa. El curso de ingreso aparece referenciado como un espacio de sociabilidad por excelencia. Muchos comenzaron a tejer sus vínculos en ese momento y los sostuvieron a lo largo de la carrera. Los lazos que se construyen allí permiten socializar las prácticas de estudio y lectura que suelen ser problemáticas durante el inicio de la carrera. Así lo aseguraban varios jóvenes quienes remarcaban que si no fuera porque se juntaban a leer y estudiar en grupo no podrían haber aprobado los exámenes.

El segundo beneficio que producen los nuevos miembros de la red es la contención afectiva para sobrellevar los sentimientos de angustia y desarraigo. Varios jóvenes comentaron que establecieron lazos más fluidos con estudiantes migrantes de otros lugares que con estudiantes de La Plata. Un joven relataba que durante los fines de semana los chicos de La Plata estaban con sus familias o veían a sus amigos locales. En cambio, los que eran de otros lugares y no podían irse hasta allí, no tenían otra opción para socializar que juntarse con otros jóvenes migrantes. Sin embargo, algunos comentaron que, a lo largo de la carrera, fueron estableciendo lazos fluidos con jóvenes platenses, y que inclusive gracias a ellos conocieron otras partes de la ciudad cuando iban de visita a sus casas.

En términos de valoración afectiva, es interesante la distinción que realizaron algunos sujetos sobre las categorías de "compañero" y "amigo". Mientras que la primera refiere a lazos que se agotan en actividades propiamente académicas, la segunda alude a otros que traspasan esa esfera. Una de las jóvenes comentaba que cuando ingresó a la universidad tuvo mucha "buena onda" con varios "compañeros", pero que solo una pudo calificarse con "amiga". La joven le contaba problemas que tenía con su familia, relaciones amorosas y otras "informaciones íntimas" que no compartiría con cualquiera. También, algunos señalan que construyeron lazos de amistad en torno a la militancia política, en donde sentían que con sus amigos los unía un proyecto de sociedad diferente.

También dentro de la universidad se establecieron relaciones de pareja o vínculos amorosos de menor formalidad. Una de las jóvenes conoció a su actual pareja en la facultad. Ambos estudiaban la misma carrera y compartieron la cursada de una materia. Se pusieron de novios un año antes de recibirse y actualmente viven juntos. También otro de 
los entrevistados conoció a su actual pareja en la facultad aunque nunca fueron compañeros de cursada y se conocieron a través de amigos en común.

Para cerrar este apartado, resaltamos el valor central que pasan a tener los vínculos con personas conocidas en la universidad cuando se convierten en miembros de la red en la ciudad de destino. De esta manera, la red se va ampliando conforme los jóvenes transitan el espacio universitario. Veremos en el siguiente capítulo que también se producen sociabilidades en otros lugares de la ciudad que transitan los jóvenes.

\section{3. "Sentirse más grande": conclusiones}

En este capítulo hemos abordado dos experiencias de inicio (vida en otra ciudad e ingreso a la universidad) como configuradoras de transiciones en los cursos de vida de los jóvenes. A su vez, vimos que estas pasan a reposicionarlos socialmente en el marco del denominado procesamiento sociocultural de la edad el cual, según Chaves, refiere a "los sentidos que las sociedades otorgan a los grupos de edad, las expectativas sobre los mismos, las prácticas que se suponen correspondientes a cada uno y los estereotipos que se generan sobre ellos" (2010:25). En este último apartado retomamos los análisis realizados

sobre los cambios de posición que ocurren en los cursos de vida a partir de estas experiencias. Cuatro cambios fueron identificados en los modos en que los sujetos gestionan aspectos de su vida. Tres están relacionados con la vida en una nueva ciudad y el cuarto con el cambio de institución educativa: la gestión del tiempo, de los recursos económicos, de las actividades domésticas y el oficio de estudiante.

El primer cambio se refirió a la gestión del tiempo que se produce por la movilidad de residencia y la vida fuera del hogar familiar. Se pasa de una posición donde la persona joven debe cumplir y respetar la organización de los horarios domésticos estipulado por los adultos hacia otra en donde los jóvenes adquieren mayor capacidad de decisión en esta organización, avanzando en una gestión autónoma del tiempo. Una vez que los jóvenes viven fuera de la casa familiar, las decisiones sobre la hora de desayunar, almorzar, cenar, 
recibir visitas, salir o entrar de la casa pasan a depender, en gran medida, de sus propias voluntades.

El segundo cambio radica en la gestión de los recursos económicos. Los estudiantes pasan a administrar una mayor cantidad de dinero que la que disponían en su lugar de origen. Dentro de esta administración los jóvenes deben hacerse cargo de abastecer los hogares y pagar alquileres y servicios, entre otros aspectos. Hemos notado que esta distribución del dinero produce un cambio de posición en la manera en que los sujetos se perciben a sí mismos y son percibidos por parte del resto de su familia. Los jóvenes se sienten "más grandes" y con mayores responsabilidades por cuidar y administrar "debidamente" el dinero otorgado.

El tercer cambio es el de la gestión de las actividades domésticas. En este aspecto hemos notado que existe una diferenciación entre varones y mujeres producto de la socialización diferencial de género. La mayoría de los varones aprenden a hacerse cargo de las actividades domésticas una vez realizado el cambio de ciudad, mientras que gran parte de las mujeres contaban con esos conocimientos desde muchos años antes. Sin embargo, para algunas mujeres la migración a La Plata también implica el aprendizaje de nuevos modos de limpiar y ordenar la casa diferente a los que tenían en Roque Pérez.

Estos tres aspectos se encuentran estrechamente relacionados con el cambio de ciudad y el comienzo de la vida por fuera del hogar familiar. Pudimos notar que en la vida de estos jóvenes se conjuga la autonomía residencial con la dependencia económica de los padres. Es decir, se produce una articulación entre autonomía y heteronomía en relación a los adultos. La autonomía residencial constituye un factor diferencial de los estudiantes migrantes con respecto a la mayoría de sus pares platenses quienes continúan viviendo en la casa de sus padres.

El último cambio de posición que analizamos estuvo vinculado con el contexto institucional educativo. Aquí pasan de ser "estudiantes secundarios" a ser "estudiantes universitarios". En la secundaria se sentían en un ambiente más “familiar" y "personal” en donde recibían apoyo de padres y docentes para encargarse de las actividades escolares. En cambio, la condición estudiantil universitaria produce que los sujetos se sientan interpelados por los otros como personas "más grandes" que deben responsabilizarse por 
aprender a manejarse por su propia cuenta dentro de la institución y cumplir con los requerimientos de la misma.

Para finalizar, interpretamos que estos cambios producen una transición hacia una condición juvenil diferente a la que se tenía en el lugar de origen, configurada por dos aspectos centrales: la migración y la condición estudiantil universitaria. Partimos de entender que la condición juvenil es una construcción sociocultural, atravesada por diferentes condicionamientos sociales que debe analizarse en contextos particulares (Criado, 1998; Chaves, 2010). En este sentido, notamos que estos cambios producen una nueva condición que es la de joven estudiante universitario migrante. Estos dos aspectos son centrales para entender la experiencia juvenil de estos sujetos. La migración y la condición estudiantil ${ }^{70}$ permiten la aparición de nuevas prácticas, deberes y autonomías que caracterizan las experiencias de los sujetos, y que colabora en la autoidentificación con una nueva posición social, sentirse más "grandes" que antes. Veremos, en los capítulos siguientes, otros condicionamientos que se ponen en juego en la experiencia juvenil estudiantil universitaria en la nueva ciudad.

\footnotetext{
${ }^{70} \mathrm{El}$ investigador francés Francois Dubet sostiene que la condición estudiantil debe entenderse por un lado como una experiencia juvenil que traspasa la propia universidad y, por otro, por condiciones de estudios particulares. Señala el autor: "A veces este encuentro es tan débil que los estudiantes solo aparecen como jóvenes que van a la universidad algunos días a la semana, pero otras aparecen al contrario como "verdaderos estudiantes" totalmente definidos por el tipo de estudio que hacen." (2005.3)
} 


\section{CAPÍTULO 3 Nuevas experiencias en La Plata: la política, lo artístico, la sexualidad y formas de gestión de la privacidad}

En el capítulo anterior analizamos el modo en que los cambios de ciudad e institución educativa configuraron una transición hacia una condición juvenil diferente a la del lugar de origen. El objetivo en estas páginas será analizar dimensiones de la vida de los estudiantes universitarios migrantes que cambian -esta es nuestra hipótesis- por el proceso de migración y autonomización en el curso de vida. No se trata de lo específicamente estudiantil sino de la participación en circuitos ${ }^{71}$ y sociabilidades que les habilitan nuevas experiencias o nuevas formas de gestionar experiencias ya atravesadas.

Nos centraremos en las tres experiencias que identificamos con mayor regularidad en la investigación: la política, lo artístico y la gestión de las esferas pública y privada de la vida, principalmente en relación a elecciones sexuales y afectivas. Estas forman parte, para varios de los sujetos, de esa nueva condición juvenil de estudiante universitario en La Plata. Analizaremos también cómo se reactualizan los imaginarios urbanos juveniles que presentamos en el capítulo 1, en donde apreciaremos que los sentidos que condensan el "pueblo", la "ciudad" y la "ciudad universitaria", entre otros, se volverán centrales para comprender estas experiencias.

La estrategia para presentar los resultados será la reconstrucción de trayectorias de diferentes jóvenes. Con estas pretendemos visibilizar el modo en que el cambio de contexto urbano ( $\mathrm{y}$ en el curso de vida) posibilita la aparición y/o la profundización de esas experiencias. Retomamos la noción de trayectoria dentro del enfoque del curso de vida que, como explicamos en la introducción, refiere a "una línea de vida o carrera, un camino a lo largo de toda la vida que puede variar en dirección, grado y proporción" (Elder, 1991:63). Las trayectorias abarcan una variedad de ámbitos (trabajo, escolaridad, migración y vida

\footnotetext{
${ }^{71}$ Utilizamos la definición de Magnani quien sostiene que la noción de circuito "designa un uso del espacio y de los equipamientos urbanos, posibilitando, por consiguiente, el ejercicio de la sociabilidad por medio de encuentros, comunicación y manejo de códigos" (2005:178). Esta noción permite analizar el modo en que los espacios urbanos son construidos y usados por los sujetos puesto que los espacios que conforman un circuito no tienen una relación natural entre si sino que se relacionan en tanto los sujetos usuarios de ellos los transitan como espacios de encuentro y sociabilidad.
} 
familiar, entre otros) que son interdependientes y que el enfoque del curso de vida intenta no escindirlos en el análisis. Es necesario señalar que las mismas fueron reconstruidas tomando como base los relatos que los sujetos hicieron de sus propias vidas sobre el pasado y que, por lo tanto, nos hablan de los sentidos que les otorgan a sus propias biografías desde la actualidad.

El capítulo se divide en cinco secciones: una introducción, tres apartados en donde analizamos cada una de las experiencias señaladas (política, gestión de las esferas pública y privada de la vida y artística) y una sección de cierre. En los tres apartados que abordan las experiencias, se reconstruyen dos trayectorias en cada uno. La última sección cierra con un análisis sobre los sentidos que se le asignan a la ciudad de La Plata como "lugar privilegiado para la experiencia juvenil’".

\section{1 "Militar y ver el mundo de otra manera": experiencias políticas}

En esta sección analizamos cómo la vida en La Plata y el ingreso a la universidad configuraron las condiciones de posibilidad para la resignificación de experiencias políticas previas o el inicio de las mismas. Lo haremos a través de dos trayectorias, Darío para el primer caso y Celina para el segundo. Sus historias nos hablan un poco del modo en que son percibidos Roque Pérez y La Plata como escenarios de posibilidad para la actividad política. En este sentido, analizaremos el carácter de "lugar privilegiado para el ejercicio político" que ambos le otorgan a la capital provincial, y su participación en circuitos específicos asociados a espacios estudiantiles en donde "se hace política". Darío llega a La Plata en el 2005 y Celina en el 2006, por lo tanto sus experiencias se inscriben en una coyuntura histórica atravesada por una marcada interpelación estatal hacia la participación política del sector juvenil (Bonvillani, Palermo, Vazquez y Vommaro, 2008; Chaves, Galimberti y Mutuverría, 2016).

Sobre la articulación entre universidad y experiencia política se han desarrollado múltiples investigaciones en nuestro país, las cuales en su mayoría pusieron el acento en el activismo político del movimiento estudiantil (Bonavena, Califa y Milán, 2007; 
Buchbinder, 2008, Naishat, Garcia Raggio y Villavicencio, 2001). En los últimos años, surgieron otras investigaciones que se centran en los modos en que el comienzo y el desarrollo de la vida universitaria son constitutivos de experiencias vinculadas a lo político (Blanco, 2016, Carli, 2012). Ambas perspectivas serán utilizadas para nuestro análisis. Cabe mencionar que la periodización que realizaron Bonavena, Califa y Millán (2007), no abarcó el periodo que nosotros estudiamos, pero es relevante como historización previa. Los autores identifican tres momentos clave en la historia del movimiento estudiantil argentino a partir de una revisión de investigaciones sobre el tema: i) La reforma universitaria de 1918 y sus consecuencias ii) el proceso de radicalización que tuvo lugar entre 1955 y 1976 y iii) las luchas del movimiento estudiantil contra las medidas neoliberales en el último cuarto de siglo ${ }^{72}$.

Con respecto a la particular relación entre migración estudiantil universitaria y experiencias políticas, algunas investigaciones en la ciudad de La Plata han mostrado las maneras en que el cambio de ciudad de residencia interviene en las trayectorias militantes (Chaves, 2010; Galimberti y Chaves, 2016; Mutuverría, 2017). Retomaremos algunos de estos aportes en nuestro análisis.

\subsection{1 “En La Plata encontré otra forma de hacer política”: La trayectoria de Darío}

Darío tiene 32 años y está terminando la carrera de Abogacía. Nació en Roque Pérez y vivió alli hasta que se fue a estudiar a La Plata en el 2005. Su papá es empleado público y su mamá era ama de casa. Sus dos abuelos habian sido trabajadores rurales y sus abuelas amas de casa. Solo conoció a dos de ellos quienes vivian en uno de los parajes rurales, en su infancia le gustaba mucho ir a visitarlos. Darío era chico cuando su mamá falleció y su papá se quedó a cargo de él y de sus hermanos.

Fue a la escuela secundaria "media" y allí se encontró con el centro de estudiantes por primera vez. Este le encantó y comenzó a participar rápidamente. Esa fue su primera experiencia de participación en un espacio

\footnotetext{
${ }^{72}$ Los autores llaman a este tercer momento: "el movimiento estudiantil hoy". En ese apartado colocan solo dos artículos, uno referente al estudiantado mendocino y otro de Bahía Blanca, que analizan el período de los años noventa hasta el 2001.
} 
de acción política colectivo. Se juntaba con sus compañeros, algunos eran de otras divisiones, y organizaban actividades para los estudiantes de la escuela o se encargaban de charlar con los profesores cuando había algún problema con algún alumno. Siempre que había que organizar algo, Dario estaba involucrado.

A muchas personas no les gustaba que él participara en el centro. Le decían que la escuela era para aprender y no para "hacer política”, pero él no los escuchaba porque disfrutaba estar "metido" en ese espacio. El año antes de terminar la secundaria, se desempeñaba como presidente del centro y se encargó de gestionar para que la escuela los llevara a La Plata para conocer la expo universidad y averiguar sobre las diferentes carreras de la UNLP. ${ }^{73}$ También se contactó con miembros de la comisión directiva del Centro de Estudiantes de Roque Pérez (CERP) para que todos pudieran conocerlo. En septiembre Darío y sus compañeros fueron en colectivo a La Plata y conocieron la expo y también el CERP.

Al año siguiente se fue a vivir al CERP en La Plata y comenzó a estudiar Derecho. La carrera le resultó difícil pero se enamoró de la vida política de la universidad y de la ciudad. Le gustaba quedarse charlando con miembros de las agrupaciones en los pasillos y, a través de ellos, comenzó a participar de reuniones políticas de una agrupación. También comenzó a ir a marchas en la ciudad. Le encantaba ver la calle 7 llena de personas y banderas moviéndose. Siempre le había gustado participar en espacios en donde "se hiciera política" pero en La Plata sintió que llenó esos espacios con contenidos "más políticos". No solo se hablaba de hacer una charla o una actividad específica sino se debatía sobre el gobierno nacional, sobre los gobiernos sudamericanos, sobre la desigualdad social y sobre muchas otras cosas.

A los pocos meses de vivir en La Plata, comenzó a militar en una agrupación universitaria que se declaraba "independiente"74 y lo que más le gustó fue su trabajo en un barrio de las afueras del Casco Urbano. Alli hacían actividades con las personas, festejaban el día del niño con los chicos, preparaban la merienda, jugaban y hablaban de "politica" entre otras cuestiones. Con la militancia se hizo muchos amigos con quienes compartía ideales y también preocupaciones. En la actualidad continúa participando de espacios políticos dentro de la facultad y fuera de ella.

\footnotetext{
${ }^{73}$ La expo universidad es un espacio en donde las diferentes facultades de la UNLP presentan todas sus carreras para aquellos que quieran conocerlas, principalmente los estudiantes secundarios que están finalizando sus estudios. Se realiza en el Pasaje Dardo Rocha ubicado en el centro del Casco Urbano Fundacional casi siempre en el mes de septiembre.

${ }^{74} \mathrm{Se}$ trata de una organización que no participa en una estructura partidaria por fuera de la universidad.
} 
En esta trayectoria se puede ver que el cambio en el curso de vida de Darío resignificó su manera de "hacer política". Mientras que en Roque Pérez la actividad vinculada al centro de estudiantes aparecía más relacionada a la "gestión" de problemas específicos, en La Plata esta actividad es dotada de un sentido diferente. No solo se trata de resolver situaciones particulares sino de debatir sobre la configuración de problemas sociales, las políticas de estado y proyectar otras formas de sociedad. Esto se posibilita no solo por la universidad y la nueva ciudad, sino por la formas de acción política y organización de las agrupaciones estudiantiles universitarias. A partir de su historia, analizaremos tres aspectos: i) los modos en que son percibidos Roque Pérez y La Plata en términos de escenarios de posibilidad para el ejercicio de la política ii) los sentidos otorgados a la militancia y iii) los circuitos específicos dentro de la ciudad vinculados a la actividad política.

Sobre el modo en que Darío percibe a cada lugar, nos interesa relacionarlo con los imaginarios que hemos desarrollado en el capítulo 1. Roque Pérez aparece como un espacio en donde la militancia pareciera estar más estigmatizada. Dentro del "pueblo" las personas que militan o participan de agrupaciones políticas parecieran estar "señaladas con el dedo". Darío remarcaba que, al igual que en muchos otros "pueblos" del interior, Roque Pérez solía ser "conservador" en términos políticos y se escuchaba con mucha frecuencia el relato del "no te metas en política". Relato que luego, en la universidad, comprendió que era heredero de los gobiernos dictatoriales que formaron parte de la historia del siglo XX en Argentina (Chaves y Núñez, 2012). Darío destacaba que cuando vivía en Roque Pérez, los jóvenes que participaban en organizaciones políticas eran fuertemente criticados en términos negativos. Esto no imposibilitó que allí conociera a varias personas que militaban activamente y que pensaban de otra manera, pero lo que nos interesa es el modo en que el "pueblo", como imaginario, aparece como una entidad conservadora y reacia a la actividad política, sobre todo en las personas jóvenes. Esto fue referenciado también por otros jóvenes en nuestra investigación.

A diferencia de Roque Pérez, La Plata aparece como un "lugar ideal" para la experiencia política. Primero, por la presencia de la universidad y las organizaciones que 
forman parte de su vida estudiantil. Segundo, por las organizaciones políticas que no formaban parte de la vida universitaria y que conoció a partir de su militancia, por ejemplo líneas internas del peronismo. Tercero, por organizaciones sindicales en diferentes ramas de la actividad cuyos reclamos fue conociendo a lo largo de su vida en La Plata (gremios docentes y no docentes). Cuarto, por la visibilidad que adquirían estas $-\mathrm{y}$ otrasorganizaciones y movimientos sociales en el espacio público a través de movilizaciones, paros y marchas que tienen como uno de sus destinos privilegiados a la capital provincial.

Con respecto a los sentidos que el joven le otorga a su práctica política, se puede apreciar una resignificación en su trayectoria luego de vivir en La Plata y comenzar la universidad. Si bien su socialización política ${ }^{75}$ había comenzado en Roque Pérez dentro del centro de estudiantes de su escuela secundaria, fue en la universidad donde comenzó a identificarse con el término de "militante". Este no solo refiere a una práctica específica sino a un punto nodal en su identidad ${ }^{76}$ y organizador de su vida diaria. Como señalan Chaves, Galimberti y Mutuverría (2016) un militante es aquel que organiza su cotidianeidad otorgando prioridad a la participación política y brinda un sentido principal, en el presente y en la proyección del futuro, a la práctica política en una organización colectiva. Notamos que esto sucede para Darío quien se autodefine como "militante" y organiza su vida y sus proyecciones futuras desde allí.

Con respecto a su circuito urbano de acción política, analizamos que este se compone de los siguientes lugares: la Facultad de Ciencias Jurídicas y Sociales; espacios de reunión fuera de la facultad como locales partidarios o de movimientos sociales, casas de compañeros y el espacio público utilizado durante las marchas o movilizaciones. Los días 24 de marzo, su circuito se expandía hasta la ciudad de Buenos Aires para participar de la marcha y el acto por el aniversario del golpe militar de 1976. Otro punto del circuito está

\footnotetext{
${ }^{75}$ Vázquez sostiene que la socialización política es: "un proceso que tiene lugar a lo largo del ciclo biográfico, a través del cual se producen aprendizajes (y olvidos) a través de los que se construyen los universos políticos de las personas; estos aprendizajes se producen en los diferentes ámbitos de la experiencia, es decir que no es posible limitar su alcance a partir de una definición estrecha de lo político. Así, cobran relevancia los aprendizajes elaborados en la escuela, los grupos de pares, la familia, el barrio, el trabajo, el activismo, etc." (2010:47).

${ }^{76}$ Tomamos el concepto de Identidad de Stuart Hall que la define como: "el punto de sutura entre, por un lado, los discursos y prácticas que intentan "interpelarnos", hablarnos o ponernos en nuestro lugar como sujetos sociales de discursos particulares y, por otros, los procesos que producen subjetividades, que nos construyen como sujetos susceptibles de decirse". (2003:20)
} 
compuesto por las zonas que abarca el "trabajo territorial". Estos sectores se encontraban por fuera del Casco Urbano Fundacional. Allí Darío iba junto con sus compañeros a militar con personas que vivían, en su mayoría, en condiciones de pobreza dentro de sectores en donde la urbanización no era igual al Casco Fundacional.

En esta trayectoria pudimos ver la manera en que el cambio en el curso de vida (atravesado por la vida en La Plata y la universidad) contribuyó a la resignificación de la práctica de participación política. En la próxima trayectoria, nos detendremos en la historia de una joven que encontró en La Plata y en la facultad a la cual ingresó un nuevo modo de "pensar" la sociedad sin haber tenido experiencia política previa. Ambas historias comparten el inicio de una nueva experiencia vinculada a lo político luego de migrar e ingresar a la universidad.

\subsection{2 “Acá pude abrir la cabeza”: La trayectoria de Celina}

Celina tiene 27 años y es graduada de la carrera de Trabajo Social. Su papá es policía y su mamá ama de casa. Tiene un hermano mayor con quien siempre ha tenido una relación muy estrecha. Nació y vivó toda su infancia y adolescencia en Roque Pérez. De chiquita estaba acostumbrada a ir a La Plata acompañando a su papá que viajaba mucho por su trabajo. La capital provincial le gustaba porque era "grande" pero también la atemorizaba.

Arrancó sus estudios secundarios en la escuela "técnica" pero luego decidió cambiarse a la "media" porque no quería estar "todo el día encerrada". Le interesaba estudiar contaduría cuando terminara la escuela, pero su poca empatía con las matemáticas la hizo desistir de seguir ese camino. El último año de escuela comenzó a pensar seriamente en qué estudiar ya que estaba decidida a irse de Roque Pérez. Una conocida le había dicho que su hermana estudiaba Trabajo Social en La Plata y que era una carrera "muy linda". A Celina nunca le habian gustado mucho los temas relacionados con "lo social" porque siempre derivaban a hablar de "politica" y eso a ella no le interesaba para nada. No obstante, le parecía que esta carrera podría otorgarle una salida laboral en muchos lugares y comenzó a averiguar. Se fijó en internet para informarse y le interesó. Al poco tiempo les contó a sus papás que se iría a La Plata a estudiar Trabajo Social. Su mamá trató de convencerla de que 
estudiara la carrera terciaria de asistente social que se dictaba en Saladillo, pero ella prefirió irse a La Plata.

Al año siguiente llegó a la capital bonaerense y se fue a vivir a una pensión con una amiga. El primer día en la facultad le llamaron la atención los colores de las remeras de los militantes, los carteles y las mesas de las agrupaciones. Notó que entraba a una facultad en donde se "hablaba mucho de política" y, para su propia sorpresa, se dio cuenta que empezó a interesarle. En ese lugar tomó conciencia que muchas veces hablaba de cosas de las que no tenía "ni idea" como la pobreza, las politicas del estado, los problemas sociales y muchas cosas más. A partir de allí comenzó a "mirar" el mundo de otra manera. Dentro de la carrera tuvo las prácticas de formación profesional ${ }^{77} y$ allí conoció "otra realidad”. Se encontró con personas en situación de pobreza, casillas de madera, barrios con escasos servicios y muchas otras situaciones que la llevaron a interesarse más por discutir asuntos vinculados con "la política"

Pero no solo se encontró con un "mundo" nuevo dentro de la facultad. También en la ciudad comenzó a ver cortes de calle, movilizaciones, marchas y reclamos que nunca había visto en Roque Pérez. Más allá de que era una ciudad capital en donde "muchos iban a protestar porque estaban los gobernantes", descubrió que era una ciudad en donde la "movida política" se veía mucho. A sus amigos no les gustaba pero a ella le gustó. Vivir en La Plata y estudiar Trabajo Social la cambió. El día en que se dio cuenta de ese cambio fue en una reunión con sus amigos de la secundaria en Roque Pérez. Unos pocos días antes, el gobierno de Cristina Fernández de Kirchner había impulsado la Asignación Universal por Hijo. Varios de sus amigos criticaban que el Estado iba a financiar "vagos" con esa política. Celina se molestó mucho y se puso a discutir, les habló de problema sociales, del desempleo y de las políticas públicas. Ahí se dio cuenta de que "a Cristina no la odiaba tanto como creía". Ese momento fue crucial para darse cuenta que su "mirada" había cambiado, no la de sus amigos, sino la de ella.

Celina nunca militó en una agrupación política pero si participaba en asambleas y movilizaciones estudiantiles. En la actualidad vive en La Plata y trabaja como profesional en una dependencia ministerial.

La trayectoria de Celina muestra el modo en que el cambio de ciudad y el ingreso a la universidad constituyeron un quiebre en sus maneras de pensar lo político. A diferencia

\footnotetext{
${ }^{77}$ Las prácticas de formación profesional constituyen una instancia curricular de la Licenciatura en Trabajo Social en donde los estudiantes deben realizar actividades en diferentes territorios, organizaciones o instituciones. Las mismas se realizan durante los cinco años de la carrera.
} 
de Darío, ella no participó en ninguna organización política ni se autodefinió como "militante". Lo político en su trayectoria se relaciona a una actitud reflexiva sobre la sociedad y, para ello, fue fundamental el ingreso a la Facultad de Trabajo Social de la UNLP. Sobre la historia de Celina nos detendremos en los modos en que ella percibe a Roque Pérez y La Plata en términos de condiciones de posibilidad para la actividad política y los modos en que la universidad cambió su "manera de pensar".

A diferencia de Darío que veía en Roque Pérez un lugar hostil para la actividad política, Celina argumenta que en su localidad natal la política "casi no se veía". Si bien ella tenía algunos pocos amigos que participaban en el centro de estudiantes de su escuela, la participación en organizaciones de otro tipo era prácticamente inexistente. En la actualidad se pregunta si la actividad política no existía cuando vivía allí o si ella no la "veía" porque no le interesaba. Lo que resulta de interés en su relato es que la acción política o el "hablar de política" era prácticamente algo invisibilizado en el "pueblo". En este contexto nunca se sintió interpelada ni siquiera a hablar sobre temas de este tipo.

Lo que cambió radicalmente su manera de pensar fue el ingreso a la universidad. Llegó a una facultad en donde el primer día la interpelaron como un sujeto que debía construir un posicionamiento sobre el mundo y allí comprendió que "decir que no le interesaba la política no era no tener un posicionamiento sino estar posicionada al respecto". Tanto la facultad como los espacios en donde realizó sus prácticas de formación constituyeron los lugares fundamentales de su circuito estudiantil en donde pudo "abrir su cabeza" en términos políticos. Además de la facultad, se encontró en una ciudad en donde la actividad política era mucho más "visible" que en Roque Pérez.

Antes de concluir este apartado, queremos destacar que, si bien nos hemos detenido en dos sujetos que interpretaron una apertura para la experiencia política, debemos decir que algunos jóvenes no sintieron despertar un interés por este tema luego de vivir en La Plata o comenzar la universidad, pero si identificaron atravesar por lugares en donde la actividad política era más "visible" que en Roque Pérez. En ese sentido, la ciudad de La Plata, como dijimos, aparece como un "lugar por excelencia para la política": hay organizaciones, movilizaciones, espacios y personas que activan la vida política dentro de la ciudad. Desde sus experiencias como estudiantes universitarios, se refuerza el imaginario 
de ciudad universitaria, del cual la experiencia política estudiantil históricamente ha sido parte.

\section{2 "Acá no hay que preocuparse por el que dirán": experiencias de gestión de las esferas pública y privada de la vida}

En este apartado nos detenemos a analizar los modos en que el cambio de ciudad posibilita una nueva gestión de las esferas privada y pública de las vidas de los sujetos. Para ello retomamos los aportes de la filósofa Hannah Arendt (2016) quien sostiene que luego de la Modernidad la distinción entre las esferas pública y privada radicó en la diferencia entre cosas que deben mostrarse y cosas que deben permanecer ocultas en la vida social. De modo que la esfera privada quedó asociada a la dimensión de la intimidad. Analizaremos que aquello que puede mostrarse y lo que debe ocultarse varía notablemente de acuerdo al contexto urbano, en este caso Roque Pérez y La Plata. Para poder analizar estas

dimensiones reconstruimos dos trayectorias de jóvenes sobre las que nos detenemos a continuación.

\subsection{1 "Me vine a La Plata para vivir libremente mi sexualidad": la trayectoria de Eugenio}

Eugenio tiene 25 años y es estudiante de Derecho en la Universidad Nacional de La Plata. Desde que tenía 11 años estaba convencido de que quería ser abogado. Su papá es mecánico y trabaja en un taller desde que Eugenio nació y su mamá es empleada administrativa en una dependencia estatal. Ambos se separaron cuando era muy pequeño. Desde esta separación, Eugenio vivó un tiempo con su mamá, otro con su papá y luego con su abuela paterna por varios años. Su abuelo paterno era militar y eso llevó a que la familia de su padre viviera en diferentes lugares del país hasta que se asentaron en Roque Pérez. Sus abuelos maternos 
migraron desde Uruguay hacia la ciudad de Buenos Aires donde continúan viviendo.

El joven reconoce que nunca "le faltó nada", siempre tuvo una casa donde vivir y su familia tenía trabajo. Pero tampoco le "sobraba nada" puesto que los ingresos económicos, tanto de sus padres como de su abuela, no eran abundantes. Cursó todos sus estudios secundarios en la escuela "media”. Sus recuerdos sobre ese momento no son muy felices. Durante esa época comenzó a sentir que le gustaban los varones pero intentaba "reprimir" esos deseos y trataba de que nadie lo notara. No obstante, sus esfuerzos no dieron frutos y comenzó a sufrir "bullying" por parte de varios de sus compañeros. La etiqueta de las burlas y los maltratos variaban entre "gay", "trolo" o "puto" pero siempre referían a su condición homosexual.

Su malestar en la escuela se convirtió en un malestar de vivir en el "pueblo". Sentía que las personas alli lo miraban, se reían y lo juzgaban. En Roque Pérez lo que le pasaba con su sexualidad no podía permanecer en el ámbito de su privacidad porque era algo de lo cual todos parecian conocer y opinar. Tanto se esforzaba en ocultar su condición sexual que vivió su época de estudiante secundario casi sin tener relaciones sexuales. Su vida en el "pueblo chico" se había convertido en un "infierno grande".

La posibilidad de irse a estudiar no solo apareció asociada al inicio de la carrera que siempre le había gustado sino también como la manera de "escapar" de Roque Pérez. Sabía que su familia tendría limitaciones económicas para apoyarlo en su proyecto y por ello comenzó a buscar opciones baratas de viviendas. Buscó por internet hasta que encontró una pensión a bajo costo y viajó a La Plata a conocerla. El edificio no lo convencía mucho pero sabía que era una de las pocas opciones que tendría para poder irse a la capital bonaerense. Al año siguiente se mudó allí y comenzó su carrera de abogacía en la Facultad de Ciencias Jurídicas y Sociales.

En La Plata conoció un "mundo nuevo" y a gente con mucha "apertura mental". En la facultad se hizo de muchos amigos y comenzó a hablar más sobre su sexualidad. A los pocos meses, una compañera de la facultad le propuso salir a un boliche gay de la ciudad. Esa fue la primera experiencia de Eugenio en un lugar así. Antes de conocerlo, imaginaba que sería una gran "orgía multitudinaria" pero se encontró con un ambiente que le gustó mucho en donde los varones podían besarse con otros varones y las mujeres con otras mujeres y "todo estaba bien”. Eugenio comenzó a frecuentar ese lugar más seguido y allí se hizo de grandes amigos.

En La Plata sintió que pudo vivir con más "libertad" su sexualidad. Allí conoció a varios chicos con quienes tuvo relaciones amorosas y también conoció a muchas 
personas con quien compartir esas "cosas intimas" de su vida. En la actualidad Eugenio está por graduarse de su carrera y tiene pensado seguir viviendo en La Plata cuando se reciba.

La trayectoria de Eugenio nos permite ver el modo en que el cambio de ciudad posibilita una gestión diferente de aquello que se muestra y aquello que se oculta sobre la vida, y sobre aquello que los demás ven. Roque Pérez aparece como un escenario donde se vuelve más dificultoso preservar la intimidad sin ser juzgado, o en términos de Arendt, la esfera privada de la vida ante los demás. La Plata, en cambio, es vista como un ámbito donde la opción sexual puede ser pública y no merece especial atención. Puede pasar inadvertida o su presencia es numerosa en algunos circuitos. En este sentido, los imaginarios sobre cada lugar son centrales para entender el comportamiento del joven. Es decir, la gestión de la vida privada varía en el "pueblo", donde debía reprimirse, y en la "ciudad", donde puede expresarse. A continuación nos detendremos mejor sobre esta cuestión.

Para poder interpretar la situación retomamos los aportes de Goffman (2012) quien sostiene que cuando el individuo se encuentra ante los demás, destaca una serie de acciones pero también omite otras. Esta elección entre las acciones que se destacan y las que se omiten suele estar condicionada por aquello que los sujetos consideran que es lo “apropiado" en cada contexto. Goffman denomina "idealización" a la forma de moldear las acciones, que los individuos realizan, para adaptarlas a las expectativas de la sociedad a la que se presenta. Así podemos ver en la historia de Eugenio que mientras vivía en Roque Pérez intentaba ocultar toda información que pudiera referir a su condición homosexual porque el auditorio de personas aparecía como un actor hostil a reconocer prácticas sexuales que difieran de la heteronormatividad. En este sentido, dentro del "pueblo" Eugenio había sido etiquetado ${ }^{78}$ (Becker, 2014) como el "gay" y eso lo marcaba como un desviado a la norma sexual hegemónica. Como bien ha señalado Becker "los grupos sociales crean la desviación al establecer las normas cuya infracción constituye la desviación” (2014:28).

\footnotetext{
${ }^{78}$ Como sostiene Becker: "Advertimos que en todas partes la gente que se involucra en una acción colectiva define aquello que es "malo" y que no debe hacerse, y en general da los pasos necesarios para evitar que se realice ese tipo de acciones". (2014:17).
} 
En La Plata, el modo en que puede ser gestionada la esfera privada de la vida cambia radicalmente. En primer lugar porque allí se encuentra habilitado, no sin disputas ${ }^{79}$, la expresión de la diversidad sexual en espacios públicos. En segundo lugar, porque en La Plata el "derecho al anonimato" (Delgado, 1998) posible por la actitud de reserva ${ }^{80}$ (Simmel, 1986) permite que las personas no estén necesariamente pendientes de la vida de los demás. Pero además, la existencia de mayor cantidad de personas posibilita una mayor capacidad de diferenciar los escenarios de interacción, posibilitando el uso estratégico de las adscripciones identitarias.

Goffman llama segregación de auditorios a la capacidad de los actuantes de diferenciar los espacios de interacción en donde se desempeñan diferentes papeles. En este sentido, La Plata aparece como un lugar en donde es posible realizar una mayor segregación de auditorios que en Roque Pérez. Para mostrarlo con un ejemplo, en la capital bonaerense Eugenio compartía el espacio de su facultad con determinadas personas, en su mayoría compañeros y docentes. Cuando terminaba la clase, se iba y lo más probable es que no volviera a ver a esas personas en otra situación de interacción. Allí su papel era ser estudiante. Luego se juntaba con amigos del "ambiente gay" en donde hablaban de otros temas y hacían otras actividades. En estos dos espacios de interacción que conformaban su circuito habitual, los auditorios estaban conformados por personas diferentes. En Roque Pérez, en cambio, su sensación era que las mismas personas que veía en la escuela eran las que se cruzaba en la calle o las que se encontraba en otros lugares de interacción. La posibilidad de segregar auditorios era mucho menor dentro del "pueblo". A continuación retomaremos la trayectoria de otra joven que también permite ver el modo en que el cambio de contexto urbano le posibilitó gestionar de manera diferente la esfera privada de su vida.

\subsection{2"En Roque Pérez es difícil preservar la privacidad": la trayectoria de Malena}

\footnotetext{
${ }^{79}$ En la ciudad de La Plata se registraron episodios de discriminación sexual por parte de dueños o empleados de comercios. En algunas ocasiones fueron repudiadas con una "besada masiva" una actividad en donde las personas debían besarse como una forma de protesta sobre lo que había ocurrido.

${ }^{80}$ Como ya hemos señalado en el capítulo 1 , Simmel denomina "reserva" a la actitud que adopta el habitante de la gran urbe en donde se muestra frío y extraño ante los demás.
} 
Malena tiene 31 años y es diseñadora gráfica. Nació en Roque Pérez y vivó allí hasta su adolescencia cuando su familia decidió mudarse a La Plata. Su papá es contador, su madre docente y tiene una hermana mayor. Su familia materna era originaria de Roque Pérez y la paterna de La Plata, a donde solía viajar con frecuencia para visitar a sus abuelos.

Desde chica le gustaron mucho las actividades artísticas y sus padres siempre la estimularon para estudiar pintura, dibujo, música y danza. También le gustaba mucho la literatura y leer constituía su "refugio" dentro de su casa. La lectura y su casa la "refugiaban" de la mirada de los otros. En Roque Pérez sentía que todo el mundo estaba pendiente de la vida de los demás y eso le molestaba mucho. Sobre todo en su época de adolescente intentaba preservar su vida privada ante el pueblo. No quería que hablaran de ella, ni de su familia, ni de su relación con sus amigos o con otras personas. Cuando iba a visitar a sus abuelos a La Plata se encontraba con una ciudad que la maravillaba. Era grande y tenía muchas cosas para hacer, sobre todo artísticas. Además tenía muchas personas que "no se metían" en la vida de las otras. Durante su adolescencia tenía a La Plata idealizada mientras que Roque Pérez le parecía un lugar muy hostil.

Antes de terminar sus estudios secundarios en la escuela "media”, sus papás se divorciaron y ella se fue a vivir a La Plata con su mamá y su hermana. En la capital provincial terminó sus estudios secundarios y luego realizó los estudios universitarios en la Facultad de Bellas Artes. La universidad le abrió un mundo que le fascinó en donde se encontró con nuevos conocimientos, espacios y amigos. Además, allí sintió que sus compañeros y docentes no "estaban pendientes de su vida privada" y eso la hacía sentir mucho más cómoda. Le gustaba ser un "número más" dentro del montón. Terminó su carrera universitaria, y junto a su pareja, decidieron regresar a Roque Pérez para trabajar allí. Siendo más grande pudo reconocer otras cualidades del "pueblo" que durante su adolescencia le costaba ver. Lo encontró como un lugar donde hay mucho afecto, calidez y cordialidad entre las personas. Cuando era chica le incomodaba no poder mantener el anonimato o privacidad en el "pueblo". En la actualidad, esto no constituye su preocupación central pero igualmente trata de preservar su intimidad ante los demás. Principalmente trata de ser cautelosa con su vida en pareja. Un modo de preservación es no salir mucho de su casa, juntarse allí con sus amigos y no desarrollar su vida muy "por fuera”. Otro modo de preservación es no escuchar comentarios sobre otras personas ni preguntar por la vida de los otros.

Al igual que en la anterior trayectoria podemos notar que Malena tuvo que gestionar de manera diferente las esferas de lo que hace público o deja en el ámbito de la privacidad 
de acuerdo al contexto urbano. También podemos ver como se refuerzan los imaginarios de "pueblo" y "ciudad" asociados a la dicotomía "anonimato-presencia" que analizamos en el capítulo 1. En Roque Pérez la posibilidad de ser un anónimo ante los demás aparece como algo dificultoso. En cambio, La Plata en su versión de "ciudad" se muestra como un escenario impersonal y anónimo por excelencia. Además del "anonimato" La Plata le ofreció una variada gama de espacios en donde fue construyendo su propio circuito como estudiante, como la Facultad de Bellas Artes y los lugares en donde realizar actividades artísticas. Nos detendremos particularmente sobre esto en la próxima sección.

Algo a destacar en esta segunda trayectoria es el cambio en la manera en que es percibida la gestión de la esfera privada en el marco del curso de vida. El período de mayor conflictividad aparece asociado a la etapa "adolescente" en donde Malena se relata a sí misma como un sujeto más vulnerable a ser afectado por la opinión de los demás. En cambio en la actualidad, autoposicionándose como adulta, considera que la gestión de la privacidad sigue siendo algo que la preocupa pero no de la manera en que la preocupaba años atrás. De este modo, evitar emitir comentarios o exponer su vida pública son estrategias que utiliza para preservar la esfera privada. También es interesante el modo en que su percepción sobre Roque Pérez se fue modificando de acuerdo a los cambios dentro del curso de vida. Retomaremos esto en la conclusión de la tesis.

\subsection{Experiencias artísticas en la ciudad}

En esta sección nos detenemos en las trayectorias de dos jóvenes artistas. La primera es la de una joven a quien siempre le fascinó hacer actividades artísticas desde que vivía en Roque Pérez, pero fue en La Plata donde comenzó a pensarse a sí misma como artista. La segunda trayectoria es la de un joven que "descubrió" las artes circenses en La Plata, antes de eso, nunca había realizado ninguna disciplina de este tipo. En ambas historias veremos el modo en que se presenta a la ciudad de La Plata como un "lugar privilegiado" para la producción artística. Si bien nos detendremos en los circuitos particulares de ambos jóvenes, es necesario señalar que diferentes investigaciones han 
mostrado la pluralidad de prácticas y producciones en diferentes campos artísticos de la capital bonaerense: sobre danza, hay trabajos dentro del clásico y contemporáneo (Mora, 2011), y break dance (Mora, 2016). También existen trabajos sobre artes circenses (Sáez, 2017), teatro independiente (Del Mármol, 2014), circuitos ligados al rock (Cingolani, 2016; Boix, 2013) y experiencias culturales en centros o colectivos artísticos (López, 2017), entre otros.

\subsection{1"En esta ciudad me di cuenta que quería ser artista": la trayectoria de Marina}

Marina tiene 25 años y es estudiante de Música Popular. Nació en la ciudad de Buenos Aires pero cuando tenía apenas un año y medio, la familia se mudó a Roque Pérez. Su papá se dedicó siempre a la docencia secundaria y su mamá a la docencia en el nivel inicial. Ambos están jubilados actualmente y tiene un hermano dos años menor que ella. Desde que era chica le gustaba mucho el arte. Amaba disfrazarse para los actos escolares y participar en todas las obras que se organizaran. Cuando tenía seis años, en un viaje familiar a la ciudad de Buenos Aires, conoció el teatro. Eso fue una experiencia fundamental en su vida y, de regreso a Roque Pérez, les pidió a sus padres que la mandaran a estudiar actuación.

Además de teatro, en Roque Pérez estudió danza y música. Le gustaba bailar folklore en los festivales que se hacian en la localidad. En la escuela se hizo muchos amigos que compartían el amor por el arte que ella tenía. Varios tenían instrumentos musicales y amaba escucharlos tocar. Muchos de ellos decían que se dedicarían a estudiar alguna carrera artística cuando terminaran la secundaria. Marina, sin embargo, no se imaginaba un futuro laboral a partir del arte. Ella sabía que cuando terminara la escuela se iría a vivir a Buenos Aires porque tenía familiares maternos allí. Le gustaba mucho la idea de irse a una ciudad tan "grande" y tan distinta a Roque Pérez. Su familia y sus amigos se sorprendieron cuando dijo que estudiaría Psicología en vez de una carrera artística. Se decidió por esa carrera porque pensaba que del arte "no podría vivir". Sus amigos de la secundaria, en cambio, habian decidido irse a estudiar a la Facultad de Bellas Artes en La Plata.

La vida en la capital nacional no fue tan "linda" como se la imaginaba. Vivía en la casa de unos tíos y debía viajar más de una hora y media en colectivo para llegar hasta la facultad. La carrera le pareció "linda pero tampoco le 
encantó". La ciudad le parecía "enorme" y se sentía muy sola. Durante las vacaciones de invierno de ese primer año que llevaba viviendo en Buenos Aires, sus amigos de la secundaria la invitaron a La Plata porque tocarían en un lugar con una nueva banda de percusión que habian creado.

Cuando llegó, la fueron a buscar a la terminal y de alli se fueron caminando hasta su casa. Las calles adoquinadas, los árboles adornando las veredas y las plazas de la capital provincial la enamoraron. Esa misma noche vio a sus amigos tocar en un centro de estudiantes regional y se encontró con un mundo lleno de universitarios que le encantó. Desde ese momento se dio cuenta que La Plata era "su lugar en el mundo". Esa misma noche se subió al escenario con sus amigos, bailó y tocó algunos de los instrumentos. Al día siguiente salió con ellos a recorrer la ciudad. Conoció el bosque, el museo y la catedral, entre otros edificios. A los pocos dias llamó a sus papás y les dijo que había tomado una nueva decisión. Al año siguiente se iría a vivir a La Plata.

Ese año decidió dejar la carrera de Psicología y volver a Roque Pérez. Al año siguiente se fue a vivir con sus amigos a La Plata. Se instaló en la casa que alquilaban y comenzó la carrera de Música Popular. En La Plata encontró un lugar en donde "se respiraba arte" todo el tiempo y en donde decidió que quería dedicarse profesionalmente a la música. Comenzó a participar en la banda de sus amigos y así fue conociendo un montón de lugares en la ciudad. Tocaban en fiestas de las facultades o en centros culturales. A su vez, todos los lunes por las noches se juntaba a ensayar con sus amigos. En la actualidad, Marina está terminando su carrera de música popular. También participa en un grupo de teatro independiente y trabaja dando clases de guitarra particulares. Sigue ensayando todos los lunes y tocando con su banda cada vez que los convocan.

La historia de Marina muestra una continuidad en el gusto hacia el arte a lo largo de su vida que se potenció cuando se fue a La Plata. Mientras vivía en Roque Pérez pudo realizar diferentes prácticas artísticas como el teatro, la música o la danza como así también participar en festivales dentro de la localidad. Pero en ese momento de su vida no se imaginaba a sí misma dedicándose profesionalmente a la actividad artística. Si bien tenía un grupo de amigos que habían decidido formarse profesionalmente como músicos, para ella "el arte" no era considerado una posibilidad de ejercicio laboral a futuro. Por eso, cuando terminó la secundaria, decidió estudiar una carrera como Psicología a la que veía como una vía laboral posible. 
Como vimos fue en La Plata donde conoció un circuito particular que la maravilló, lleno de personas que compartían sus gustos y amor por lo que hacían. Además contaba con una red de amigos que la hicieron conocer la ciudad y fortalecieron su deseo de instalarse allí. El circuito particular por el que comienza a moverse dentro de la capital bonaerense está compuesto por lugares que se asocian a la práctica artística. En primer lugar, podemos ubicar a la Facultad de Bellas Artes, el ámbito académico en donde estudia. Allí no solo se forma profesionalmente sino que sociabiliza con personas que la llevan hacia otros lugares vinculados con el arte.

Gran parte de los lugares que componen su circuito artístico en la ciudad están atravesados por la banda de percusión en la que participa. El primero de ellos es el lugar del ensayo, casi siempre en la casa que alquila uno de los integrantes de la banda. Otros lugares son los sitios donde actúan. Cuando conocimos a Marina, la banda solía tocar al menos una vez por mes. Durante estos eventos, al grupo le ingresaba dinero que casi siempre era invertido en comprar instrumentos o vestuario ya que no les alcanzaba para los gastos de la vida diaria. Marina conseguía dinero dando clases de guitarra particulares en su casa o a veces en la casa de sus alumnos. Cuando la conocimos, tenía cinco alumnos particulares. Si bien a la joven le gustaba la actividad artística desde siempre, vivir en La Plata fue decisorio para darse cuenta que quería dedicarse al arte profesionalmente, ya sea como miembro de una banda musical o como docente. En la actualidad se encuentra finalizando su carrera en la UNLP.

\subsection{3 “Acá conocí el arte”: la trayectoria de Daniel}

Daniel tiene 29 años y trabaja como malabarista en diferentes lugares de la ciudad de La Plata. A veces en la calle o en eventos que lo contratan. Nació en una localidad del Conurbano Bonaerense, de donde son originarios sus padres, y cuando tenía dos años toda la familia se fue a Roque Pérez. Allí nacieron sus tres hermanos menores. Su papá trabaja como empleado municipal y su mamá se jubiló como maestra. Daniel y sus hermanos crecieron al cuidado de la 
abuela paterna quien se mudó también a Roque Pérez para colaborar en la crianza de los niños.

Fue a la escuela "media" y lo que más le gustaba hacer, durante su época de estudiante secundario, era jugar al fútbol. Con sus amigos solian juntarse para ir a las 33 hectáreas a jugar. Cuando estaba terminando la escuela y llegó el momento de decidir si irse o quedarse en Roque Pérez, eligió irse a vivir a otro lugar. La mayoría de sus amigos se iban a La Plata y pensó que debía hacer lo mismo. No sabía qué estudiar y ninguna carrera le llamaba la atención. Como le gustaba mucho jugar al fútbol supuso que debería elegir algo vinculado a los deportes. El Profesorado en Educación Física fue lo único que se le ocurrió y decidió anotarse allí. Se mudó a una pensión, al año siguiente, junto a uno de sus compañeros de secundaria y comenzó a cursar la carrera en la Facultad de Humanidades. No le gustó mucho pero allí conoció a dos chicos que "hacían circo" en un centro cultural y eso sería decisivo en su vida.

Comenzó acompañándolos a los ensayos y le gustó mucho lo que hacían. Al poco tiempo empezó a aprender de la mano de ellos y asi fue "progresando" mucho. A los meses de comenzar su formación, uno de sus amigos le propuso ir a una esquina a trabajar haciendo malabares a cambio de dinero. Daniel antes no había pensado que se podía "trabajar" haciendo malabares. Le daba vergüenza y pasó un largo tiempo hasta que se animó y acompañó a su amigo a trabajar. Cuando terminaron ese día volvió a su casa con "varios pesos en el bolsillo" y un gran sentimiento de felicidad. Comenzó a tomarse sus ensayos "más seriamente", entrenaba todos los días y fue aprendiendo actividades nuevas como hacer equilibrio caminando sobre una soga o danza aérea con tela.

A la par que dedicaba mucho tiempo a su entrenamiento, se dio cuenta que la carrera universitaria no lo "enganchaba" y la dejó. Lo más difícil fue "tomar el valor" para decírselo a sus papás y varios meses pasaron hasta que finalmente les contó. Al principio a sus padres no les gustó que deje la facultad para dedicarse a trabajar como artista callejero, pero finalmente lo aceptaron al ver que era "feliz". Daniel viajó por varios países trabajando como artista callejero y actualmente vive en La Plata dedicándose a lo mismo.

Esta trayectoria también nos permite analizar la manera en que el cambio de localidad repercute fuertemente en la producción de la experiencia artística. De algún modo, Daniel "descubrió" un nuevo mundo vinculado a la actividad circense viviendo en La Plata. A diferencia de Marina, nunca se había interesado por ninguna disciplina artística mientras vivía en Roque Pérez y, en ese sentido, fue la vida en La Plata la que le posibilitó 
el inicio de esa experiencia. De hecho, en el momento en que tuvo que elegir una carrera para estudiar, no tuvo en cuenta seleccionar ninguna de orientación artística y se decidió por Educación Física por su afinidad con los deportes, en particular el fútbol.

Se puede ver aquí también la influencia de las sociabilidades que se producen en la universidad en lo que respecta al inicio de las actividades artísticas. Fueron dos personas que conoció en la facultad quienes lo familiarizaron con las prácticas circenses y le fueron enseñando a lo largo del tiempo. Dentro del circuito asociado a esta práctica artística se identifican tres grandes lugares. El primero es el centro cultural en donde aprendió a realizar malabares, colgarse a la tela y hacer equilibrio. Es decir, su lugar de aprendizaje y de ensayo y sobre todo un espacio de entrenamiento del cuerpo ${ }^{81}$. Los otros dos lugares están compuestos por el área laboral. Dentro de estos se encuentran las esquinas de diferentes calles en donde, mientras el semáforo está en rojo, Daniel realiza sus malabares para los conductores de los autos. El otro está compuesto por casas, centros culturales o salones de fiesta en donde Daniel es contratado como artista.

Si bien la razón por la cual el joven se trasladó a esa ciudad fue el comienzo de la universidad, con el tiempo ésta fue perdiendo importancia. Esto no estuvo exento de conflictividades, principalmente relacionadas a tener que contárselo a sus padres. Al principio a ellos no les agradó la idea de que Daniel dejara la carrera pero, con el tiempo, lo fueron aceptando ${ }^{82}$. Sobre todo porque Daniel logró independencia económica con respecto a ellos a partir de sus ingresos como artista callejero.

La trayectoria de Daniel muestra además que la actividad artística se puede volver una actividad laboral, conformándose como un espacio de construcción identitaria profesional en donde se invierte tiempo de formación y expectativas a futuro (Infantino, 2011). Podemos analizar que en Daniel la práctica artística no solo constituye su sostén económico sino también conforma un anclaje identitario en términos profesionales que se

\footnotetext{
${ }^{81}$ No analizaremos aquí sus prácticas y representaciones en torno a la corporalidad. Sobre este tema recomendamos el trabajo de Julieta Infantino (2010) que analiza prácticas y representaciones sobre la corporalidad en artistas circenses de Buenos Aires y el de Mariana Sáez (2017) que trabaja una temática similar en La Plata.

${ }^{82}$ en el próximo capítulo nos detendremos sobre los compromisos y acuerdos que se generan entre los jóvenes y sus padres.
} 
materializa con la categoría de "artista callejero". Con esta el joven se autodefine, ubicando a su práctica artística laboral como un punto nodal de su identidad.

En ambas trayectorias podemos ver el modo en que la vida en la ciudad de La Plata posibilita la producción de nuevas experiencias relacionadas con la actividad artística que se vuelven también actividades laborales. La capital provincial, suma al imaginario de ciudad universitaria, la representación de escenario de excelencia para el desarrollo artístico. En la próxima sección nos detendremos a analizar el carácter que adquiere La Plata como "lugar privilegiado" para la experiencia juvenil.

\subsection{La Plata "lugar privilegiado" para la experiencia juvenil: conclusiones}

A lo largo de estas historias hemos podido analizar la aparición o resignificación de diferentes experiencias que fueron posibilitadas por la vida en la ciudad de La Plata y los cambios en el curso de vida. En ellas encontramos un común denominador que es la identificación de la capital bonaerense como un "lugar privilegiado" para el ejercicio de esas experiencias. En el caso de las artísticas y políticas, La Plata aparece como "lugar privilegiado" bajo el imaginario de la "ciudad universitaria". En las experiencias vinculadas a la gestión de la privacidad, la capital provincial asociada al imaginario de "ciudad" posibilita el derecho al anonimato y se presenta como un lugar en donde pueden mostrarse aspectos de la vida que en Roque Pérez no. En estos últimos párrafos analizamos esta expresión nativa de "lugar privilegiado" que se le otorga a la capital de la Provincia de Buenos Aires.

Lo primero que señalamos es la utilización del término "lugar" que puede interpretarse referido a sentimientos de apropiación y pertenencia del espacio por parte de los grupos sociales (Torres, 2012). La Plata aparece como un "lugar" que es "privilegiado" para vivenciar un momento particular del curso de vida que podemos vincular con la condición juvenil. En la conclusión de la tesis analizaremos que Roque Pérez también aparece como un "lugar" asociado a otro momento del curso de vida, la adultez. Pero aquí nos detendremos sobre el carácter de "lugar privilegiado" de La Plata para ser joven. ¿Por 
qué aparece de ese modo? Nuestra hipótesis sostiene que las características de la ciudad, sumado a los circuitos y sociabilidades que atraviesan la vida de los estudiantes migrantes, posibilita el ejercicio de experiencias asociadas a las representaciones clásicas de la condición juvenil: el modelo de la moratoria social. A continuación explicaremos mejor esta idea.

Es necesario aclarar que la aparición de la juventud, a mediados de siglo XX, como un sector diferenciado dentro de la sociedad occidental se vinculó con una "Revolución cultural" (Hosbawn, 2012) que traía grandes modificaciones en el terreno de la política, la sexualidad y el arte. Según Hosbawn, la emergencia de este grupo social ${ }^{83}$ no podría pensarse aislado de la prolongación de los estudios y de la convivencia de jóvenes del mismo grupo de edad en las universidades. Esto fue posible por el desarrollo del Estado de Bienestar que permitió que los sectores jóvenes pudiesen vivir en una cierta moratoria social que le otorgaba una singularidad en relación a otros grupos etarios. Recordemos que la moratoria social alude al período de tiempo en el cual los sujetos, principalmente de sectores sociales medios y altos, pueden postergar las responsabilidades propias del mundo adulto y dedicarse al estudio y también al ocio (Margulis y Urresti, 1998).

Lo que nos interesa precisar es que la representación hegemónica que se construye sobre el sector juvenil, a mediados de siglo XX, está asociada con términos como política, música, drogas y sexo (Chaves, 2010). A partir de las trayectorias que aquí reconstruimos pudimos analizar que La Plata se muestra como un espacio que posibilita fuertemente el ejercicio tanto de la actividad política, artística, universitaria y sexual, entre otras. Es decir, la capital bonaerense constituye un "lugar" donde se pueden producir experiencias históricamente asociadas a la condición juvenil bajo el modelo de la moratoria social. Discutiremos sobre esta última categoría en las conclusiones de la tesis. En el próximo

\footnotetext{
${ }^{83}$ Según Carles Feixa (1998) fueron múltiples los factores que posibilitaron la aparición del sector juvenil: i) la emergencia Estado de Bienestar que creó las condiciones para un crecimiento económico sostenido y para la protección social de los grupos dependientes ii) la crisis de la autoridad patriarcal, lo cual llevó a los jóvenes a rebelarse en contra de los valores y mandatos de las generaciones anteriores iii) la aparición de un mercado de consumo específicamente destinado a los jóvenes que se habían convertido en un grupo que aumentaba su capacidad adquisitiva iv) la emergencia de los medios de comunicación de masas que permitió la creación de una verdadera cultura juvenil internacional y popular v) la erosión de la moral puritana, en donde tuvo su lugar la denominada "revolución sexual" cuyos protagonistas fueron los sectores juveniles y que abrió el camino hacia relaciones amorosas más libres. Estas condiciones sociales posibilitaron la construcción de una imagen cultural hegemónica de lo juvenil asociado a la transgresión de normas, liberación sexual y cuestionamiento político entre otros aspectos.
} 
capítulo veremos que las experiencias de los jóvenes también se encuentran atravesadas por desigualdades de clase y género, entre otras. 


\section{CAPÍTULO 4 Universidad y movilidad social: expectativas, proyecciones y realizaciones}

El objetivo de este capítulo es analizar las expectativas, proyecciones y realizaciones de movilidad social en torno a la educación universitaria. En este sentido, sostenemos como hipótesis que irse a La Plata implica una apuesta por la acumulación de capital escolar, como forma institucionalizada de capital cultural ${ }^{84}$, asociado a la posibilidad de conversión en capital económico y/o simbólico en el futuro (Bourdieu, 1979). A su vez, en términos nativos, la migración aparece unida a un relato de progreso y ascenso social que permite ver el modo en que el desplazamiento en el espacio geográfico se asocia al desplazamiento en el espacio social (Jiménez Zunino, 2013). Analizaremos que estos aspectos atraviesan las decisiones de los jóvenes sobre: i) quedarse en Roque Pérez luego de terminar la secundaria (no migrar); ii) irse a La Plata a estudiar; y iv) regresar (o no) una vez graduado. La educación universitaria aparece fuertemente referenciada como motor para la movilidad social ascendente, actualizándose muchas de las ideas propias del relato de origen de la clase media en Argentina (Visacovsky, 2014).

La universidad también juega un rol primordial en la autopercepción de clase de los jóvenes como miembros de familias de "clases medias". Para esto no solo analizaremos los relatos de los sujetos sino que también caracterizaremos hasta dos generaciones (padres y abuelos) de miembros de la familia en sus aspectos educativos, laborales y de propiedad de la vivienda en la que viven. Estos datos permiten reconstruir trayectorias familiares en donde veremos similitudes y diferencias en el grupo de referencia. Como un dato destacado se mostrará que la mayoría de los jóvenes conforman una primera generación de estudiantes universitarios.

\footnotetext{
${ }^{84}$ Para Pierre Bourdieu el capital cultural: "puede existir bajo tres formas: en el estado incorporado, es decir, bajo la forma de disposiciones duraderas en el organismo; en el estado objetivado, bajo la forma de bienes culturales, cuadros, libros, diccionarios, instrumentos, maquinarias, los cuales son la huella o la realización de teorías o de críticas a dichas teorías y de problemáticas, etc., y finalmente en el estado institucionalizado, como forma de objetivación muy particular, porque tal como se puede ver con el título escolar, confiere al capital cultural- que supuestamente debe garantizar- las propiedades totalmente originales (1979:12).
} 
Para poder abordar el objetivo, el capítulo se divide en cinco secciones. En primer lugar esta introducción. Luego se presentan tres secciones: quedarse en Roque Pérez, irse a La Plata y regresar a Roque Pérez una vez finalizada la carrera. En ellos se analizan los sentidos en términos de posibilidades (o no) de movilidad social. Por último, cierran al capítulo algunos comentarios finales.

\subsection{Familias de "clase media": educación, trabajo y vivienda de los grupos familiares}

Casi la totalidad de los jóvenes se autopercibieron como pertenecientes a familias de "clase media". Por lo menos esta era la respuesta que daban a la pregunta ¿A qué clase social considerás que perteneces? Solo Celina y Darío, cuyas experiencias políticas analizamos en el capítulo anterior, respondieron "clase trabajadora". De hecho, Darío comentó que el término "clase media" era una "mentira para no reconocer que una persona o es propietaria de los medios de producción o vende su fuerza de trabajo", parafraseando a la estructura de clases sociales a la que aludía Karl Marx. El resto de los jóvenes se autoreconocieron como "clase media" y algunos le agregaron "baja" subdividiendo en ello al sector. En las próximas páginas, y sobre todo en el final del capítulo, nos detendremos a analizar las valoraciones y sentidos colocados dentro de esta expresión nativa de "clase media". Coincidimos con Oliven (2014) en que esta categoría más que referenciar a una posición en la estructura social, nos habla del modo en que los sujetos se identifican a sí mismos e identifican a otros (tanto por semejanza o distinción) poniendo en juego sus expectativas y aspiraciones.

Antes de comenzar con el análisis de sus relatos, nos gustaría precisar algunos datos sobre características económicas y educativas de los grupos familiares de estos jóvenes. No porque consideremos que exista una determinación entre estas y sus expectativas en términos de clase sino para mostrar la heterogeneidad en el grupo. La información que presentamos fue relevada a partir de la aplicación de un cuestionario estandarizado a los 16 jóvenes unas semanas después de haber sido entrevistados. Allí se indagaron aspectos 
laborales, educativos y de propiedad de la vivienda en padres y abuelos con el fin de reconstruir estructura y volumen de algunos capitales.

En el siguiente cuadro (Cuadro 2) presentamos la información relevada sobre padre, madre, abuelo paterno, abuela paterna, abuelo materno y abuela materna de cada uno de los jóvenes. Es preciso señalar que, con respecto a los abuelos, los datos fueron más imprecisos porque varios de los jóvenes no habían conocido a todos. En algunos casos, algunos familiares les ayudaron a completar el cuestionario y, en otros casos, no pudieron porque sus familiares cercanos también desconocían la información sobre los abuelos fallecidos. Las variables que se analizan sobre cada miembro de la familia son:

a) Máximo nivel educativo alcanzado: Aquí se detalla el nivel escolar hasta el que llegó y si fue completado o no.

b) Actividad laboral: Se detalla el trabajo que realizan (o realizaron en caso de jubilados o fallecidos) los familiares de los jóvenes.

c) Propiedad de la vivienda: Se especifica si el padre, madre, abuelos y abuelas son (o fueron en caso de fallecimiento) propietarios de la vivienda en la que viven (o vivieron).

Cuadro 2 Escolaridad, trabajo y vivienda de padres y abuelos

\begin{tabular}{|c|c|c|c|c|c|c|c|}
\hline \multirow[t]{4}{*}{ Darío } & & Padre & Madre & $\begin{array}{l}\text { Abuelo } \\
\text { paterno }\end{array}$ & $\begin{array}{l}\text { Abuela } \\
\text { paterna }\end{array}$ & $\begin{array}{l}\text { Abuelo } \\
\text { materno }\end{array}$ & $\begin{array}{l}\text { Abuela } \\
\text { materna }\end{array}$ \\
\hline & $\begin{array}{l}\text { Máximo } \\
\text { nivel } \\
\text { educativo } \\
\text { alcanzado }\end{array}$ & $\begin{array}{l}\text { Terciario } \\
\text { completo }\end{array}$ & $\begin{array}{l}\text { Secundario } \\
\text { completo }\end{array}$ & $\begin{array}{l}\text { Primario } \\
\text { incompleto }\end{array}$ & $\begin{array}{l}\text { Primario } \\
\text { incompleto }\end{array}$ & $s / d$ & $s / d$ \\
\hline & $\begin{array}{l}\text { Actividad } \\
\text { laboral }\end{array}$ & $\begin{array}{l}\text { Empleado } \\
\text { público }\end{array}$ & $\begin{array}{l}\text { Ama de } \\
\text { casa }\end{array}$ & $\begin{array}{l}\text { Empleado } \\
\text { rural }\end{array}$ & $\begin{array}{l}\text { Ama de } \\
\text { casa }\end{array}$ & $\begin{array}{l}\text { Trabajador } \\
\text { por cuenta } \\
\text { propia }\end{array}$ & $\begin{array}{l}\text { Ama de } \\
\text { casa }\end{array}$ \\
\hline & $\begin{array}{l}\text { Propiedad } \\
\text { de la } \\
\text { vivienda }\end{array}$ & $\mathrm{Si}$ & $S i$ & $\mathrm{Si}$ & $S i$ & No & $\mathrm{No}$ \\
\hline Noelia & & Padre & Madre & $\begin{array}{l}\text { Abuelo } \\
\text { paterno }\end{array}$ & $\begin{array}{l}\text { Abuela } \\
\text { paterna }\end{array}$ & $\begin{array}{l}\text { Abuelo } \\
\text { materno }\end{array}$ & $\begin{array}{l}\text { Abuela } \\
\text { materna }\end{array}$ \\
\hline
\end{tabular}




\begin{tabular}{|c|c|c|c|c|c|c|c|}
\hline & $\begin{array}{l}\text { Máximo } \\
\text { nivel } \\
\text { educativo } \\
\text { alcanzado }\end{array}$ & $\begin{array}{l}\text { Secundari } \\
o \\
\text { incomplet } \\
o\end{array}$ & $\begin{array}{l}\text { Primario } \\
\text { completo }\end{array}$ & $s / d$ & $s / d$ & $\begin{array}{l}\text { Primario } \\
\text { incompleto }\end{array}$ & $\begin{array}{l}\text { Primario } \\
\text { incompleto }\end{array}$ \\
\hline & $\begin{array}{l}\text { Actividad } \\
\text { laboral }\end{array}$ & $\begin{array}{l}\text { Empleado } \\
\text { rural }\end{array}$ & $\begin{array}{l}\text { Empleada } \\
\text { rural }\end{array}$ & $s / d$ & $s / d$ & $\begin{array}{l}\text { Empleado } \\
\text { rural }\end{array}$ & $\begin{array}{l}\text { Ama de } \\
\text { casa }\end{array}$ \\
\hline & $\begin{array}{l}\text { Propiedad } \\
\text { de la } \\
\text { vivienda }\end{array}$ & $\mathrm{Si}$ & $\mathrm{Si}$ & $s / d$ & $s / d$ & $\mathrm{Si}$ & $\mathrm{Si}$ \\
\hline \multirow[t]{4}{*}{ Lucía } & & Padre & Madre & $\begin{array}{l}\text { Abuelo } \\
\text { paterno }\end{array}$ & $\begin{array}{l}\text { Abuela } \\
\text { paterna }\end{array}$ & $\begin{array}{l}\text { Abuelo } \\
\text { materno }\end{array}$ & $\begin{array}{l}\text { Abuela } \\
\text { materna }\end{array}$ \\
\hline & $\begin{array}{l}\text { Máximo } \\
\text { nivel } \\
\text { educativo } \\
\text { alcanzado }\end{array}$ & $\begin{array}{l}\text { Universit } \\
\text { ario } \\
\text { completo }\end{array}$ & $\begin{array}{l}\text { Universitari } \\
\text { o completo }\end{array}$ & $s / d$ & $\begin{array}{l}\text { Primario } \\
\text { incompleto }\end{array}$ & $\begin{array}{l}\text { Secundario } \\
\text { completo }\end{array}$ & $\begin{array}{l}\text { Secundario } \\
\text { completo }\end{array}$ \\
\hline & $\begin{array}{l}\text { Actividad } \\
\text { laboral }\end{array}$ & Docente & $\begin{array}{l}\text { Profesional } \\
\text { en salud } \\
\text { pública }\end{array}$ & $s / d$ & $\begin{array}{l}\text { Trabajador } \\
\text { a por } \\
\text { cuenta } \\
\text { propia }\end{array}$ & $\begin{array}{l}\text { Empleado } \\
\text { público }\end{array}$ & $\begin{array}{l}\text { Ama de } \\
\text { casa }\end{array}$ \\
\hline & $\begin{array}{l}\text { Propiedad } \\
\text { de la } \\
\text { vivienda }\end{array}$ & $\mathrm{Si}$ & $\mathrm{Si}$ & $s / d$ & $\mathrm{Si}$ & $\mathrm{Si}$ & $\mathrm{Si}$ \\
\hline \multirow[t]{4}{*}{ Victoria } & & Padre & Madre & $\begin{array}{l}\text { Abuelo } \\
\text { paterno }\end{array}$ & $\begin{array}{l}\text { Abuela } \\
\text { paterna }\end{array}$ & $\begin{array}{l}\text { Abuelo } \\
\text { materno }\end{array}$ & $\begin{array}{l}\text { Abuela } \\
\text { materna }\end{array}$ \\
\hline & $\begin{array}{l}\text { Máximo } \\
\text { nivel } \\
\text { educativo } \\
\text { alcanzado }\end{array}$ & $\begin{array}{l}\text { Primario } \\
\text { completo }\end{array}$ & $\begin{array}{l}\text { Primario } \\
\text { completo }\end{array}$ & $s / d$ & $s / d$ & $\begin{array}{l}\text { Primario } \\
\text { incompleto }\end{array}$ & $\begin{array}{l}\text { Primario } \\
\text { incompleto }\end{array}$ \\
\hline & $\begin{array}{l}\text { Actividad } \\
\text { laboral }\end{array}$ & $\begin{array}{l}\text { Empleado } \\
\text { rural }\end{array}$ & $\begin{array}{l}\text { Empleada } \\
\text { rural }\end{array}$ & $s / d$ & $s / d$ & $\begin{array}{l}\text { Empleado } \\
\text { rural }\end{array}$ & $\begin{array}{l}\text { Empleada } \\
\text { rural }\end{array}$ \\
\hline & $\begin{array}{l}\text { Propiedad } \\
\text { de la } \\
\text { vivienda }\end{array}$ & $\mathrm{Si}$ & $\mathrm{Si}$ & $s / d$ & $s / d$ & $\mathrm{No}$ & No \\
\hline \multirow[t]{3}{*}{ Liliana } & & Padre & Madre & $\begin{array}{l}\text { Abuelo } \\
\text { paterno }\end{array}$ & $\begin{array}{l}\text { Abuela } \\
\text { paterna }\end{array}$ & $\begin{array}{l}\text { Abuelo } \\
\text { materno }\end{array}$ & $\begin{array}{l}\text { Abuela } \\
\text { materna }\end{array}$ \\
\hline & $\begin{array}{l}\text { Máximo } \\
\text { nivel } \\
\text { educativo } \\
\text { alcanzado }\end{array}$ & $\begin{array}{l}\text { Primario } \\
\text { completo }\end{array}$ & $\begin{array}{l}\text { Primario } \\
\text { completo }\end{array}$ & $s / d$ & $\begin{array}{l}\text { Primario } \\
\text { incompleto }\end{array}$ & $\begin{array}{l}\text { Primario } \\
\text { incompleto }\end{array}$ & $\begin{array}{l}\text { Sin } \\
\text { escolarizaci } \\
\text { ón }\end{array}$ \\
\hline & Actividad & Trabajad & $A m a$ & $s / d$ & Empleada & Empleado & Empleada \\
\hline
\end{tabular}




\begin{tabular}{|c|c|c|c|c|c|c|c|}
\hline & laboral & $\begin{array}{l}\text { or por } \\
\text { cuenta } \\
\text { propia }\end{array}$ & casa & & doméstica & rural & doméstica \\
\hline & $\begin{array}{l}\text { Propiedad } \\
\text { de la } \\
\text { vivienda }\end{array}$ & $\mathrm{No}$ & $\mathrm{Si}$ & $s / d$ & $\mathrm{No}$ & $\mathrm{Si}$ & $\mathrm{Si}$ \\
\hline \multirow[t]{4}{*}{ Vanesa } & & Padre & Madre & $\begin{array}{l}\text { Abuelo } \\
\text { paterno }\end{array}$ & $\begin{array}{l}\text { Abuela } \\
\text { paterna }\end{array}$ & $\begin{array}{l}\text { Abuelo } \\
\text { materno }\end{array}$ & $\begin{array}{l}\text { Abuela } \\
\text { materna }\end{array}$ \\
\hline & $\begin{array}{l}\text { Máximo } \\
\text { nivel } \\
\text { educativo } \\
\text { alcanzado }\end{array}$ & $\begin{array}{l}\text { Primario } \\
\text { completo }\end{array}$ & $\begin{array}{l}\text { Primario } \\
\text { incompleto }\end{array}$ & $s / d$ & $s / d$ & $\begin{array}{l}\text { Primario } \\
\text { incompleto }\end{array}$ & $\begin{array}{l}\text { Sin } \\
\text { escolarizaci } \\
\text { ón }\end{array}$ \\
\hline & $\begin{array}{l}\text { Actividad } \\
\text { laboral }\end{array}$ & $\begin{array}{l}\text { Empleado } \\
\text { rural }\end{array}$ & $\begin{array}{l}\text { Empleada } \\
\text { doméstica }\end{array}$ & $\begin{array}{l}\text { Empleado } \\
\text { rural }\end{array}$ & $\begin{array}{l}\text { Empleada } \\
\text { doméstica }\end{array}$ & $\begin{array}{l}\text { Trabajador } \\
\text { por cuenta } \\
\text { propia }\end{array}$ & $\begin{array}{l}\text { Empleada } \\
\text { doméstica }\end{array}$ \\
\hline & $\begin{array}{l}\text { Propiedad } \\
\text { de la } \\
\text { vivienda }\end{array}$ & $\mathrm{Si}$ & $\mathrm{Si}$ & $\mathrm{No}$ & $\mathrm{No}$ & $\mathrm{Si}$ & $\mathrm{Si}$ \\
\hline \multirow[t]{4}{*}{ Elena } & & Padre & Madre & $\begin{array}{l}\text { Abuelo } \\
\text { paterno }\end{array}$ & $\begin{array}{l}\text { Abuela } \\
\text { paterna }\end{array}$ & $\begin{array}{l}\text { Abuelo } \\
\text { materno }\end{array}$ & $\begin{array}{l}\text { Abuela } \\
\text { materna }\end{array}$ \\
\hline & $\begin{array}{l}\text { Máximo } \\
\text { nivel } \\
\text { educativo } \\
\text { alcanzado }\end{array}$ & $\begin{array}{l}\text { Primario } \\
\text { completo }\end{array}$ & $\begin{array}{l}\text { Primario } \\
\text { incompleto }\end{array}$ & $\begin{array}{l}\text { Primario } \\
\text { incompleto }\end{array}$ & $\begin{array}{l}\text { Primario } \\
\text { incompleto }\end{array}$ & $s / d$ & $\begin{array}{l}\text { Sin } \\
\text { escolarizaci } \\
\text { ón }\end{array}$ \\
\hline & $\begin{array}{l}\text { Actividad } \\
\text { laboral }\end{array}$ & $\begin{array}{l}\text { Empleado } \\
\text { rural }\end{array}$ & $\begin{array}{l}\text { Ama de } \\
\text { casa }\end{array}$ & $\begin{array}{l}\text { Empleado } \\
\text { rural }\end{array}$ & $\begin{array}{l}\text { Ama de } \\
\text { casa }\end{array}$ & $s / d$ & $\begin{array}{l}\text { Ama de } \\
\text { casa }\end{array}$ \\
\hline & $\begin{array}{l}\text { Propiedad } \\
\text { de la } \\
\text { vivienda }\end{array}$ & $\mathrm{No}$ & $\mathrm{No}$ & $\mathrm{Si}$ & $\mathrm{Si}$ & $s / d$ & $\mathrm{No}$ \\
\hline \multirow[t]{4}{*}{ Esteban } & & Padre & Madre & $\begin{array}{l}\text { Abuelo } \\
\text { paterno }\end{array}$ & $\begin{array}{l}\text { Abuela } \\
\text { paterna }\end{array}$ & $\begin{array}{l}\text { Abuelo } \\
\text { materno }\end{array}$ & $\begin{array}{l}\text { Abuela } \\
\text { materna }\end{array}$ \\
\hline & $\begin{array}{l}\text { Máximo } \\
\text { nivel } \\
\text { educativo } \\
\text { alcanzado }\end{array}$ & $\begin{array}{l}\text { Primario } \\
\text { completo }\end{array}$ & $\begin{array}{l}\text { Terciario } \\
\text { completo/ } \\
\text { universitari } \\
o \\
\text { incompleto }\end{array}$ & $\begin{array}{l}\text { Primario } \\
\text { completo }\end{array}$ & $\begin{array}{l}\text { Primario } \\
\text { incompleto }\end{array}$ & $\begin{array}{l}\text { Secundario } \\
\text { completo }\end{array}$ & $\begin{array}{l}\text { Primario } \\
\text { completo }\end{array}$ \\
\hline & $\begin{array}{l}\text { Actividad } \\
\text { laboral }\end{array}$ & $\begin{array}{l}\text { Productor } \\
\text { agropecu } \\
\text { ario }\end{array}$ & $\begin{array}{l}\text { Productora } \\
\text { agropecuar } \\
\text { ia }\end{array}$ & $\begin{array}{l}\text { Productor } \\
\text { agropecuar } \\
\text { io }\end{array}$ & $\begin{array}{l}\text { Productora } \\
\text { agropecuar } \\
\text { ia }\end{array}$ & $\begin{array}{l}\text { Productor } \\
\text { agropecuar } \\
\text { io }\end{array}$ & $\begin{array}{l}\text { Ama de } \\
\text { casa }\end{array}$ \\
\hline & Propiedad & $\mathrm{Si}$ & $\mathrm{Si}$ & $\mathrm{Si}$ & $\mathrm{Si}$ & $\mathrm{Si}$ & $\mathrm{Si}$ \\
\hline
\end{tabular}




\begin{tabular}{|c|c|c|c|c|c|c|c|}
\hline & $\begin{array}{l}\text { de la } \\
\text { vivienda }\end{array}$ & & & & & & \\
\hline \multirow[t]{4}{*}{ Malena } & & Padre & Madre & $\begin{array}{l}\text { Abuelo } \\
\text { paterno }\end{array}$ & $\begin{array}{l}\text { Abuela } \\
\text { paterna }\end{array}$ & $\begin{array}{l}\text { Abuelo } \\
\text { materno }\end{array}$ & $\begin{array}{l}\text { Abuela } \\
\text { materna }\end{array}$ \\
\hline & $\begin{array}{l}\text { Máximo } \\
\text { nivel } \\
\text { educativo } \\
\text { alcanzado }\end{array}$ & Posgrado & $\begin{array}{l}\text { Terciario } \\
\text { completo/ } \\
\text { universitari } \\
\text { o } \\
\text { incompleto }\end{array}$ & $\begin{array}{l}\text { Secundario } \\
\text { completo }\end{array}$ & $\begin{array}{l}\text { Terciario } \\
\text { completo }\end{array}$ & $\begin{array}{l}\text { Primario } \\
\text { incompleto }\end{array}$ & $\begin{array}{l}\text { Secundario } \\
\text { completo }\end{array}$ \\
\hline & $\begin{array}{l}\text { Actividad } \\
\text { laboral }\end{array}$ & $\begin{array}{l}\text { Empleado } \\
\text { público }\end{array}$ & Docente & $\begin{array}{l}\text { Comerciant } \\
e\end{array}$ & Docente & $\begin{array}{l}\text { Empleado } \\
\text { público }\end{array}$ & $\begin{array}{l}\text { Trabajador } \\
\text { a por } \\
\text { cuenta } \\
\text { propia }\end{array}$ \\
\hline & $\begin{array}{l}\text { Propiedad } \\
\text { de la } \\
\text { vivienda }\end{array}$ & $\mathrm{Si}$ & $\mathrm{No}$ & $\mathrm{Si}$ & $\mathrm{Si}$ & $\mathrm{Si}$ & $\mathrm{Si}$ \\
\hline \multirow[t]{4}{*}{ Daniel } & & Padre & Madre & $\begin{array}{l}\text { Abuelo } \\
\text { paterno }\end{array}$ & $\begin{array}{l}\text { Abuela } \\
\text { paterna }\end{array}$ & $\begin{array}{l}\text { Abuelo } \\
\text { materno }\end{array}$ & $\begin{array}{l}\text { Abuela } \\
\text { materna }\end{array}$ \\
\hline & $\begin{array}{l}\text { Máximo } \\
\text { nivel } \\
\text { educativo } \\
\text { alcanzado }\end{array}$ & $\begin{array}{l}\text { Secundari } \\
o \\
\text { completo }\end{array}$ & $\begin{array}{l}\text { Terciario } \\
\text { completo }\end{array}$ & $\begin{array}{l}\text { Primario } \\
\text { incompleto }\end{array}$ & $\begin{array}{l}\text { Primaria } \\
\text { completa }\end{array}$ & $\begin{array}{l}\text { Primario } \\
\text { completo }\end{array}$ & $\begin{array}{l}\text { Secundaria } \\
\text { completa }\end{array}$ \\
\hline & $\begin{array}{l}\text { Actividad } \\
\text { laboral }\end{array}$ & $\begin{array}{l}\text { Empleado } \\
\text { público }\end{array}$ & Docente & $\begin{array}{l}\text { Trabajador } \\
\text { por cuenta } \\
\text { propia }\end{array}$ & $\begin{array}{l}\text { Ama de } \\
\text { casa }\end{array}$ & $\begin{array}{l}\text { Empleado } \\
\text { bancario }\end{array}$ & $\begin{array}{l}\text { Empleada } \\
\text { pública }\end{array}$ \\
\hline & $\begin{array}{l}\text { Propiedad } \\
\text { de la } \\
\text { vivienda }\end{array}$ & $\mathrm{Si}$ & $\mathrm{Si}$ & Si & $\mathrm{Si}$ & $\mathrm{Si}$ & $\mathrm{Si}$ \\
\hline \multirow[t]{4}{*}{ Camilo } & & Padre & Madre & $\begin{array}{l}\text { Abuelo } \\
\text { paterno }\end{array}$ & $\begin{array}{l}\text { Abuela } \\
\text { paterna }\end{array}$ & $\begin{array}{l}\text { Abuelo } \\
\text { materno }\end{array}$ & $\begin{array}{l}\text { Abuela } \\
\text { materna }\end{array}$ \\
\hline & $\begin{array}{l}\text { Máximo } \\
\text { nivel } \\
\text { educativo } \\
\text { alcanzado }\end{array}$ & $\begin{array}{l}\text { Secundari } \\
o \\
\text { incomplet } \\
o\end{array}$ & $\begin{array}{l}\text { Terciario } \\
\text { completo }\end{array}$ & $\begin{array}{l}\text { Primario } \\
\text { completo }\end{array}$ & $\begin{array}{l}\text { Secundario } \\
\text { completo }\end{array}$ & $\begin{array}{l}\text { Secundario } \\
\text { completo }\end{array}$ & $\begin{array}{l}\text { Terciario } \\
\text { completo }\end{array}$ \\
\hline & $\begin{array}{l}\text { Actividad } \\
\text { laboral }\end{array}$ & $\begin{array}{l}\text { Empleado } \\
\text { público }\end{array}$ & Docente & $\begin{array}{l}\text { Comerciant } \\
e\end{array}$ & $\begin{array}{l}\text { Ama de } \\
\text { casa }\end{array}$ & $\begin{array}{l}\text { Empleado } \\
\text { bancario }\end{array}$ & Docente \\
\hline & $\begin{array}{l}\text { Propiedad } \\
\text { de la } \\
\text { vivienda }\end{array}$ & $\mathrm{Si}$ & $\mathrm{Si}$ & Si & $\mathrm{Si}$ & $\mathrm{Si}$ & $\mathrm{Si}$ \\
\hline Marina & & Padre & Madre & Abuelo & Abuela & Abuelo & Abuela \\
\hline
\end{tabular}




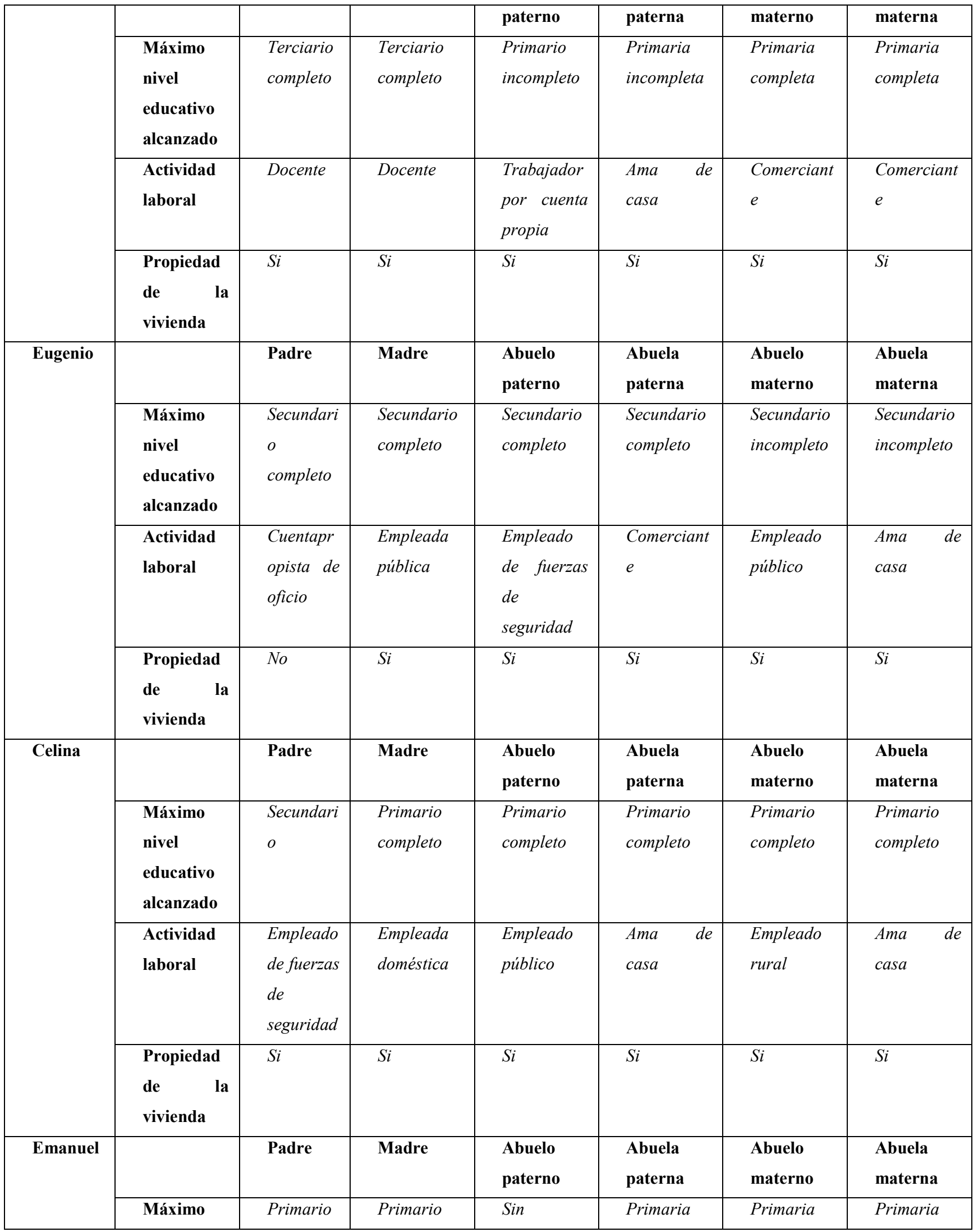




\begin{tabular}{|c|c|c|c|c|c|c|c|}
\hline & $\begin{array}{l}\text { nivel } \\
\text { educativo } \\
\text { alcanzado }\end{array}$ & completo & completo & $\begin{array}{l}\text { escolarizaci } \\
\text { ón }\end{array}$ & incompleta & completa & incompleta \\
\hline & $\begin{array}{l}\text { Actividad } \\
\text { laboral }\end{array}$ & $\begin{array}{l}\text { Empleado } \\
\text { rural }\end{array}$ & $\begin{array}{l}\text { Empleada } \\
\text { doméstica }\end{array}$ & $\begin{array}{l}\text { Empleado } \\
\text { rural }\end{array}$ & $\begin{array}{l}\text { Empleada } \\
\text { doméstica }\end{array}$ & $\begin{array}{l}\text { Comerciant } \\
e\end{array}$ & $\begin{array}{l}\text { Empleada } \\
\text { doméstica }\end{array}$ \\
\hline & $\begin{array}{l}\text { Propiedad } \\
\text { de la } \\
\text { vivienda }\end{array}$ & $\mathrm{Si}$ & $\mathrm{Si}$ & $\mathrm{No}$ & No & $\mathrm{Si}$ & $\mathrm{Si}$ \\
\hline \multirow[t]{4}{*}{ Ariel } & & Padre & Madre & $\begin{array}{l}\text { Abuelo } \\
\text { paterno }\end{array}$ & $\begin{array}{l}\text { Abuela } \\
\text { paterna }\end{array}$ & $\begin{array}{l}\text { Abuelo } \\
\text { materno }\end{array}$ & $\begin{array}{l}\text { Abuela } \\
\text { materna }\end{array}$ \\
\hline & $\begin{array}{l}\text { Máximo } \\
\text { nivel } \\
\text { educativo } \\
\text { alcanzado }\end{array}$ & $\begin{array}{l}\text { Primario } \\
\text { incomplet } \\
o\end{array}$ & $\begin{array}{l}\text { Primario } \\
\text { completo }\end{array}$ & $\begin{array}{l}\text { Sin } \\
\text { escolarizaci } \\
\text { ón }\end{array}$ & $\begin{array}{l}\text { Sin } \\
\text { escolarizaci } \\
\text { ón }\end{array}$ & $\begin{array}{l}\text { Primario } \\
\text { completo }\end{array}$ & $\begin{array}{l}\text { Primario } \\
\text { completo }\end{array}$ \\
\hline & $\begin{array}{l}\text { Actividad } \\
\text { laboral }\end{array}$ & $\begin{array}{l}\text { Empleado } \\
\text { rural }\end{array}$ & $\begin{array}{l}\text { Ama de } \\
\text { casa }\end{array}$ & $s / d$ & $\begin{array}{l}\text { Ama de } \\
\text { casa }\end{array}$ & $\begin{array}{l}\text { Comerciant } \\
e\end{array}$ & $\begin{array}{l}\text { Comerciant } \\
e\end{array}$ \\
\hline & $\begin{array}{l}\text { Propiedad } \\
\text { de la } \\
\text { vivienda }\end{array}$ & $\mathrm{Si}$ & $\mathrm{Si}$ & $s / d$ & No & $\mathrm{Si}$ & $\mathrm{Si}$ \\
\hline
\end{tabular}

Fuente: elaboración propia

Con respecto a las categorías laborales, realizamos las siguientes aclaraciones:

a) Empleado rural: refiere a trabajadores en relación de dependencia en el ámbito rural.

b) Productor rural: pequeños y medianos propietarios de hectáreas que producen por cuenta propia.

c) Comerciante: refiere a dueños de comercios.

d) Empleado público: trabajadores en relación de dependencia en los diferentes niveles de la administración pública.

e) Trabajador por cuenta propia: personas que realizan su trabajo de manera independiente. Dentro del grupo de referencia había albañiles, plomeros, parteras y modistas. 
A partir de estos datos se pueden notar regularidades y heterogeneidades en el grupo de referencia. En lo que respecta al máximo nivel educativo, se observa que la generación de los padres alcanzó mayores niveles que la de los abuelos. Con respecto a estos últimos, seis de los jóvenes no tuvieron ningún abuelo que haya terminado sus estudios primarios (y en algunos casos no fueron escolarizados nunca) -recordemos que el total de jóvenes fue 16-. Cuatro jóvenes tuvieron al menos un abuelo que completó el primario como máximo nivel. Otros cuatro tuvieron algún abuelo o abuela que finalizó la secundaria y solo dos tuvieron una abuela con terciario completo. Ningún abuelo llegó a tener estudios universitarios. Con respecto a los padres, no hubo ninguno que no haya sido escolarizado, solo tres jóvenes tuvieron un padre o madre que no completó la primaria. Siete de los jóvenes tienen padres que completaron el primario como máximo nivel. Dos tienen padres que llegaron hasta el nivel secundario y seis tiene padres con terciario completo. En el nivel universitario, dos tienen padres que terminaron sus carreras y dos que no completaron el nivel. De este modo, se puede apreciar una tendencia al aumento del capital escolar que va desde la generación de los abuelos hacia la de los padres.

Con respecto a las actividades laborales de abuelos varones, se puede notar que la mayoría se dedicaron a trabajos vinculados al agro (ocho de los jóvenes tuvieron abuelos empleados rurales y uno tuvo abuelos productores agropecuarios) y en menor medida algunos fueron empleados públicos, trabajadores de la construcción y comerciantes. Solo un joven tuvo un abuelo militar. Las abuelas mujeres en su mayoría fueron amas de casa (diez de los jóvenes así las referenciaron), empleadas domésticas y comerciantes. En relación al trabajo agropecuario, uno de los jóvenes tiene una abuela productora y una tuvo una abuela empleada rural. Dos jóvenes tuvieron abuelas docentes que llegaron a cargos directivos (directora y vicedirectora) en escuelas y uno tuvo una abuela empleada pública en el poder judicial. Dos tuvieron abuelas que se desempeñaban como trabajadoras independientes (partera y modista).

Con respecto al trabajo del padre, la principal actividad era el empleo rural (seis jóvenes), empleados públicos (tres jóvenes) y docencia (dos). Solo uno tenía un padre productor agropecuario. Las otras actividades fueron albañilería, policía, mecánico y profesional independiente (contador). Las madres fueron en mayor medida docentes (cuatro 
casos), amas de casa (cuatro) y empleadas domésticas (tres). En relación al contexto rural, una madre es productora agropecuaria y dos son empleadas rurales. Las otras dos madres trabajan de empleada pública y profesional en un hospital. En términos generales, se aprecia una notable continuidad laboral en el contexto agrícola entre abuelos varones y padres varones. Sin embargo, estos últimos obtuvieron más empleos en dependencias estatales (como administrativos o docentes) que los primeros. En las generaciones de mujeres, se puede analizar que las madres se desempeñaron mayormente fuera del ámbito doméstico familiar en comparación con las abuelas.

Sobre la propiedad de la vivienda, se puede apreciar que la mayoría de padres y abuelos son (o han sido) propietarios de la vivienda en donde residen. Solo cuatro de los

jóvenes tiene algún padre o madre que no es propietario de la vivienda. Con respecto a los abuelos, siete jóvenes tuvieron alguno de sus abuelos (maternos o paternos) que no son (o fueron) propietarios de la vivienda. Cabe mencionar que en algunos pocos casos, hay padres y abuelos que poseen más de una vivienda bajo su propiedad. En este sentido, esta variable es la que se muestra más constante en términos intergeneracionales.

Con la descripción de estos datos hemos pretendidos brindar algunos elementos sobre la situación económica y educativa de las familias que permita analizar mejor las experiencias de jóvenes que presentaremos a continuación.

\subsection{Quedarse en Roque Pérez}

Si bien esta tesis está centrada en las experiencias de jóvenes que se fueron a estudiar a La Plata, consideramos importante realizar un análisis breve sobre algunas situaciones de aquellos que no migraron. Es decir, los jóvenes que se quedan en Roque Pérez una vez terminada la secundaria o que se van a estudiar a otra ciudad pero regresan a las pocas semanas. Para realizar este análisis tomamos como fuentes los relatos de jóvenes que se quedaron en Roque Pérez y también los de jóvenes migrantes sobre sus amigos, familiares o compañeros que no migraron. Sobre todos estos relatos nos detendremos a caracterizar dos situaciones que aparecieron con regularidad. La primera refiere a los 
sujetos que no deseaban migrar y prefirieron quedarse en Roque Pérez una vez terminada la escuela secundaria. En algunos casos se fueron a La Plata pero decidieron volver enseguida porque la ciudad capital no les gustó para nada. La segunda situación alude a aquellos que, deseando irse a otra ciudad, vieron truncado el proyecto migratorio por diferentes razones o tuvieron que regresar a Roque Pérez antes de lo planeado.

En primer lugar, es necesario señalar que no todos los jóvenes deciden irse de Roque Pérez una vez que terminan la escuela secundaria. Muchos se quedan a estudiar carreras, principalmente terciarias, en la localidad o en los partidos vecinos y también consiguen empleo. A varios les gusta la vida del "pueblo" y no desean irse a vivir lejos. Ariel, un joven de 25 años, no quería irse de Roque Pérez luego de terminar la escuela secundaria pero, como muchos de sus amigos se iban a La Plata, decidió hacer lo mismo. Se fue en febrero del año siguiente y se volvió a Roque Pérez a las pocas semanas. La capital provincial no le había gustado para nada. El ruido, la gente y los autos lo habían “abrumado". Él se autodenomina como un "pibe de pueblo" a quien le gusta la vida en un lugar más “tranquilo y familiar”. En Roque Pérez consiguió trabajo, primero en el comercio de un conocido de su papá y luego en la municipalidad. Ariel cuestiona la idea de que los jóvenes "deben irse de Roque Pérez para tener un mejor futuro" porque eso supone que "el único camino posible para progresar es ir a la facultad" (nos detendremos sobre la categoría nativa de "progreso" más adelante).

Al igual que Ariel otros jóvenes sostuvieron que irse a estudiar no era el "único camino posible" sino que eso dependía de los proyectos de vida que tuviera cada persona. La oferta de educación terciaria regional, que describimos en el capítulo 1, es valorada por muchos como una posible continuidad de sus estudios sin tener que salir de Roque Pérez. Esto posibilita la apuesta por aumentar el capital escolar (aunque no sea con titulación universitaria) sin tener que migrar. Principalmente las carreras vinculadas con el mercado agropecuario y la docencia en los niveles inicial, primario y secundario aparecen como las que habilitan mayores salidas laborales.

Es interesante señalar los modos en que los jóvenes que se fueron a estudiar se refieren sobre aquellos que no se trasladaron. Muchos de los que estaban estudiando en La Plata atribuían sentidos diversos a sus amigos, familiares o compañeros de escuela que no 
se habían ido a estudiar. Uno de ellos era el reconocimiento de la existencia de diferentes proyectos de vida no asociados a la apuesta por la profesionalización universitaria. Otro se relacionaba con la imposibilidad de "progresar" sin este capital escolar y otro estaba relacionado con la idea de que en Roque Pérez la salida posible para quien no se va a estudiar es conseguir un empleo y formar una familia "tradicional". Así varios jóvenes migrantes relataban que sus amigos que no migraron, se pusieron en pareja, tuvieron hijos y buscaron un empleo que les otorgue cierta estabilidad económica.

La segunda situación que abordaremos es la de algunos jóvenes que desean irse a estudiar a otra ciudad pero las condiciones de posibilidad para desarrollar el proyecto migratorio no son favorables. Más adelante analizaremos que allí se configura una lógica del "sacrificio" en quienes deben superar las adversidades para poder irse. Aquí podemos ver la historia de Emanuel, un joven de 28 años, que se fue a estudiar a La Plata y luego de un episodio de robo, decidió regresar a Roque Pérez. Esta situación lo angustió mucho porque sintió truncado su proyecto para "progresar". Hijo de un trabajador rural y una empleada doméstica, Emanuel abandonó la escuela secundaria cuando tenía 18 años porque había conseguido trabajo en la empresa avícola de la localidad. Su familia se encontraba en una mala situación económica y su nuevo trabajo le permitía cierta solvencia. El dejar la escuela no trajo aparejado abandonar el contacto con sus amigos del secundario, sino que seguía participando en todas las actividades y espacios de diversión, nocturnidad y recreación con ellos. No los tenía como compañeros de escuela pero si como compañeros de "joda". El problema llegó cuando sus compañeros egresaron a fin de año y, muchos de ellos se fueron a estudiar a otra ciudad. Emanuel sintió que se quedaba "estancado" y esto lo llevó a proponerse terminar la escuela, lo que consiguió dos años después.

Cuando terminó la secundaria decidió irse a estudiar a La Plata y, para ello, tuvo que ahorrar y conseguir empleo en la capital provincial. Durante las mañanas estaba en una casa de comida y luego cursaba por las tardes. Una noche mientras volvía al Centro de Estudiantes de Roque Pérez, en donde vivía, lo asaltaron, lo golpearon y le robaron. Este episodio fue crucial en su vida y decidió regresar a Roque Pérez interrumpiendo sus estudios. El miedo a la "ciudad peligrosa” lo obligó a anticipar su retorno. Emanuel regresó 
a su localidad natal con mucha frustración después de todo el "sacrificio" que había hecho. Se puede ver en su historia un proyecto de profesionalización que queda trunco.

Otro de los condicionantes que incide en que los jóvenes tengan que regresar antes de finalizar sus estudios es la situación económica familiar. Varios de los jóvenes que se encontraban en La Plata comentaban de conocidos suyos que debieron volverse a Roque Pérez porque sus padres habían perdido el empleo que tenían o no les alcanzaba el dinero para mantenerlos estudiando allí. Veremos más adelante que varios de los sujetos realizaron diferentes estrategias para superar estos condicionantes y poder sostener sus vidas en La Plata. En el próximo apartado nos detenemos en los jóvenes que se fueron a vivir a La Plata y que pudieron sostenerse allí.

\subsection{Irse a La Plata}

En esta sección abordamos los sentidos que se atribuyen al proyecto de irse a estudiar a La Plata. Allí confluyen deseos personales y también expectativas y estrategias familiares $^{85}$ en torno al aumento del capital escolar de los miembros jóvenes. Algunos de estos supieron "desde siempre” que se irían a estudiar. Como señalaba Lucía, para ella irse a La Plata era un "hecho", algo indiscutido dentro de su familia. Sus hermanos lo habían realizado con anterioridad y también era el deseo de sus padres quienes se encargaban de los gastos que implicaba la vida en La Plata. Para otros, en cambio, la migración implicó buscar un trabajo para poder costear los gastos de vida en la nueva ciudad. En todas las historias se ponen en juego diferentes sentidos sobre el proyecto de "irse" a estudiar.

Subdividimos esta sección en cuatro. En la primera analizamos los sentidos en torno a la categoría nativa de "progreso" que fue utilizada como un horizonte o meta del proyecto

\footnotetext{
${ }^{85}$ Según Bourdieu: "Las estrategias educativas, de las cuales las estrategias escolares de las familias o de los niños escolarizados son un caso particular, son estrategias de inversión a muy largo plazo que no necesariamente son percibida como tales y no se reducen, como lo cree la economía del "capital humano", solo a su dimensión económica e incluso, monetaria; en efecto, ellas tienden, antes que todo, a producir los agentes sociales dignos y capaces de recibir la herencia del grupo, es decir, de transmitirla en su momento al grupo. Es el caso específico de las estrategias "éticas" que buscan inculcar la sumisión del individuo y de sus intereses al grupo y a sus superiores, y que por ese hecho, cumplen una función fundamental asegurando la reproducción de la familia que es ella misma el "sujeto" de la reproducción." (2002:6).
} 
migratorio. En segundo lugar nos detenemos en el análisis de la categoría de "sacrificio" con la que algunos explican sus experiencias de irse a La Plata. En tercer lugar analizamos las lógicas de merecimiento que se actualizan en base al estudio y, por último, analizamos un clivaje de género que atraviesa la decisión de migrar para estudiar.

\subsection{1 "Me voy para progresar": movilidad social y "enriquecimiento personal"}

Varios de los jóvenes sostuvieron que se fueron a estudiar a La Plata para "progresar". Identificamos dos sentidos sobre esta categoría: i) progresar en tanto mayor acumulación de experiencias de vida vinculado a una expectativa de "enriquecimiento personal" (no asociado a una dimensión económica); y ii) progresar en tanto mayor acumulación de capitales escolares acompañado de la expectativa de convertirlos en capital económico y simbólico.

El primer sentido que identificamos de la categoría de "progreso" está relacionado con el "enriquecimiento personal" más allá de la formación universitaria. Esta noción refiere a la posibilidad de nuevos aprendizajes relacionados a la vida fuera del "pueblo". Camilo, relataba que "gracias a Dios tuvo la oportunidad de conocer otra realidad que la del pueblo" haciendo referencia a la posibilidad de llevar adelante prácticas que, como vimos en el capítulo anterior, posibilitan el ejercicio de una condición juvenil diferente a la del lugar de origen. Otros jóvenes lo relataron como "poder ver el mundo" dando a entender una idea similar. De esta manera, la búsqueda de "progreso" no se limita solamente a una mejora en términos económicos sino también a la búsqueda de nuevas experiencias culturales, artísticas y políticas como también han señalado algunas investigaciones sobre migración estudiantil (Luchillo, 2006, Jensen y Perret, 2011, Gamallo y Núñez, 2013).

El segundo sentido, como dijimos, se relaciona a un relato de ascenso social vía la educación. Una de las jóvenes señalaba que decidió irse a La Plata para "progresar" porque tanto en Roque Pérez, o donde sea, "es imposible conseguir un buen trabajo sin título universitario". En términos más drásticos lo afirmaba Camilo cuyo padre, dueño de un comercio, le dijo que "debía estudiar si quería ser alguien en la vida". La titulación 
universitaria aparece como una condición central para el ascenso social, tanto como posibilidad laboral a futuro como por el prestigio que otorga. Como señala Bourdieu: "El título profesional o escolar es una especie de regla jurídica de percepción social, garantizado como un derecho. Es un capital simbólico, institucionalizado, legal (y ya no solamente legítimo)" (1984:296). En la sección "Volver", de este mismo capítulo, veremos también cómo el hecho de ser universitario reposiciona a los jóvenes en términos de capital simbólico en su localidad de origen.

Dentro de este segundo sentido que analizamos de "progreso" se actualiza un relato histórico que, en Argentina, ha vinculado a la educación universitaria con las posibilidades de movilidad social ascendente. El antropólogo Sergio Visacovsky (2014) sostiene que, durante la primera mitad de siglo $\mathrm{XX}$, se fue estableciendo un relato arquetípico sobre el ascenso social, principalmente de los migrantes internacionales que llegaban a Buenos Aires, que se constituyó como el relato de origen de la clase media en el país. La eficacia y la vigencia de ese relato radicaron en su capacidad de brindar un camino moral basado en valores como el esfuerzo y el trabajo duro que se sostiene hasta la actualidad.

Para que ese relato sobre el ascenso social cobrara fuerza, la universidad pública tuvo una centralidad especial al quedar asociada a una figura impulsora de la movilidad social y a las clases medias (Colabella y Vargas, 2013). Como sostiene Carli (2012) a diferencia de países como Brasil en donde las universidades públicas se formaron para las elites, en Argentina quedaron asociadas a las clases medias no solo por la gratuidad de las carreras sino por el ingreso irrestricto ${ }^{86}$. Incluso esta visión tuvo su legitimación científica de la mano de investigadores como Gino Germani (1950) que contribuyeron con sus resultados de investigación a fortalecer la asociación entre universidad y ascenso social de las clases medias (Visacovsky, 2014). Ese relato originario de la clase media es actualizado dentro de este primer sentido que analizamos sobre la categoría nativa de "progreso".

\footnotetext{
${ }^{86}$ Señala Carli: "Si ese es el devenir histórico de la universidad pública argentina durante la segunda mitad del siglo XX, una mirada comparativa con Brasil revela el peso de la selectividad a través del examen de ingreso. Según estudios comparados, mientras en Brasil la educación universitaria estuvo estrechamente ligada a la formación de elites, en Argentina se ha vinculado con la formación de clases medias y de una clase media movilizada entre los años cincuenta y setenta." (2012:71).
} 
"Progresar" significa así estudiar y conseguir un título que habilite el ejercicio de una profesión y posibilite una "vida mejor".

Es necesario mencionar, sobre la relación entre universidad y ascenso social, que varias investigaciones sobre estructura social y movilidad social en Argentina han argumentado que el acceso a la educación de nivel superior genera mejores oportunidades de vida, y particularmente de ingresos en los estratos sociocupacionales medios ${ }^{87}$ (Salvia, Pla y Quartulli, 2009; Chávez Molina y Gutiérrez Ageitos, 2009; Chávez Molina, 2013). Existe un marcado consenso entre investigadores (Kessler y Espinoza, 2007; Chávez Molina, 2013 y Fernández Melián, De la Fuente y Clemenceau, 2013) que las principales movilidades se producen dentro de estos sectores, mientras que los extremos de la estructura social (clases altas y pobres) suelen presentar mayor tendencia a la reproducción de la posición de origen. Estos hallazgos permiten analizar que la educación superior, dentro de los sectores medios, no solo constituye una expectativa de movilidad social sino también una posibilidad de realización de la misma.

Así como en el relato de origen de la clase media argentina, en donde los inmigrantes europeos llegaban al país con las expectativas de una vida mejor, en los jóvenes de esta investigación la movilidad en el espacio (particularmente la migración) también está acompañada de proyecciones de "progreso", tanto en términos de movilidad social como de "enriquecimiento personal". Como señala Chaves: "Pareciera que las migraciones en su movimiento geográfico traen siempre un desplazamiento en el espacio social pero, como bien sabemos, esto no se da necesariamente en las condiciones objetivas, lo que no le quita peso a su carácter simbólico, confirmatorio de la necesidad y el éxito de dicho traslado" (2016: 43).

\footnotetext{
${ }^{87}$ La construcción de estratos sociocupacionales para el análisis de las clases sociales varía de acuerdo a los estudios y continúa siendo una discusión dentro de las ciencias sociales. Un esquema que suele ser ampliamente utilizado es el de Susana Torrado (1998) que se conforma de la siguiente manera: 1) Clases altas (Directores de empresas) 2) Clases medias que se subdividen en autónomas (profesionales en función específica, propietarios de pequeñas empresas y pequeños productores autónomos) y asalariada (Profesionales en función específica, Cuadros técnicos y asimilados y empleados administrativos y vendedores) 3) Clase obrera subdividida en autónoma (trabajadores especializados autónomos), asalariada (obreros calificados y obreros no calificados) y trabajadores marginales (peones autónomos y empleados domésticos).
} 


\subsection{2 "Sacrificarse"}

Algunos jóvenes refirieron al "sacrificio" como uno de los componentes de la apuesta a una trayectoria de movilidad social. Esta categoría fue utilizada por quienes se reconocen principalmente de familias de "clase media baja". Es interesante señalar que el apelativo de "baja" fue utilizado para distinguirse de otros (amigos o compañeros de escuela) que eran de "clase media". Así algunos comentaban que sus amigos de "clase media sabían desde siempre" que se iban a ir a estudiar a la universidad cuando terminaran la secundaria porque era algo "normal" en la familia. En casi todos los casos, los padres habían estudiado en la universidad y financiarían los gastos de sus hijos para que se graduaran. En cambio, los de "clase media baja" sabían que además de estudiar deberían trabajar para autosostenerse en La Plata y eso implicaba un "sacrificio".

Esteban, un abogado de 36 años que se fue a estudiar a La Plata en el año 2001 fue uno de los que relató su experiencia de irse a estudiar a La Plata como un gran "sacrificio". $\mathrm{Su}$ padre era productor agropecuario y su actividad estaba en bancarrota a raíz de la situación económica nacional que, ese mismo año, llegó a una fuerte crisis generalizada en el mes de diciembre. El padre le dijo a Esteban que pensara en estudiar alguna carrera corta o aprender algún oficio porque no podrían seguir viviendo de su producción agropecuaria. El joven no tenía pensado irse a estudiar hasta que esa conversación con su padre lo hizo cambiar de opinión. La crisis nacional y su repercusión en la actividad laboral familiar constituyó un tourning point ${ }^{88}$ en su vida que lo obligó a redireccionar su trayectoria abandonando la producción agropecuaria e invirtiendo en capital escolar.

Decidió irse a La Plata para estudiar Derecho y vivió un tiempo en la casa del padre de un conocido suyo que se ubicaba en una localidad de la periferia platense. Después se mudó a una casa que se encontraba dentro de un estacionamiento. A la facultad iba caminando para ahorrar el dinero del transporte. Él siempre se las "arregló" para encontrar un lugar donde vivir sin tener que pagar y buscaba "changas" todo el tiempo para poder

\footnotetext{
${ }^{88}$ Utilizamos este concepto desde el enfoque del curso de vida que lo define como eventos que provocan modificaciones e introducen virajes en la dirección del curso de vida. Estos solo pueden ser analizados contemplando cada historia particular. Para un sujeto un tourning point puede surgir a partir de la muerte de un familiar o algún otro evento significativo que le implique un cambio de situación en el curso de vida (Blanco, 2011).
} 
sostenerse en la ciudad. Con un amigo trabajaban pintando viviendas, también trabajó varios años en el buffet de su facultad y con eso tenía garantizados los almuerzos. Sostenerse en La Plata fue un "sacrificio inmenso" pero logró terminar su carrera 7 años después. A diferencia de muchos de sus compañeros que podían invertir todo el tiempo en estudiar, él debía trabajar y eso le permitió construir una cierta narrativa heroica (Vargas, 2014) sobre su propia biografía.

La lógica del sacrificio se inscribe dentro de una narrativa en donde el padecimiento o las privaciones se justifican en pos de conseguir un logro o un fin posterior. Como sostiene Loic Wacqant en su investigación sobre boxeadores: "El sacrificio es al mismo tiempo medio y fin, obligación vital y misión orgullosa, exigencia práctica y obsesión etiológica" (2006:149). El "sacrificio" se erige en una clave de lectura (Bover, 2016) que permite justificar un camino de sufrimientos y resignaciones a cambio de una meta o de un bienestar futuro. En nuestra investigación analizamos que el "sacrificio" se vincula con tener que "rebuscárselas" trabajando para poder costear la estadía en La Plata y los estudios. A diferencia de otros que pueden gozar de la moratoria social financiada por sus familias, los que "se sacrifican", quienes han acumulado desventajas (Saraví, 2006) a lo largo de sus vidas, deben financiar sus propios recorridos universitarios con el objetivo de obtener el ansiado título.

Si en Esteban se puede analizar su relato como una narrativa heroica, en Emanuel la historia es diferente. Como ya relatamos, él tuvo que trabajar para ahorrar dinero y poder irse a La Plata y también tuvo que trabajar en la capital provincial. Durante las mañanas estaba en una casa de comida y luego cursaba por las tardes. Una noche mientras volvía al Centro de Estudiantes de Roque Pérez donde vivía, lo asaltaron, lo golpearon y le robaron. Este episodio fue crucial en su vida y decidió regresar a Roque Pérez interrumpiendo sus estudios. Emanuel regresó a su localidad natal con mucha frustración por no haber conseguido el título profesional después de todo el "sacrificio" que había hecho.

\subsection{3 "Merecer estudiar en La Plata": el estudio como orden moral}


En este apartado analizamos la configuración de una lógica de merecimiento en base al estudio, que identificamos a partir de las frases nativas. "no todos merecen estudiar en La Plata" y "menos que sus familias los sostengan económicamente". Las lógicas de merecimiento organizan las relaciones sociales, permitiendo justificar la distribución y diferenciación de los sujetos entre quienes son merecedores de algo y quienes no a partir de sus propias acciones y comportamientos (Chaves, Fuentes y Vecino, 2016). A partir de la lógica de merecimiento que analizamos se construyen, a grandes rasgos, dos tipos de sujetos diferentes; los que "estudian en serio" y los que "están de joda”. Los primeros son valorados positivamente como aquellos que "utilizan bien" los recursos que sus familias invierten en ellos, mientras que los segundos son negativamente valorados como aquellos que "se aprovechan del esfuerzo de sus familias" para estar divirtiéndose en La Plata.

Se identifica por un lado una positiva valoración del "esfuerzo" propio por llevar adelante y cumplir con los requerimientos de la universidad y además se conjuga, en la mayoría de los casos, con el reconocimiento del "esfuerzo" por parte de los grupos familiares para poder sostenerlos. Se puede ver que la red familiar que analizamos en el capítulo 2, configura una serie de acuerdos y responsabilidades entre los jóvenes que están en La Plata y sus familias, que funcionan como sistemas de reciprocidad. Como señalara Marcel Mauss (2009) en todas las situaciones de intercambio, cuando alguien brinda algo se establece un compromiso moral por devolver en algún momento. Si la familia es la que brinda el sostén económico ¿qué deben devolver los jóvenes? Devuelven a sus familias aprobando exámenes y avanzando en las cursadas de sus carreras. La posibilidad de no cumplir, de no poder hacerlo, es muchas veces motivo de fuertes angustias.

Camilo, por ejemplo, contaba que cuando comenzó a estudiar su carrera en la Facultad de Periodismo y Comunicación Social, le costó mucho y le fue mal en sus primeros exámenes. Esta situación lo angustiaba porque sabía que sus padres estaban haciendo un "esfuerzo grande" para sostenerlo en la ciudad de La Plata y, hasta en un momento, decidió que regresaría a Roque Pérez. Fueron varios meses los que vivó con la "culpa" de no poder avanzar en la carrera y, al terminar el primer año, se lo dijo a su mamá. Ella lo escuchó y le dijo que "todas las personas podían tener un mal año" alentándolo a no abandonar los estudios. Acordaron que, como la carrera duraba cinco años y él ya había 
transcurrido uno, le financiaría cuatro años más. Camilo regresó a La Plata y de a poco fue "enganchándole el ritmo" a la universidad. Cuando su madre vio que el joven iba transitando con menos problemas la facultad, le dijo que hiciera la carrera "tranquilo" y que ella lo "bancaría" hasta que terminara.

La situación de Celina también nos permite analizar estas dinámicas de intercambio. Cuando comenzó a cursar el segundo año de su carrera en Trabajo Social, se dio cuenta que podría haber "metido" más materias que las que había aprobado y se sintió culpable por haber estado de “joda” durante el primer año en que estuvo en La Plata. Sabía que para sus padres era un "esfuerzo" que ella estuviera viviendo en la capital provincial y decidió “esforzarse" más en la facultad. Al año siguiente, cursó una mayor cantidad de materias y limitó sus salidas nocturnas con amigos para poder dedicar más tiempo al estudio.

A partir de estas historias se puede analizar el modo en que se construye una diferenciación entre quienes se "esfuerzan" en la universidad y quienes no, los cuales son peyorativamente categorizados, muchas veces, como los que "están de joda". El "estar de joda" es algo negativizado incluso por aquellos que reconocen haber estado en esa situación. Los que "están de joda" son aquellos que no "merecen" estar viviendo en La Plata porque se "aprovechan" del sostén económico que les brindan sus padres incumpliendo su papel dentro del sistema de reciprocidad.

\subsection{4 "Hay que irse del pueblo para no ser maestra jardinera o niñera": género y proyecciones de movilidad social}

En una escena de la película Eva Perón ${ }^{89}$ podemos ver a la popular primera dama argentina, enferma y recostada en su cama, hablando con su modista personal sobre su aspiración a la vicepresidencia de la nación. Está enojada porque sus enemigos políticos la juzgan por su pasado. Le cuestionan si “se levantó” (o no) al

\footnotetext{
${ }^{89}$ Película argentina dirigida por Juan Carlos Desanzo y estrenada en 1996. El personaje de Eva Perón fue interpretado por la actriz Esther Goris.
} 
cantante Agustín Magaldi ${ }^{90}$ para escaparse de Junin, en ese entonces un pequeño pueblo en la Provincia de Buenos Aires. Evita mira a su interlocutor fijamente y exclama: "¿y qué? ;Yo me hubiera levantado al mismísimo petiso orejudo con tal de rajarme de ahí! Con tal de no estudiar dactilografía o corte y confección”. Ese parecía ser el destino para la mujer de pueblo en los años 30. Su sueño era ser actriz, no le quedaba otra que irse.

(Fragmento de escena en Eva Perón, dirigida por Juan Carlos Desanzo, 1996)

A lo largo de la investigación pudimos identificar que el clivaje de género atraviesa en muchos casos, la decisión de irse a estudiar vinculado con la oferta laboral diferencial que hay en Roque Pérez para varones y mujeres. Varias de las jóvenes argumentaron que, sin formación profesional no podrían tener trabajos con buenos salarios. Liliana sostenía que las mujeres en Roque Pérez tienen dos grandes opciones cuando finalizan los estudios secundarios, irse a estudiar a otra ciudad o quedarse en la localidad a trabajar como niñera o empleada en un comercio o, en todo caso, estudiar alguna carrera terciaria en la zona que "casi siempre termina en maestra jardinera". ${ }^{91}$ En cambio, para los varones que no quisieran irse a estudiar la oferta laboral era diferente.

¿En qué radica esta diferencia que señalan varias jóvenes? Al ser Roque Pérez una localidad fundamentalmente agrícola ganadera, las principales fuentes de trabajo son las empresas porcina y avícola. Estos establecimientos emplean mayor fuerza de trabajo masculina. Los jóvenes varones tienen más posibilidades de conseguir empleos agrícolas con mayores remuneraciones económicas que las mujeres. En este sentido, la estructura de oportunidades $^{92}$ (Kessler y Espinoza, 2007) de acuerdo al género son desiguales en el lugar de origen y eso conlleva a que muchas mujeres sientan una mayor necesidad de migrar. En

\footnotetext{
${ }^{90}$ Algunas biografías sobre María Eva Duarte de Perón (1919-1952) sostienen que fue este artista quien la lleva hacia la ciudad de Buenos Aires cuando tenía 15 años. Esta versión además ha sido utilizada en musicales y películas basadas en su vida. Otros biógrafos refutan esta idea.

${ }^{91}$ Es necesario señalar que en una charla con funcionarios municipales de Roque Pérez, ambos comentaron que la oferta de carreras terciarias creció mucho durante los últimos años. Esto también fue afirmado por varios de los jóvenes. Sin embargo, en el período en que los sujetos que participaron de nuestra investigación migraron, la oferta no era tan numerosa.

92 El concepto de estructura de oportunidades refiere la capacidad de vinculación de los sujetos con los canales de movilidad y con las "vacantes" creadas por la estructura económica, la dinámica demográfica o los procesos migratorios (Kessler y Espinoza, 2007).
} 
este sentido, numerosas investigaciones (Parella Rubio, 2012, Courtis y Pacceca, 2010; Pedone, Romero y Gil Araujo, 2012) sobre migraciones han analizado un fenómeno similar en otros territorios que vinculan los flujos migratorios de acuerdo al género con las condiciones de las localidades de origen.

Una de las jóvenes comentaba que para ella Roque Pérez era "su lugar en el mundo" y sentía que no quería irse lejos de su familia pero sabía que allí no podría conseguir un trabajo que le gustara sino estudiaba una carrera en otro lugar. En este sentido, muchas de las jóvenes mujeres sienten que ocupan una posición desfavorable en la distribución de actividades laborales de acuerdo al género, en una localidad agrícola ganadera en donde la mayor cantidad de puestos de trabajo son para los varones. La migración estudiantil aparece como una práctica necesaria para, en el caso de volver a Roque Pérez, conseguir un puesto laboral con mayores salarios y prestigio. Con respecto a los varones, si bien el trabajo en el ámbito agrícola y ganadero aparece como la fuente laboral más "segura", la opción de migrar es preferida por aquellos que no quieren dedicarse a esas actividades.

Este clivaje de género se pudo analizar también durante la realización de un taller con estudiantes secundarios del último año de la Escuela Secundaria Básica $N^{\circ} 1$ (conocida popularmente como la "media"). ${ }^{93}$ En este taller quisimos indagar, entre otros aspectos, si para los estudiantes que iban a egresar la migración estudiantil aparecía como un proyecto a desarrollar. Fueron las mujeres quienes tenían más decidida la idea de migrar, argumentando que sus posibilidades laborales en Roque Pérez eran muy reducidas. De los varones que participaron, casi todos trabajaban con sus familias (en trabajos de albañilería, jardinería o en la cosecha) y solo dos tenían pensado migrar para estudiar.

\subsection{Volver a Roque Pérez (o no): proyecciones}

La pregunta sobre dónde se establecerían (quedarse en La Plata, regresar a Roque Pérez o irse a otro lugar) cuando terminaran sus carreras no tuvo una respuesta única. Aquellos jóvenes que se encontraban al inicio de sus carreras argumentaban que era

\footnotetext{
${ }^{93}$ Esta actividad fue realizada en conjunto con la directora de esta tesis el 13 de noviembre del 2015.
} 
"demasiado pronto" para pensar en ello. Los que se encontraban próximos a graduarse sostenían que esa decisión los "preocupaba bastante". De los que habían egresado, tres vivían en La Plata y una en Roque Pérez. La mayoría de los jóvenes se imaginaban regresando a Roque Pérez una vez graduados. El motivo principal era que lo consideraban un "lugar ideal" para establecerse y formar una familia. Como hemos analizado en el imaginario de "Pueblo como lugar de las buenas costumbres", Roque Pérez es visto como un espacio "más sano" para la infancia y también para el desarrollo de la vida adulta.

Por otro lado, varios sostenían que cuando iban a Roque Pérez se sentían reconocidos de otra manera por los demás a partir de ser estudiantes universitarios. Así lo contaba Vanesa, estudiante de Medicina de primera generación de universitarios, que cuando iba de visita a Roque Pérez sus familiares y conocidos le consultaban sobre posibles enfermedades y medicaciones que podrían tomar. La joven bromeaba diciendo que "para ellos es como que ya soy médica". También otros jóvenes contaban que muchas personas conocidas en Roque Pérez valoraban muy positivamente que ellos estuvieran estudiando en La Plata. Podemos interpretar que el capital escolar se convierte en capital simbólico en el contexto de relaciones del lugar de origen (Bourdieu, 1979).

Una de las tensiones que aparece para aquellos que quieren regresar a Roque Pérez una vez graduados es si podrán ejercer su profesión. Así lo comentaba Esteban quien se quedó en La Plata cuando se recibió de abogado porque en Roque Pérez no le era sencillo conseguir trabajo. Algo similar le pasaba a Camilo a quien le "encanta" Roque Pérez pero "sabía" que se le iba a volver muy difícil poder trabajar como periodista allí. Algo diferente le pasaba a Liliana, estudiante de veterinaria, puesto que ella apostaba a conseguir trabajo dentro de la industria ganadera. En este sentido, las profesiones relacionadas con el mercado agropecuario o la docencia son las consideradas con mayores posibilidades de inserción en el mercado laboral de Roque Pérez.

Una menor proporción de jóvenes sostuvieron que no regresarían a Roque Pérez porque habían encontrado su "lugar" en La Plata. Allí realizaban sus actividades diarias y se habían acostumbrado al "ritmo" de la ciudad. Algo a destacar en estos relatos es que con el tiempo fueron notando que la capital provincial les parecía más un "pueblo grande" que una "ciudad". Noelia comentaba que, si bien no volvería a vivir en un "pueblo tan chico" 
como Roque Pérez tampoco viviría en una ciudad tan "enquilombada" como Buenos Aires. Ella "había crecido en un pueblo" y le gustaba que los lugares fueran "tranquilos". En La Plata había encontrado un lugar donde poder hacer "muchas cosas" pero que tenía un aspecto más de "pueblo".

\subsection{Autopercepción de clase y apuesta por la movilidad social: conclusiones}

En este capítulo nos hemos detenido en las expectativas, proyecciones $\mathrm{y}$ realizaciones de movilidad social vinculados a la universidad, identificando las maneras en que estos aspectos atraviesan las decisiones de los jóvenes sobre quedarse, irse y regresar a Roque Pérez. La búsqueda de capital escolar se vuelve central en las trayectorias de los jóvenes como factor que motoriza la movilidad social ascendente, tanto porque puede convertirse en capital económico a futuro y también porque se convierte en capital simbólico, sobre todo en el lugar de origen. Pero además la movilidad social se relaciona con la acumulación de experiencias de vida que posibilitan un "enriquecimiento" y “crecimiento" a nivel personal.

En esta conclusión queremos detenernos en los sentidos que aparecen en torno a la categoría "clase media" con la cual casi todos los jóvenes identifican su pertenencia de clase. Como ya hemos señalado al principio, la categoría de "clase media" funciona como un significante que permite identificarse y diferenciarse de otros. Sin embargo, hemos analizado que esta no es homogénea dentro del grupo de referencia. Es así que muchos se perciben como integrantes de "clase media" y otros de "clase media baja" o como exclamaba una joven hija de un trabajador rural "clase media baja baja". Estas dos categorías parecieran construir dos grupalidades. ¿En qué consisten estas diferencias?

Los jóvenes de "clase media", desde la óptica de los otros, parecieran semejarse a los "herederos" "94 que describían Bourdieu y Passerón (2003). Provienen de familias con

\footnotetext{
${ }^{94}$ Los sociólogos franceses Pierre Bourdieu y Jean Claude Passeron analizaron el impacto del origen social en las trayectorias educativas de universitarios en Francia durante los años sesenta. Aquí los investigadores construyeron la figura del "heredero" para dar cuenta de que los estudiantes provenientes de las clases de mayor capital económico y cultural, eran los más exitosos en la institución universitaria.
} 
capitales económicos suficientes como para financiar la continuidad de los estudios universitarios y sostener un estadio de moratoria social. En muchos casos, también provienen de familias con amplio volumen de capital cultural aunque esto no siempre es una constante. Para estos jóvenes el proyecto migratorio es algo naturalizado en el curso de vida. Una experiencia que "siempre supieron que llegaría luego de terminado el secundario" y que podría entenderse como un tipo particular de habitus migratorio ${ }^{95}$. En varios casos porque realizar estudios universitarios es algo naturalizado en la familia (generalmente en hijos de profesionales) y en otros casos, aunque las familias no tengan estudios universitarios, apuestan a que sus hijos logren ese capital escolar. Estos jóvenes migrantes no solo crecieron en un contexto en donde el discurso de la migración los atravesó sino que fueron testigos de la experiencia migratoria de sus hermanos mayores o de sus amigos.

En cambio, aquellos que se autodenominan de "clase media baja" pertenecen a familias que, en términos generales, no poseen el capital económico necesario para financiar los estudios de sus hijos. En estos jóvenes, la adjetivación de "baja" puede interpretarse como algo que está por debajo de una cierta norma. A diferencia de los jóvenes de "clase media" que pueden gozar del privilegio de la moratoria social porque sus familias cuentan con los capitales económicos necesarios, los de "clase media baja" deben conseguir los recursos para poder sostenerse como estudiantes y esto posibilita la construcción de una lógica del "sacrificio" que hemos analizado con anterioridad.

Estos dos grandes grupos funcionan como categorías que dan sentido a las experiencias (propias y de otros) pero, como hemos visto, no pueden reducirse a esta tipología puesto que son más variadas y heterogéneas. A pesar de las diferencias atribuidas a cada grupo podemos encontrar una notable similitud que radica en la apuesta por la acumulación de capital escolar y la representación del "progreso". Es decir, en la asociación entre acumulación de capital escolar y movilidad social ascendente podemos encontrar similitudes en todos los jóvenes. Estudiar y profesionalizarse aparecen como

\footnotetext{
${ }^{95}$ Las investigadoras Laura Golpe y Luisa Bidegain (1998) en sus estudios sobre migraciones internas desarrollan esta categoría a partir de la noción de "habitus" de Pierre Bourdieu. De este modo, los significados sociales sobre la migración son incorporados a los esquemas de percepción y acción de los sujetos, lo cual establece una serie de principios ordenadores de sus prácticas a partir de la infancia.
} 
estructuradores en términos de proyección del curso de vida para todos ellos. Para aquellos que se van a La Plata, luego de terminado el secundario, la movilidad geográfica aparece como la posibilidad de obtener una titulación universitaria; para los que se quedan en Roque Pérez, la apuesta por capital escolar (en institutos terciarios o extensiones de universidades en la zona) también suele ser una prioridad. Retomaremos estas afirmaciones en la conclusión de la tesis. 


\section{CONCLUSIONES FINALES}

El objetivo que nos propusimos en esta tesis fue comprender la relación entre migración de localidad, movilidad en el curso de vida y condición estudiantil universitaria. Para ello analizamos las experiencias de jóvenes originarios de Roque Pérez que se trasladaron a La Plata para realizar estudios superiores. En esta última sección presentamos las conclusiones finales de la tesis, retomando elementos de cada capítulo y discusiones teóricas del campo de las ciencias sociales. A los fines de organizar la presentación, formulamos cuatro discusiones finales: i) La relación entre imaginarios urbanos juveniles, estilos de vida y prácticas migratorias; ii) La discusión sobre moratoria social; iii) Los procesos de autonomización en el curso de vida; y iv) Los procesos de movilidad social asociados a la acumulación de capital escolar. Luego de desarrollar cada una de estas, presentamos dos líneas de trabajo para profundizar en futuras investigaciones sobre el tema.

La primera conclusión es que notamos que los imaginarios urbanos sobre las localidades se asocian a determinados estilos de vida y ello incide en las prácticas migratorias de los sujetos. De esta manera, los imaginarios analizados sobre Roque Pérez (Pueblo, Pueblo como Lugar de Buenas Costumbres, Pueblo como Infierno Grande y Pueblo Tranquilo) actualizan un ideal de estilo de vida anclado en la noción de comunidad que, como vimos, se asocia a valores de afectividad, lazos estrechos y conocimiento mutuo entre sus miembros (Nisbet, 1969). En cambio, tres de los imaginarios sobre La Plata (Ciudad, Ciudad Peligrosa, Ciudad Universitaria) remiten a una idea de sociedad caracterizada por vínculos más impersonales y por la actitud de reserva (Simmel, 1986). Solo el imaginario de Pueblo Grande articula características de los otros imaginarios. Estos estilos de vida y valoraciones asociadas a cada localidad posibilitan que las mismas se configuren en lugares específicos para vivir determinados momentos del curso vital. Recordemos que el concepto de lugar refiere a sentimientos de apropiación, valoración y pertenencia del espacio por parte de los grupos sociales (Torres, 2012) y, en este sentido, Roque Pérez y La Plata se constituyen en lugares para transitar determinados momentos de la vida. Roque Pérez aparece como el escenario privilegiado para el desarrollo de la 
infancia y de la vida adulta donde juega un papel central el estilo de vida comunitario cargado de afectos, familiaridad y cuidados que se ligan a las representaciones de la familia y la infancia como instituciones a proteger. De este modo, el "pueblo" se configura en el espacio óptimo para que los niños crezcan fuera de los peligros asociados a la "ciudad". Tanto para ser niño como para ser padre o madre de familia, el "pueblo" de Roque Pérez se constituye en un escenario idealizado para vivir.

En cambio, La Plata aparece como el lugar por antonomasia para vivenciar la condición juvenil estrechamente ligada al modelo de la moratoria social, sobre el que discutiremos en la próxima conclusión. La capital bonaerense con su oferta de circuitos de sociabilidades políticas, artísticas, educativas y recreativas, sumado a la posibilidad de la autonomía de vivienda familiar, se configura en el lugar privilegiado para vivenciar la experiencia juvenil estudiantil universitaria. De este modo, podemos interpretar que las prácticas migratorias de los sujetos se vinculan estrechamente con los estilos de vida asociados a cada localidad. Para decirlo en una frase ilustrativa, se va a La Plata para ser joven estudiante universitario y se vuelve a Roque Pérez para formar una familia.

Sobre esta primera conclusión debemos realizar dos aclaraciones. La primera es que la misma no se aplica de manera lineal a las experiencias de todos los jóvenes. Varios de ellos no migraron a La Plata porque querían vivenciar una experiencia juvenil asociada al modelo de la moratoria social, sino simplemente para estudiar carreras que en Roque Pérez no podían. También hay jóvenes que no quisieron regresar a Roque Pérez para formar sus familias. Pero, hecha esta aclaración, es interesante destacar la asociación entre imaginarios, estilos de vida y los modos en que estos orientan las prácticas migratorias de muchos de los sujetos. La segunda aclaración es que las prácticas migratorias no solo se relacionan con los imaginarios sino también con otros elementos que hemos analizado como la existencia de redes (tanto en el lugar de origen como el de destino), la apuesta por el capital escolar y el prestigio asignado a la Universidad Nacional de La Plata, entre otras.

La segunda conclusión se vincula con las discusiones en torno a la categoría de moratoria social dentro del campo de estudios sobre juventudes. Como ya hemos mencionado, esta refiere a un período de tiempo en donde los sujetos vivirían sin las responsabilidades propias del mundo adulto, postergando esos roles y dedicándose al 
estudio y al ocio. Esta noción tuvo un impacto central en la construcción de una imagen hegemónica sobre el sujeto joven que podría resumirse en el enunciado de que es joven todo aquel sujeto que pueda gozar de esta condición. Como ha señalado Eric Hosbawn (2012) la emergencia de la juventud como actor social y político, a mediados de siglo XX, no puede desligarse de fenómenos como la prolongación de los estudios, la dependencia económica familiar y la convivencia dentro de las universidades. Sin embargo, este modelo de juventud asociado a la moratoria social ha sido objeto de fuertes críticas. Margulis y Urresti (1998) dan cuenta de que la noción de moratoria social tiene un fuerte componente de clase puesto que solo es aplicable a familias de sectores medios y altos que tienen la posibilidad de extender a sus miembros jóvenes un período de dependencia económica para que se eduquen y diviertan. Esto no ocurre en otros sectores sociales donde las familias no cuentan con los recursos necesarios para promover este estadio.

En nuestra tesis interpretamos que el modelo de la moratoria social funciona como un parámetro sobre lo que debería ser la experiencia juvenil, lo cual pudimos analizar en dos aspectos. El primero es que, como ya dijimos, la ciudad de La Plata aparece como un escenario ideal para la experiencia juvenil porque posibilita el ejercicio de prácticas como la educación, la política, la sexualidad, el arte y el ocio que se asocian a la representación del joven bajo el modelo de la moratoria social. Por otro lado, porque esta condición aparece como parámetro de normalidad de lo juvenil tanto para quienes pueden y no pueden gozar de ella. Para quienes pueden, funciona como parámetro por el hecho de que crecieron sabiendo que estarían bajo esa condición cuando migraran para ir a la universidad, lo cual estaba naturalizado en el contexto familiar. En cambio, los que no pueden, debido a los escasos recursos económicos, sienten que no hacen lo que "se debe" cuando se es joven estudiante y esto es dedicarse solamente a estudiar. En todos los casos la moratoria social funciona como un parámetro de lo que debería ser la experiencia juvenil estudiantil universitaria.

Pero a pesar de que funciona como un parámetro, a lo largo de la tesis vimos que para algunos jóvenes, la realización del proyecto migratorio para estudiar en la universidad supone tener que "sacrificarse" lo cual implica trabajar (además de estudiar) para conseguir los recursos que las familias no pueden brindar. De este modo, apreciamos que no todos se 
encuentran en condiciones de gozar de los beneficios de la moratoria social y eso conlleva a la movilización de capacidades de agencia por parte de los sujetos para poder realizar sus proyectos de profesionalización.

La tercera conclusión se relaciona a los procesos de autonomización en el marco de los cursos de vida. Como hemos señalado, la autonomía refiere a la situación en la cual los jóvenes pueden conducir sus vidas de acuerdo a normas propias (Ballesteros Guerra, 2012). Los cambios de localidad de residencia y en el curso de vida posibilitan que los jóvenes adquieran autonomías en sus vidas vinculadas a los modos de gestionar y organizar la vida doméstica, el tiempo cotidiano, el propio cuerpo y las sociabilidades. Asimismo, la transición entre estudiante secundario y estudiante universitario posibilita que los sujetos se autoperciban como "más grandes" y con mayores responsabilidades por transitar sus carreras y permanecer en la facultad. Este proceso de autonomización no solo se produce por la salida del hogar familiar sino que puede explicarse también en relación al contexto del lugar de origen. Como hemos visto, la salida del "pueblo" permite el ejercicio de nuevas prácticas tanto en el plano de la sexualidad, como del ejercicio político y el arte.

Ahora bien, estas mayores autonomías vinculadas con algunos planos de la vida conviven, con mayores o menores tensiones, con heteronomías en otros, principalmente en lo que respecta al factor económico. La mayoría de los jóvenes continúan siendo dependientes económicamente de sus grupos familiares y eso conlleva a que deban seguir atravesados por acuerdos y normativas que provienen de sus hogares en el lugar de origen. Como hemos visto, la circulación del dinero y otros recursos económicos que posibilitan la estadía en la ciudad de destino, genera acuerdos, deberes y compromisos dentro de la red familiar. A su vez, la administración de estos recursos reposiciona a los jóvenes dentro de las redes sociales, donde deben adquirir responsabilidades que antes de migrar no tenían. De este modo, podemos apreciar que se produce una tensión autonomía/heteronomía que atraviesa las vidas de la mayoría de los sujetos migrantes.

La cuarta conclusión se relaciona a los procesos de movilidad social. Si bien hemos analizado que la migración a La Plata posee diversas motivaciones (como enriquecerse personalmente o ejercer la sexualidad de otra manera, entre otras), es necesario remarcar la centralidad que adquiere la apuesta por acumular capital escolar, como forma 
institucionalizada del capital cultural, en las trayectorias de los sujetos. La educación universitaria constituye la principal apuesta de "progreso" mediante la cual el capital escolar puede convertirse en capital económico y simbólico y configura el principal anclaje de la identificación como "clase media". Pero esto no es solo una expectativa sino que produce efectos en las vidas de los sujetos.

En términos de capital simbólico, la condición de estudiante universitario reposiciona a los jóvenes en el contexto del lugar de origen. Cuando visitan Roque Pérez reciben el reconocimiento, prestigio y la positiva valoración de estar estudiando una carrera universitaria. Los miembros del lugar de origen comienzan a tratarlos como personas que van teniendo cierta experticia en temas de salud, derecho, política e ingeniería, entre otros. De esta manera, la condición estudiantil y la apuesta por conseguir la titulación universitaria se convierte en un fuerte capital simbólico para los jóvenes. Esto se acentúa en los casos de jóvenes que se gradúan y regresan a Roque Pérez a trabajar de sus profesiones ya que son colocados en nuevas posiciones dentro del lugar de origen vinculadas al tipo de inserción socio-laboral. Sin embargo, notamos que no todos tienen posibilidades de ejercer sus profesiones en Roque Pérez y eso suele ser motivo para no regresar.

Además de capital simbólico, el capital escolar puede convertirse en capital económico. Sobre esta cuestión pudimos notar que los jóvenes que se habían graduado pudieron, con mayores o menores dificultades, conseguir empleos como profesionales, y habían logrado la independencia económica con respecto a sus grupos familiares de origen. De esta manera, la posesión de un título universitario habilitó espacios laborales profesionales para quienes lo obtuvieron. Sin embargo, aún nos quedará por profundizar el estudio sobre las características de sus trayectorias laborales y el impacto de la titulación universitaria en las mismas.

Antes de finalizar queremos mencionar dos aspectos que aparecieron a lo largo de la investigación y que consideramos pertinente mencionar para profundizar en futuras investigaciones. El primero de ellos se vincula con el ingreso y la permanencia en las diferentes facultades de la UNLP. Pudimos registrar una serie de dificultades que se les presentan a los jóvenes para transitar la institución universitaria, principalmente en la brecha que visualizan entre los requerimientos y exigencias de la escuela secundaria y los 
de la universidad. Sumado a esto, se identificaron heterogeneidades entre primeras y segundas generaciones de estudiantes universitarios que nos permitirían comprender diferencias en relación a los capitales culturales de los sujetos. En este sentido, consideramos que queda abierto para una futura investigación analizar los recorridos y estrategias de afiliación institucional en diferentes facultades de la UNLP para explorar con mayor detenimiento las particularidades de cada institución y las prácticas de los estudiantes.

El otro aspecto que emergió fue el modo en que son nombrados los jóvenes que se trasladan desde localidades del interior del país hacia La Plata. A lo largo de la tesis los denominamos como jóvenes migrantes estudiantiles, pero notamos que casi nadie utilizó esa denominación. Solo uno de los funcionarios municipales entrevistado mencionó que se encontraban trabajando en fortalecer la oferta de estudios superiores en Roque Pérez para “evitar la migración masiva de jóvenes". Con excepción a esa referencia, nadie utilizó el término migración. La denominación que utilizaron los jóvenes y que también escuchamos en muchas otras personas de La Plata fue la de "estudiante del interior". Esta es la categoría nativa que identifica a los universitarios no platenses. Quizá esto pueda deberse al prestigio de este tipo de movilidad espacial. Mientras que otras investigaciones han señalado que el migrante trabajador, sobre todo originario de países limítrofes o de otras provincias del país, constituye un sujeto estigmatizado y negativizado (Domenech, 2011; Caggiano y Torres, 2011), el "estudiante del interior" es aquel que viene a educarse y que forma parte de algo positivamente valorado en la capital provincial. Tal vez sea por eso que no se le adjudica el término "migrante" casi en ninguna ocasión. Consideramos que aquí se abre otra línea para continuar con el estudio de este fenómeno. 


\section{BIBLIOGRAFÍA}

Anderson, B. (2014). Encountering affect. Capacities, apparatuses, conditions. Durham: Ashgate.

Arendt, H. (2016). La condición humana. Buenos Aires. Paidós.

Arias, C. (1998). "Reconstrucción de la red social en una comunidad receptora. El caso de los estudiantes universitarios migrantes de la UNMP” En: Golpe, L. y Herrán, C. (comp): Mar del Plata: perfiles migratorios e imaginarios urbanos. Buenos Aires. Ediciones ADIP.

Aries, P. (1987). El niño y la vida familiar en el Antiguo Régimen. Madrid. Taurus.

Badenes, D. (2012). Un pasado para La Plata: Producción editorial y disputa de sentidos sobre la historia de la ciudad en su centenario- 1982. (Tesis de maestría). Facultad de Humanidades y Ciencias de la Educación. Universidad Nacional de La Plata

Ballesteros Guerra, J. C.; Megías Quirós, I. y Rodríguez San Julián, E. (2012). Jóvenes y emancipación en España. Madrid: FAD, Fundación de Ayuda contra la Drogadicción.

Barba, E. F. (1998). La Universidad Nacional de La Plata en su Centenario 18971997. La Plata. Edulp.

Barberis, J. (2011). "El comportamiento reciente del empleo" Entre líneas de la política económica, $\mathrm{N}^{\circ} 28$, año5, pp.15-24.

Barreiro, H. (2000). Juancito Sosa: el indio que cambió la historia. Buenos Aires. Editorial Tehuelche.

Becker, H. (2014). Outsiders: hacia una sociología de la desviación. Buenos Aires. Siglo veintiuno editores. 
Benza, G. (2016). “Cap.4 La estructura de clases argentina durante la década 20032013" En: Kessler, G. (comp.) La sociedad argentina hoy: radiografia de una nueva estructura. $1^{\circ}$ ed. Buenos Aires. Siglo XXI editores.

Bergé, E. y Cingolani, J. (2017). "La Plata Ciudad Rock. Tensiones y disputas por la territorialización de un sonido." Revista Planeo. Espacio para territorios urbanos y regionales. Santiago de Chile. En prensa

Bermúdez Rico, R. (2015). "La movilidad internacional por razones de estudio: Geografía de un fenómeno global” En: Migraciones Internacionales, vol. 8, núm. 1, pp. 95125. El Colegio de la Frontera Norte, A.C. Tijuana, México

Bertaux, D. (1989). "Los relatos de vida en el análisis social” En: Historia y Fuente Oral, núm. 1, Barcelona, pp. 87-96

Biagini, H. (2012). La contracultura juvenil: de la emancipación a los indignados. Capital intelectual. Buenos Aires. Capital intelectual.

Blanco, M. (2011). "El enfoque del curso de vida: orígenes y desarrollo" En: Revista Latinoamericana de Población. Vol.5. Nº.CEPAL

Blanco, R. (2014). Universidad intima y sexualidades públicas: la gestión de la identidad en la experiencia estudiantil. Buenos Aires: Mino y Dávila editores.

Blanco, R. (2016). Escenas militantes: Lenguajes, identidades políticas y nuevas agendas del activismo estudiantil universitario. Buenos Aires: Grupo editor universitario.

Boix, O. A. (2013). Sellos emergentes en La Plata: Nuevas configuraciones de los mundos de la música. (Tesis de maestría). Facultad de Humanidades y Ciencias de la Educación. Universidad Nacional de La Plata.

Bonavena, P., Califa, J. y Millán, M. (2007). El movimiento estudiantil argentino. Historias con presente. Buenos Aires. Cooperativas. 
Bonvillani, A., Palermo, A., Vázquez, M. y Vommaro, P. (2008) "Juventud y Política en la Argentina (1968-2008) Hacia la construcción de un estado del Arte.” En: Revista Argentina de Sociología. Año6. N¹1. Pp 44-73.

Bourdieu, P. (1979). "Los tres estados del capital cultural” En: Sociológica, UAMAzcapotzalco, México, N5, pp. 11.17.

Bourdieu, P. (1984). "Espacio social y génesis de las clases" En: Sociología y Cultura. México D.F. Grijalbo.

Bourdieu, P. (2002). "Estrategias de reproducción y modos de dominación" En: Colección Pedagógica universitaria, $\mathrm{N}^{\circ}$, pp. 37-38.

Bourdieu, P. y Passeron, J. C. (2003). Los herederos. Los estudiantes y la cultura. Buenos Aires, Siglo XXI.

Bourdieu, P. (2010). El sentido Práctico. Buenos Aires. Siglo XXI editores.

Bover, Tomás (2016). Trayectorias policiales: producción de instituciones y agentes sociales en la Policía Federal Argentina. (Tesis de doctorado). Instituto de Altos Estudios Sociales. Universidad de San Martín.

Bracchi, C. (2007). "Los 'recién llegados' y el intento para convertirse en 'herederos'. Un estudio socioeducativo sobre estudiantes universitarios". En: V Encuentro Nacional y II Latinoamericano La universidad como objeto de investigación. Universidad Nacional del Centro de la provincia de Buenos Aires.

Bryceson, D. y Vuorela. U. (2002). The Transnational Family: New European Frontiers and Global Networks. Oxford: Berg.

Buchbinder, P. (2008). ¿Revolución en los claustros? La reforma universitaria de 1918. Buenos Aires. Sudamericana.

Caggiano, S. y Torres, A. (2011). "Negociando categorías, temas y problemas: investigadores y organismos internacionales en el estudio de la migración indígena. En 
Feldman-Bianco, B. y otros (Comps.) La construcción social del sujeto migrante en América Latina. Prácticas, representaciones y categorías. Quito: CLACSO, FLACSO, Universidad Alberto Hurtado.

Carli, S. (2006). "Figuras de la amistad en tiempos de crisis: la universidad pública y la sociabilidad estudiantil." En: Diker G. y Frigerio G.: Educar: Figuras y efectos del amor. Buenos Aires. Del estante.

Carli, S. (2012). El estudiante universitario: hacia una historia del presente de la educación pública. Buenos Aires. Siglo veintiuno editores.

Carlón, F. (2014). “Una vuelta de tuerca más: repensando los malones en la frontera de Buenos Aires durante el siglo XVIII” Revista Tefros. Vol. 12, N¹, Pp 26-49.

Casco, M. (2007). "Prácticas comunicativas del ingresante y afiliación intelectual". En: $V$ Encuentro Nacional y II Latinoamericano La universidad como objeto de investigación. Universidad Nacional del Centro de la provincia de Buenos Aires.

Chaves, M. y Nuñez, P. (2012). "Youth studies in Argentina: youth and politic in democratic Argentina (1983-2008)". Young. Nordic Journal of Youth Studies. 20(4) 357376, Copenhagen, Sage.

Chaves, M. (2010). Jóvenes, territorios y complicidades. Una antropología de la juventud urbana. Buenos Aires. Espacio editorial.

Chaves, M. (2016). "Según qué para quién y depende de su esfuerzo": fronteras y lógicas de merecimiento con jóvenes de sectores populares": En: Chaves, M., Fuentes, S. y Vecino, L.: Experiencias juveniles de la desigualdad: fronteras y merecimientos en sectores populares, medios y altos. Buenos Aires. Grupo editor Universitario.

Chaves, M., Galimberti, C. y Mutuverría M. (2016). " 'Cuando la juventud se pone en marcha el cambio es inevitable': juventudes, acción política, organizaciones y Estado en Argentina". En: Vommaro, P.: Cuadernos de Pensamiento Crítico, Movimientos juveniles y revoluciones sociales en el Siglo XXI, La Habana: Ruth Casa Editorial. 
Chaves, M., Fuentes, S. y Vecino, L. (2016). Experiencias juveniles de la desigualdad: fronteras y merecimientos en sectores populares, medios y altos. Buenos Aires. Grupo editor Universitario.

Chávez Molina, E. (2013). "Desigualdad y movilidad social en un contexto de heterogeneidad estructural: notas preliminares" En: Chávez Molina, E. y Pla, J.: Desigualdad y movilidad social en el mundo contemporáneo: aportes empiricos y conceptuales. Argentina, China, España y Francia. Buenos Aires. Imago Mundi.

Chávez Molina, E. y Gutiérrez Ageitos, P. (2009). "Movilidad intergeneracional y marginalidad económica. Un estudio de caso en el Conurbano Bonaerense" En: Población de Buenos Aires. Revista semestral de datos y estudios sociodemográficos urbanos. Año 6, número 10, Buenos Aires: Dirección General de Estadística y Censos (dgeyc) del Gobierno de la Ciudad de Buenos Aires.

Cingolani, J. (2016). “¿Qué distingue a la otra ciudad? Pensar la cultura rock platense a partir del análisis de un evento" En: Estudios sobre Juventudes en Argentina, $N^{\circ}$ 4,: San Luis, pp. $201-213$

Cleve, A. (2016). "El lugar de las familias en las migraciones internas de estudiantes hacia La Plata. Argentina. Apoyo económico, acuerdos y construcción de redes" En: Odisea. Revista de Estudios Migratorios No 3, pp. 53-77.

Colabella, M. L. y Vargas, P. B. (2013). La Jauretche": una universidad popular en la trama del sur del Gran Buenos Aires. Clacso. Buenos Aires.

Coulon, A. (1995). Etnometodología y Educación. Buenos Aires. Paidós.

Courtis, C. y Pacceca, M. I. (2010). "Género y trayectoria migratoria: mujeres migrantes y trabajo doméstico en el Área Metropolitana del Gran Buenos Aires" En: Papeles de población, Vol 16, № 63, Universidad Autónoma del Estado de México, Pp 155-185. 
Criado, E. M. (1998). Producir la juventud: crítica de la sociología de la juventud. Madrid. Istmo.

Del Mármol, M. (2014) "Estudiar teatro desde la antropología. Un recorrido de investigación" En: Cuerpo del Drama, №2, UNICEN.

Delgado, M. (1998). "Racismo y espacio público" En Revista Acciones e Investigaciones Sociales. Nㅜㄱ, Zaragoza. Escuela universitaria de estudios sociales, Pp 727.

Delgado, M. (2007). Sociedades movedizas. Pasos hacia una antropología de las calles. Barcelona, Anagrama.

Di Doménico, M. C. (1998). "Adolescencia, migración y cambio educativo" En: Golpe, L. y Herrán, C. (comp): Mar del Plata: perfiles migratorios e imaginarios urbanos. Buenos Aires. Ediciones ADIP.

Dolado, J. y Fernández Yusta, C. (2002). "Los nuevos fenómenos migratorios: retos y políticas", En: Cuarta Jornada del CREI. Universidad Pompeu Fabra.

Domenech, E. (2011). "Crónica de una 'amenaza' anunciada. Inmigración e 'ilegalidad': visiones de Estado en la Argentina contemporánea" En: FeldmanBianco, B. y otros (Comps.) La construcción social del sujeto migrante en América Latina. Prácticas, representaciones y categorías. Quito: CLACSO, FLACSO, Universidad Alberto Hurtado.

Dubet, F. (2005). “Los estudiantes” En: CPU-e. Revista de Investigación educativa, $N^{\circ} 1$.

Eguía, A. (1994). "Estrategias familiares de reproducción social en sectores populares urbanos del Gran La Plata" En: IV Congreso Argentino de Antropología Social, Olavarría.

Elder, G. (1994). "Time, Human Agency and Social Change: Perspectives on the Life Course" Social Psychology Quarterly, Vol.57, N¹, pp. 4-15. 
Elder, G. (2001). "Life course: sociological aspects". Neil Smelser y Paul Baltes. (Eds.): International Encyclopedia of the Social and Behavioral Sciences, vol. 13, Oxford: Elsevier.

Falappa, F. y Andrenacci, L. (2009). "La política social de la Argentina democrática (1983-2008)”. Instituto del Desarrollo Humano -Coedición UNGS-Biblioteca Nacional.

Feixa, C. (1998). Cap. 1 "De púberes, efebos, mozos y muchachos". En: De jóvenes, bandas y tribus (Antropología de la juventud). Ariel. Barcelona.

Ferrarotti, F. (1993) "Sobre la autonomía del método biográfico". En: Marinas J. M. y C. Santamarina (eds.), La historia oral: métodos y experiencias. Madrid.Debate.

Fernández Melián, M. C., Rodriguez de la Fuente, J. y Clemenceau, L. (2013). "Tendencias de movilidad social en la Ciudad Autónoma de Buenos Aires 2012 -2013: entre ascensos, descensos y reproducción.” En: VII Jornadas de Jóvenes Investigadores del Instituto Gino Germani. Universidad de Buenos Aires.

Ferreira Dos Santos, S., Korolik, E., Jaimsky, G. y Schlafman, S. (2013). "Migración en adolescentes tardíos: trazando problemáticas" En: V Congreso Internacional de Investigación y Práctica Profesional en Psicología y XX Jornadas de Investigación Noveno Encuentro de Investigadores en Psicología del MERCOSUR. Facultad de Psicología - Universidad de Buenos Aires, Buenos Aires

Galeano, D. (2009). "Médicos y policías durante la epidemia de fiebre amarilla (Buenos Aires, 1871)" En: Salud Colectiva, N5, pp. 107-120.

Gamallo, G. y Nuñez, P. (2013). "La "aventura del héroe”: proyectos migratorios de los estudiantes universitarios de Río Negro" En: Trabajo y Sociedad, №20 pp. 71-88.

García Canclini, N. (2007). “¿Qué son los imaginarios urbanos y cómo actúan en la ciudad?" En: Revista eure, Vol. 23, No 99, pp. 89-99. 
Germani, G. (1950). "La clase media en la Argentina con especial referencia a sus sectores urbanos" En Materiales para el estudio de la clase media en América Latina, I. Washington, DC. Unión Panamericana.

Giddens, A. (1993) Las nuevas reglas del método sociológico: crítica positiva a las sociologías interpretativas. Buenos Aires. Amorrortu editores.

Giménez Romero, C. y Suárez Navaz, L. (2000). "Menores no Acompañados que han entrado en territorio español sin representación legal” Informe de investigación.

Goffman, E. (2012). La presentación de la persona en la vida cotidiana. Buenos Aires. Amorrortu.

Golpe, L. y Bidegain, L. (1998). "Imaginarios urbanos y prácticas migratorias" En: Golpe, L. y Herrán, C.: Mar del Plata: perfiles migratorios e imaginarios urbanos. Buenos Aires. Ediciones ADIP.

Guber, R. (2009). El salvaje metropolitano. Reconstrucción del conocimiento social en el trabajo de campo. Buenos Aires. Paidós.

Hall, S. (2003). "Introducción: ¿Quién necesita identidad?” En: Hall, S. y Du Gay, P. (comps.) Cuestiones de identidad cultural. Buenos Aires. Amorrortu.

Hernández, María Celeste (2017). Crecer en la ciudad: usos y representaciones del espacio urbano entre niños y niñas de La Plata (Provincia de Buenos Aires). (Tesis de doctorado). Instituto de Altos Estudios Sociales. Universidad Nacional de San Martín.

Hobsbawn, E. (2012). Historia del siglo XX. Buenos Aires. Crítica.

Infantino, J. (2010). "Prácticas, representaciones y discursos de corporalidad. La ambigüedad en los cuerpos circenses" En: RUNA XXXI, No 1, pp. 49-65.

Infantino, J. (2011). “Trabajar como artista. Estrategias, prácticas y representaciones del trabajo artístico entre jóvenes artistas circenses" Cuadernos de antropología social, Nº34 pp. 141-163. 
Jay, M. (2009). Cantos de experiencia. Variaciones modernas sobre un tema universal. Buenos Aires. Paidós.

Jensen, F. y Perret, G. (2011). "Migración chilena a la Argentina: entre el exilio político y la migración económica- cultural” En: Revista Sociedad y Equidad, №2, pp. 143162.

Jiménez Zunino, C. (2013). "Trayectorias sociales de los migrantes argentinos en España" En: Karasik, G. (comp.) Migraciones internacionales: reflexiones y estudios sobre la movilidad territorial contemporánea. Buenos Aires. Ediciones CICCUS.

Jodelet, D. (2011). "Aportes del enfoque de las representaciones sociales al campo de la educación” En: Espacios en Blanco. Serie indagaciones, №21, pp. 133-154

Kessler, G. (2011). "La extensión del sentimiento de inseguridad en américa latina: relatos, acciones y políticas en el caso argentino". En: Revista Sociol. Polit., Curitiba, Vol $19, \mathrm{~N}^{\circ} 40$, pp. 83-97,

Kessler, G. y Espinoza, V. (2007). "Movilidad social y trayectorias ocupacionales en Buenos Aires. Continuidades, rupturas y paradojas" En: Franco, R., León, A. y Atria, R (coord.) Estratificación y movilidad social en América Latina. Transformaciones estructurales de un cuarto de siglo, Santiago de Chile. LOM-CEPAL-GTZ.

Le Bretón, D. (2013). "Por una antropología de las emociones" En: Revista Latinoamericana de estudios sobre Cuerpo, Emociones y Sociedad, №10, pp. 69-79.

Lindón, A. (2007). "La ciudad y la vida urbana a través de los imaginarios" En: Revista eure, Santiago de Chile, Vol. 23, No 99, pp. 7-16.

Lódola, A. y Brigo, R. (2007). "Diagnóstico Socioeconómico de La Plata y sus Centros Comunales" Documento de Trabajo N87. Departamento de Economía. Facultad de Ciencias Económicas. Universidad Nacional de La Plata. 
López, M. (2017). Cambio de piel: intervenciones culturales, acción colectiva y politicidad emergente en el espacio público de La Plata. (Tesis de doctorado). Facultad de Periodismo y Comunicación Social. Universidad Nacional de La Plata.

Luchillo, L. (2006). "Movilidad de estudiantes universitarios e internacionalización de la educación superior" En: Revista iberoamericana de ciencia, tecnología y sociedad, versión On-line, CABA, Vol. 3, Nº7, pp. 105-133.

Magnani, J. G. (2005). “Os circuitos dos jovens urbanos” En: Tempo Social, Revista de Sociología da USP, vol. 17, número 2 pp. 173-205.

Margulis, M. y Urresti, M. (1998). "La construcción social de la condición de juventud" En: Cubides, H., Laverde, M.C y Valderrama, C. (eds.) «Viviendo a toda» Jóvenes, territorios culturales y nuevas sensibilidades. Bogotá. Siglo del Hombre-Depto. Investigaciones, Universidad Central.

Marradi, A., Archenti, N., y Piovani, J. I. (2007). Metodología de las ciencias sociales. Buenos Aires. Emecé editores.

Martí, S. (2011). "Migración y transiciones juveniles. Un esbozo de vinculación en jóvenes paraguayos y bolivianos en el GBA". En: IX Jornadas de Sociología de la UBA.

Mauss, M. (2009). Ensayo sobre el don: forma y función del intercambio en las sociedades arcaicas. Buenos Aires. Katz ediciones.

Miranda, A., Cravino, M. C. y Martí, S. (2012). "Transiciones juveniles de migrantes paraguayos en la Argentina: condiciones de vida y vigencia de las redes" En: Revista Última Década, №37, Centro de Estudios Sociales, Valparaiso, pp. 11-39.

Mora, S. (2010). El cuerpo en la danza desde la antropología. Prácticas, representaciones y experiencias durante la formación en danzas clásicas, contemporáneas y expresión corporal. (Tesis de doctorado). Facultad de Ciencias Naturales y Museo. Universidad Nacional de La Plata. 
Mora, S. (2016). “Al menos nací el mismo día que Eminem. Alteridades y cercanías en el trabajo de campo con jóvenes raperos." En : II Jornadas de Investigación Cuerpo, Arte y Comuniación: metodologías y Métodos. Facultad de Humanidades y Ciencias de la Educación. Universidad Nacional de La Plata.

Murga, W. (2013). "Las viejas historias: centenario de la autonomía de Roque Pérez". Publicado en: La guía de Roque Pérez.

Mutuverria, M. (2017). Juventudes y participación política: la condición juvenil en el peronismo platense contemporáneo. (Tesis de doctorado). Universidad Nacional de General Sarmiento.

Naishtat, F., García Raggio, A. M. y Villavicencio, S. (2001). "La universidad hoy: crisis de esa 'Buena Idea'.” En: Filosofias de la universidad y conflicto de racionalidades. Buenos Aires. Colihue.

Nisbet, R. (1969). "Las ideas-elementos de la sociología". En: La formación del pensamiento sociológico. Buenos Aires. Amorrortu editores.

Oliven, R. (2014) "Clase media, consumo y ciudadanía" En: Adamovsky, E., Visacovsky, S. y Vargas, P. B. (comp.): Clases medias: nuevos enfoques desde la sociología, la historia y la antropología. Buenos Aires. Ariel.

Organización Iberoamericana de Juventud. (2007). La juventud en Iberoamérica: Tendencias y Urgencias. Santiago de Chile.

Parella Rubio, S. (2012). "Familia transnacional y redefinición de los roles de género. El caso de la migración boliviana en España" En: Revista de sociología, Vol.97, $\mathrm{N}^{\circ} 3$, Pp. 661-684.

Pavón Pereyra, E. (1953). Perón 1985-1942. Ediciones Espiño. 
Pedone, C., Agrela Romero, B. y Gil Araujo, S. (2012). "Políticas públicas, migración y familia. Una mirada desde el género” En: Revista de sociología, Vol. 97, №3, pp. 541-568.

Pierella, M. P. (2011). "El ingreso a la universidad como experiencia subjetiva y cultural en estudiantes de la Universidad Nacional de Rosario" En: Revista Argentina de Educación Superior, №3, pp. 26-48.

Ramella, F. (1994). "Por un uso fuerte del concepto de red en los estudios migratorios" En: María Bjerg y Hernán Otero (Comps.) Inmigración y redes sociales en la Argentina moderna. Buenos Aires: CEMLA/Instituto de Estudios Histórico-Sociales.

Ramirez Parra, M. E. (2003). "Migración de menores de edad en el Soconusco, Chiapas" En: Primer coloquio internacional Migración y Desarrollo: transnacionalismo y nuevas perspectivas de integración. Zacatecas, pp. 23-25.

Roberti, M. E. (2015) La nueva condición juvenil en tiempos de desestructuración: Un estudio de las trayectorias laborales de los jóvenes del barrio Aluvión y su imbricación con otras esferas vitales (La Plata, Pcia de Buenos Aires). (Tesis de Maestría). Facultad de Humanidades y Ciencias de la Educación. Universidad Nacional de La Plata.

Rodriguez Vignoli, J. (2004). "Migración interna en América Latina y el Caribe: estudio regional del período 1980-2000” En: Serie Población y Desarrollo, ํ50, Santiago de Chile, Comisión Económica para América Latina y el Caribe (CEPAL), Publicación de las Naciones Unidas.

Rodriguez Vignoli, J. (2008). "Migración interna de la población joven: el caso de América Latina” En: Revista Latinoamericana de Población, Vol. 2, №3, Pp 9-26.

Rodríguez Vignoli, J. y Busso, G. (2009). "Migración interna y desarrollo en América Latina entre 1980 y 2005. Un estudio comparativo con perspectiva regional basado en siete países”. Santiago, Chile. Comisión Económica para América Latina y El Caribe. 
Sáez, M. (2017). Presencias, riesgos e intensidades. Un abordaje socioantropológico sobre y desde el cuerpo en los procesos de formación de acróbatas y bailarines/as de danza contemporánea en la ciudad de La Plata. (Tesis de doctorado). Facultad de Filosofía y Letras. Universidad de Buenos Aires.

Salvia, A., Pla, J. y Quartulli, D. (2009). “Movilidad económico - ocupacional y desigualdad económica en la Argentina post reformas estructurales: 2007 - 2008”. En: Reunión científica: Re-actualizando los debates sobre la estructura y la movilidad social. Instituto de Investigaciones Gino Germani, Facultad de Ciencias Sociales, Universidad de Buenos Aires.

Saraví, G. (2006) "Biografías de exclusión: desventajas y juventud en Argentina" En: Perfiles latinoamericanos, Vol 13, N²8, Pp 83-116.

Schütz, A. (1962). El problema de la realidad social. Amorrortu editores. Buenos Aires.

Scott, J. W. (1999). “Experiencia” En: Hiparquía, vol. 10, º 1, pp. 59-83.

Segura, R. (2015). Vivir afuera: antropología de la experiencia urbana. San Martín. UNSAM EDITA.

Shouse, E. (2005). "Feeling, Emotion, Affect," M/C Journal, Vol 8, №6.

Silva, A. (2006). Imaginarios urbanos. Bogotá. Arango editores.

Simmel, G. (1986). "Las grandes ciudades y la vida del espíritu” En: Cuadernos Políticos. N45. México D.F.

Suárez Návaz, L. (2006). Cap I “Un nuevo actor migratorio: jóvenes rutas y ritos juveniles transnacionales. En: Checa y Olmos et al: Menores tras la frontera: otra inmigración que aguarda. Barcelona. Ed. Icaria.

Torrado, S. (1998). Familia y diferenciación social. Cuestiones de método. Buenos Aires. Eudeba. 
Torres, F. (2012). "Territorios, lugares e identidades, una perspectiva de análisis espacial sobre la CTD Aníbal Verón.” En Retamozo, M., Schuttemberg, M. y Viguera, A.: Peronismos, izquierdas y organizaciones populares. Movimientos e identidades políticas en la Argentina contemporánea. La Plata. EDULP.

Tosi, Ana. (2009). "Migrar para estudiar” En: Revista Cátedra Paralela, №6, pp. $78-92$.

Vallejo, G. (2001). "La Plata y la ideología del progreso: redes y espacios culturales en la reprodución de un habitus laicista, 1882-1916" En: Anuario del Instituto de Historia Argentina, $\mathrm{N}^{\circ} 2$, pp. 367-405.

Vargas, P. B. (2014). "La hormiguita burguesa: narrativas de ascenso social y actualizaciones de clase (media) entre los diseñadores porteños" En: Adamovsky, E., Visacovsky, S. y Vargas, P. B. (comp.): Clases medias: nuevos enfoques desde la sociología, la historia y la antropología. Buenos Aires. Ariel.

Vasilachis de Gialdino, I. (2006). "La investigación cualitativa" En: Vasilachis de Gialdino, I. (coord.) Estrategias de investigación cualitativa. Barcelona. Gedisa Editorial.

Vázquez, M. (2010). Socialización política y activismo. Carreras de militancia política de jóvenes referentes de un movimiento de trabajadores desocupados. (Tesis doctoral). Facultad de Ciencias Sociales. Universidad de Buenos Aires.

Vazquez, M. y Vommaro, P. (2008). "La participación juvenil en los movimientos sociales autónomos. El caso de los Movimientos de Trabajadores Desocupados (MTDs)”, En: Revista Latinoamericana de Ciencias Sociales, Niñez y Juventud, Manizales, Colombia Vol. 6, Nro. 2, pp. 485-522.

Visacovsky, S. (2014). "Inmigración, virtudes genealógicas y los relatos de origen de la clase media argentina”. En: En: Adamovsky, E., Visacovsky, S. y Vargas, P. B. (comp.): Clases medias: nuevos enfoques desde la sociología, la historia y la antropología. Buenos Aires. Ariel. 
Vommaro, P. (2015). Juventudes y políticas en la Argentina y en América Latina. Tendencias, conflictos y desafios. Buenos Aires. Grupo Editor Universitario.

Wacquant, L. (2006). Entre las cuerdas: cuadernos de un aprendiz de boxeador. Buenos Aires. Siglo XXI editores argentina S.A.

Walker, S. y Barton, L. (Eds.) (1983). Gender, class and education. Nueva York: The Falmer Press.

Wilkis, A. (2015). "Sociología moral del dinero en el mundo popular" En: Estudios sociológicos de el colegio de México, Vol. 23, ํ99, pp. 553-578.

Williams, R. (2001). El campo y la ciudad. Buenos Aires. Paidós.

Zenklusen, D. (2016). "De cómo la familia de Marta organiza el cuidado. Un análisis sobre la relación entre familias migrantes, género y cuidado" En: Odisea. Revista de Estudios Migratorios, $\mathrm{N}^{\mathrm{o}}$ 3, pp.30-52.

\section{FUENTES DOCUMENTALES}

Anuario Estadístico de la Universidad de Buenos Aires. Año 2016. http://www.uba.ar/institucional/contenidos.php?id=194

Anuario Estadístico de la Universidad Nacional de Córdoba. Año 2016. https://www.unc.edu.ar/acad\%C3\%A9micas-programa-de-estad\%C3\%ADsticasuniversitarias/anuario-estad\%C3\%ADstico-unc-2016

Anuario Estadístico de la Universidad Nacional de La Plata. Año 2005. https://unlp.edu.ar/frontend/media/11/3611/4ef5a11a0105ad7923622ffd3f750dfd.pdf 
Anuario Estadístico de la Universidad Nacional de La Plata. Año 2006. https://unlp.edu.ar/frontend/media/11/3611/4ef5a11a0105ad7923622ffd3f750dfd.pdf

Anuario Estadístico de la Universidad Nacional de La Plata. Año 2007. https://unlp.edu.ar/frontend/media/1/3601/9c65becef23eec8cd0364c3dc137cdbc.pdf

Anuario Estadístico de la Universidad Nacional de La Plata. Año 2008. https://unlp.edu.ar/frontend/media/91/3591/4b3f8b8d557fa36c561dd6eedb1ae489.pdf

Anuario Estadístico de la Universidad Nacional de La Plata. Año 2009. https://unlp.edu.ar/frontend/media/81/3581/1961a3fd26ceae6570bedd6225676fcc.pdf

Anuario Estadístico de la Universidad Nacional de La Plata. Año 2010. https://unlp.edu.ar/frontend/media/71/3571/a8ca2442b6f8742fde8705261dc2de63.pdf

Anuario Estadístico de la Universidad Nacional de La Plata. Año 2011 https://unlp.edu.ar/indicadores/anuario_de indicadores-5328

Anuario Estadístico de la Universidad Nacional de La Plata. Año 2012. https://unlp.edu.ar/indicadores/anuario de indicadores 2012-5376

Dirección General de Cultura y Educación de la Provincia de Buenos Aires. http://servicios.abc.gov.ar/escuelas/mapaescolar/default.cfm

Memoria del directorio del ferrocarril del oeste. Biblioteca de la Honorable Cámara de Senadores de la Provincia de Buenos Aires, 1884.

Ministerio de Economía de la Provincia de Buenos Aires. Dirección Provincial de Estudios y Proyecciones Económicas.

http://www.ec.gba.gov.ar/areas/estudios_proyecciones/principales_cultivos.php

Registro oficial de la Provincia de Buenos Aires. Año 1882.

Registro oficial de la Provincia de Buenos Aires. Año 1913. 


\section{ANEXO}

\section{Cuadro de entrevistas realizadas}

\begin{tabular}{|c|c|c|c|c|c|c|}
\hline $\mathrm{N}^{\circ}$ & Nombre & Edad & Carrera & $\begin{array}{l}\text { Situación en } \\
\text { relación a la } \\
\text { carrera al } \\
\text { momento de la } \\
\text { entrevista }\end{array}$ & $\begin{array}{l}\text { Localidad } \\
\text { donde vivía } \\
\text { cuando fue } \\
\text { entrevistado }\end{array}$ & $\begin{array}{l}\text { Fecha de la } \\
\text { entrevista }\end{array}$ \\
\hline 1 & Darío & 32 & Derecho & Estudiante & La Plata & $24 / 08 / 2014$ \\
\hline 2 & Noelia & 23 & Ingeniería & Estudiante & La Plata & $25 / 08 / 2014$ \\
\hline 3 & Victoria & 21 & Medicina & Estudiante & La Plata & $30 / 08 / 2014$ \\
\hline 4 & Liliana & 26 & Veterinaria & Estudiante & La Plata & $31 / 08 / 2014$ \\
\hline 5 & Vanesa & 20 & Medicina & Estudiante & La Plata & $20 / 09 / 2014$ \\
\hline 6 & Elena & 19 & Bioquímica & Estudiante & La Plata & $06 / 10 / 2014$ \\
\hline 7 & Lucía & 28 & Trabajo Social & Graduada & La Plata & $12 / 03 / 2015$ \\
\hline 8 & Celina & 26 & Trabajo Social & Graduada & La Plata & $06 / 05 / 2015$ \\
\hline 9 & Esteban & 36 & Derecho & Graduado & La Plata & $09 / 07 / 2015$ \\
\hline 10 & Camilo & 26 & Periodismo & Graduado & La Plata & $17 / 09 / 2015$ \\
\hline 11 & Emanuel & 28 & Tec. Radiología & Abandonó & Roque Pérez & $13 / 10 / 2015$ \\
\hline 12 & Malena & 31 & Diseño gráfico & Graduada & Roque Pérez & $14 / 10 / 2015$ \\
\hline 13 & Ariel & 25 & $\begin{array}{l}\text { Contador } \\
\text { Público }\end{array}$ & Abandonó & Roque Pérez & $16 / 10 / 2015$ \\
\hline 14 & Eugenio & 25 & Derecho & Estudiante & La Plata & $30 / 03 / 2016$ \\
\hline 15 & Marina & 25 & Música popular & Estudiante & La Plata & $18 / 04 / 2016$ \\
\hline 16 & Daniel & 29 & $\begin{array}{l}\text { Educación } \\
\text { Física }\end{array}$ & Abandonó & La Plata & $27 / 04 / 2016$ \\
\hline
\end{tabular}

